\title{
WestVirginiaUniversity
}

THE RESEARCH REPOSITORY @ WVU

Graduate Theses, Dissertations, and Problem Reports

2004

\section{Development of gas production type curves for coalbed methane reservoirs}

Anangela Garcia Arenas

West Virginia University

Follow this and additional works at: https://researchrepository.wvu.edu/etd

\section{Recommended Citation}

Garcia Arenas, Anangela, "Development of gas production type curves for coalbed methane reservoirs" (2004). Graduate Theses, Dissertations, and Problem Reports. 1431.

https://researchrepository.wvu.edu/etd/1431

This Thesis is protected by copyright and/or related rights. It has been brought to you by the The Research Repository @ WVU with permission from the rights-holder(s). You are free to use this Thesis in any way that is permitted by the copyright and related rights legislation that applies to your use. For other uses you must obtain permission from the rights-holder(s) directly, unless additional rights are indicated by a Creative Commons license in the record and/ or on the work itself. This Thesis has been accepted for inclusion in WVU Graduate Theses, Dissertations, and Problem Reports collection by an authorized administrator of The Research Repository @ WVU. For more information, please contact researchrepository@mail.wvu.edu. 


\title{
DEVELOPMENT OF GAS PRODUCTION TYPE CURVES FOR COALBED METHANE RESERVOIRS
}

\author{
Anangela Garcia Arenas \\ Thesis Submitted to the \\ College of Engineering and Mineral Resources \\ At West Virginia University \\ In partial fulfillments of the requirements \\ For the degree of \\ Master of Science \\ In \\ Petroleum and Natural Gas Engineering
}

Kashy Aminian, PhD., Chair

Samuel Ameri, M.S.

Shahab Mohaghegh, Ph.D.

Department of Petroleum and Natural Gas Engineering

Morgantown, West Virginia

2004

Keywords: Petroleum and Natural Gas Engineering, Coalbed Methane, Type Curves, Gas Production Prediction.

Copyright 2004 Anangela Garcia Arenas 


\title{
ABSTRACT \\ DEVELOPMENT OF GAS PRODUCTION TYPE CURVES FOR COALBED METHANE RESERVOIRS
}

\begin{abstract}
Anangela Garcia Arenas
Coalbed methane is an unconventional gas resource that consists on methane production from the coal seams. The unique coal characteristic results in a dual-porosity system. CBM reservoir performance is also influenced by the interrelationship of reservoir, geologic, and operation parameters. Coalbed methane production data is considered a complex and difficult to analyze especially at the early stages of the recovery.

This study was conducted to develop a simple and reliable tool to predict the performance of CBM in The Northern Appalachian Basin. To achieve this objective, four steps were performed. A unique set of gas production type curves for coalbed methane was developed as a simple and economical tool for small producer to evaluate economic feasibility, increase recovery, and maximize efficiency. A correlation for peak gas rate estimation was also proposed as an alternative to forecast gas production without having production data. This approach was performed as a contribution to the development and growth of gas reservoirs in the Northern Appalachian Basin.
\end{abstract}




\section{ACKNOWLEDGEMENTS}

I would like to express my appreciation and gratitude to my academic advisor, Dr. Kashy Aminian, for your support and guidance during my graduate program. Your help, professional assistance, and advices always guide my career and made possible the culmination of my degree.

I would also like to extent my appreciation and gratitude to Dr. Sam Ameri for his continuous motivation and support. I also appreciate your participation and enthusiasm to be part of my committee.

I would like to take this opportunity to express my special and sincere gratitude to Dr. Shahab Mohaghegh, for his encouragement, friendship, and continuous advice. Your participation in my Committee is very much appreciated.

I would like to express a special thanks to Ms. Beverly Matheny for her assistance and enthusiasm, which helped me every semester in the department.

Thank you to my friends, Olga Velez, Janaina Pereira, and Manuel Sanchez for helping me and being really special coworkers. I would also like to thank in a warm and very special manner to Eric McClusky for all his help, support, and continuous encouragement.

Sincere gratitude to Carlos Ruiz Bolivar for helping me in each step in my life. Having your support and orientation always make me feel special.

Special thanks to my dad, Juan Garcia, for his encouragement and support. Your believe in me has helped me during all my life.

Finally, I dedicate my work to my mom who represents the best inspiration in my life. Thank you very much for all your guidance, support, encouragement, and for the most important, the love that you always have given me. 


\section{TABLE OF CONTENTS}

ACKNOWLEDGEMENTS

Page

iii

TABLE OF CONTENTS

iv

LIST OF FIGURES

vi

LIST OF TABLES

viii

NOMENCLATURE

ix

CHAPTER I. INTRODUCTION

CHAPTER II. LITERATURE REVIEW

2.1 Coalbed Methane

2.1.1 Gas Storage in Coal Reservoirs

2.1.2 Gas Transport Mechanisms in Coal Reservoirs

2.1.3 Coalbed Methane Production

2.2 Northern Appalachian Basin Coalbed Methane

2.3 Computer Modelling Group

CHAPTER III. OBJECTIVE AND METHODOLOGY

3.1 Development of a base model for coalbed methane production in Northern Appalachian Basin

3.2 Development and verification of the dimensionless groups for type curve generation

3.3 Generation of the CBM production type curve

3.4 Validation of the CBM production type curve

CHAPTER IV. RESULTS AND DISCUSSIONS 
Appendix A. Comparison between gas production using different permeability values and the CBM production type curve.

Appendix B. Comparison between gas production using different porosity values and the $\mathrm{CBM}$ production type curve.

Appendix C. Comparison between gas production using different areas and the CBM production type curve.

Appendix D. Comparison between gas production using different thickness and the CBM production type curve.

Appendix E. Comparison between gas production using different matrix pressures and the CBM production type curve.

Appendix F. Comparison between gas production using different fracture pressures and the CBM production type curve.

Appendix G. Comparison between gas production using different sorption times and the CBM production type curve.

Appendix H. Comparison between gas production using different flowing bottomhole pressures and the CBM production type curve.

Appendix I. CBM Production Type Curve in log-log scale. 


\section{LIST OF FIGURES}

Figure 2.1 Coalification process.

Figure 2.2 Major U.S. coalbed methane resources. 6

$\begin{array}{lll}\text { Figure 2.3 Typical desorption isotherm as a function of coal rank. } & 7\end{array}$

Figure 2.4 Langmuir Isotherm. 8

Figure 2.5 Typical coalbed methane production profiles for gas and water rates: 15 three phases of producing life.

Figure 3.1 Effect of permeability on the first set of Type Curves. 27

Figure 3.2 Langmuir isotherm calculated. 29

Figure 3.3 Effect of matrix pressure on the first set of Type Curves. 29

Figure 3.4 Effect of matrix pressure on the second set of Type Curves. 30

Figure 4.1 Effect of permeability on the first set of Type Curves. 34

Figure 4.2 Effect of area on the first set of Type Curves. 34

Figure 4.3 Effect of fracture pressure on the first set of Type Curves. 35

Figure 4.4 Effect of bottomhole pressure on the first set of Type Curves. 35

Figure 4.5 Effect of thickness on the first set of Type Curves. 36

Figure 4.6 Effect of Sorption Time on the first set of Type Curves. 36

Figure 4.7 Effect of porosity on the first set of Type Curves. 37

Figure 4.8 Effect of matrix pressure on the first set of Type Curves. 38

Figure 4.9 Effect of permeability on the second set of Type Curves. 39

Figure 4.10 Effect of permeability in different directions (i, j, and k) on the 40

Figure 4.11 Effect of the permeability on the second set of type curve in log-log 41 scale.

Figure 4.12 Effect of porosity on the second set of Type Curves. 42

Figure 4.13 Effect of porosity on the second set of Type Curves in log-log scale. 42

Figure 4.14 Effect of area on the second set of Type Curves. 43

Figure 4.15 Effect of area on the second set of Type Curves in log-log scale. 45

Figure 4.16 Effect of thickness on the second set of Type Curves. 46 
Figure 4.17 Effect of thickness on the second set of Type Curves in log-log scale. 46

Figure 4.18 Effect of matrix pressure on the second set of Type Curves. 47

Figure 4.19 Effect of matrix pressure on the second set of Type Curves in log-log 47 scale.

Figure 4.20 Effect of fracture pressure on the second set of Type Curves. 48

Figure 4.21 Effect of fracture pressure on the second set of Type Curves in log- 48 $\log$ scale.

Figure 4.22 Effect of sorption time on the second set of Type Curves. 49

Figure 4.23 Effect of sorption time on the second set of Type Curves in log-log 50 scale.

Figure 4.24 Effect of flowing bottomhole pressure on the second set of Type 51 Curves.

Figure 4.25 Effect of flowing bottomhole pressure on the second set of Type 51 Curves in log-log scale.

Figure 4.26 Effect of matrix pressure on the second set of Type Curves at BHP 52 50 psi.

Figure 4.27 Effect of matrix pressure on the second set of Type Curves at BHP 52 75 psi.

Figure 4.28 Effect of matrix pressure on the second set of Type Curves at BHP 53 100 psi.

Figure 4.29 CBM Production Type Curve for different flowing bottomhole 53 pressures.

Figure 4.30 CMG Model relative permeability curve. 56

Figure 4.31 Simulated relative permeability curve for Rock Creek-Oak Grove. 56

$\begin{array}{lll}\text { Figure 4.32 Relative permeability curve. } & 57\end{array}$

Figure 4.33 Production Type Curve in Cartesian Scale. 57

Figure 4.34 Effect of relative permeability curve on the Production Type Curve. 58

Figure 4.35 Comparison of gas production prediction: case one. 61

Figure 4.36 Comparison of gas production prediction: case two. 61

Figure 4.37 Correlation among dimensionless peak gas rate, porosity, and matrix 62 pressure. 


\section{LIST OF TABLES}

Page

Table 2.1 Generalized stratigraphic column of the coal-bearing formations in the Northern Appalachian Basin.

Table 2.2 Major reservoir and geologic characteristics in Northern Appalachian Basin.

Table 3.1 Values for the CBM base model in CMG.

Table 3.2 Parameters range varied during simulations. 26

Table 4.1 Input data for case one and two.

Table 4.2 Summary of gas in place calculations for cases one and two. 


\section{CHAPTER I}

\section{INTRODUCTION}

Coalbed methane production data is considered a complex and difficult to analyze especially at the early stages of the recovery. CBM reservoir performance is influenced by the interrelationship of a set of reservoir, geologic, and operation parameters. Within the reservoir structure the geology of the coal reveals that the natural fracture network is present in two major forms, one is known as macropore media (cleats) and the other one as a micropore media (matrix). This unique coal characteristic results in a dual-porosity system. Consequently, the gas storage mechanism differs significantly from the conventional gas reservoirs.

The majority of the gas is held in the matrix by adsorption and a very small percentage is in a free state flowing in the cleats. Moreover, at initial conditions the system is usually water saturated so, in order to produce gas, the water has to be removed from the cleat system first by lowering hydrostatic pressure. This reduction in pressure allows the gas to be released from the matrix by desorption. During dewatering process, the gas desorbs from the coal, gas rate increases and water saturation decreases.

The desorption process is described by the Langmuir isotherm, which relates the adsorbed gas volume to the pressure of the gas phase. The Langmuir isotherm varies widely for each coal reservoir. The porosity, permeability and relative permeability control the fluid flow within the natural fracture system. Thus, the water rate experiences a decline while the gas rate increases. The dewatering period is one of the most sensitive and non uniform stages in CBM production. The dewatering process can take a few days or several months. Generally, the water production greatly decline until the gas rate reaches the peak value. This time-to-peak-gas is a critical parameter since the gas production starts declining after the peak has been reached. The behavior of CBM production becomes similar to conventional reservoirs after the peak gas rate is reached. 
Since CBM is an anisotropic medium, dual-porosity, initially water saturated and multiphase flow system, gas production rate is directly influenced by a combination of reservoir and geological parameters (dual porosity, anisotropic permeability, relative permeability, desorption time, nonlinear Langmuir sorption isotherm, water saturation) especially at the early time of recovery. Production decline curves are usually used by reservoir engineers in order to forecast the future behavior of the wells. They represent one of the most important tools for recovery factor assessments, future revenue evaluation and well performance. However, the conventional decline curve methods can not properly apply to predict CBM well behavior because of the complicate nature of coals and complex production behavior of coalbed methane. As a result, the best tool that takes in account all the parameters and mechanisms that control CBM production in order to predict performance is a numerical reservoir simulator.

On the other hand, reservoir simulators are expensive and require a user with enough knowledge and preparation in order to handle and use the simulator in a proper manner. Smaller producers generally can not afford the time and economical requirements to use the simulator to evaluate CBM projects. Moreover, they might not have the necessary data to run the simulator. Consequently, there is the need to provide an economical and simple tool to predict and analyze gas production for CBM.

As a result, this study was conducted in order to develop an alternative solution for producers in The Northern Appalachian Basin. The Northern Appalachian Basin is one of the most potential and growing basins in US. The purpose of this research is to supply a tool to predict the performance of CBM wells with good accuracy in order to contribute to the development and growth of gas reservoirs in the Northeast region of the country. 


\section{CHAPTER II}

\section{LITERATURE REVIEW}

\subsection{Coalbed Methane}

Coalbed methane is an unconventional gas resource that started growing since 1983. Basically, CBM consists on methane production from the coal seams. The coal is a material rich in carbon that has been formed by the chemical and thermal alteration of organic debris. The organic material is buried, compressed, and dewatered. The peat is formed as a result of the decomposition and disintegration of plants that grow in mashes and swamps. During peat formation, the carbon content increases from $45 \%$ to $50 \%$. At the same time, the peat is affected by pressure and temperature as it is buried deeper and drive off water and volatiles progressively. This process by which the vegetal matter is transformed progressively through peat, lignite, sub-bituminous, bituminous to anthracite is called coalification. Methane and other gases are produced by anaerobic fermentation, bacterial and fungal alteration and finally by coalification. (Figure 2.1) illustrates the major steps and products during coalification process.

Generally, methane represents the larger portion of generated gases and it is produced by two processes: biogenic and thermogenic. The biogenic methane is formed by microbial decomposition of the organic material at temperatures below $50{ }^{\circ} \mathrm{C}$ in the early stages. The thermogenic gas generation occurs at temperatures above $50^{\circ} \mathrm{C}$. As temperature increase the depth of burial and coal rank also increases with time. This time-temperature relationship (also termed as "time-depth of burial") determines the coal rank that directly controls the volume of methane, carbon dioxide and nitrogen generated. Ethane, propane, and butane are also produced, but in smaller amount. Rightmire and others said "Analysis of gas produced from coalbed either in wells or during desorption testing shows that, with a few exceptions, these gases contain in excess of 95\% methane, trace to very minor amounts of higher hydrocarbons (ethane, propane, etc.), and less than 3\% each of nitrogen and carbon dioxide". 
The methane is one by-product generated from coalification. During this process the amount of methane produced greatly exceeds the capacity of the coal to hold the gas. Some of the gas is naturally released as its burial depth decrease and the remaining gas is stored in the coal seam. In that manner, the coal can hold two to three times as much gas in place as the same volume of a conventional sand reservoir (Kuuskraa, V. and Brandenburg C, 1989). Thus, this storage system places the coal as a very attractive source and reservoir rock for gas production.

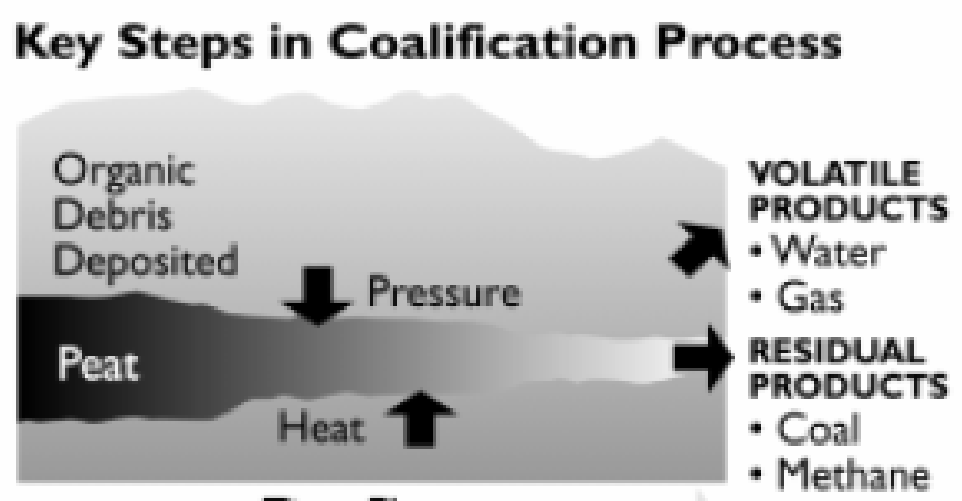

Time Elapses

Figure 2.1 Coalification Process

However, it was not until 1983 when the industry recognized the potential of coalbed methane as a source of low-cost gas. In effect, it was after the disastrous coal mine explosion in Farmington, West Virginia, in 1968 when the US Bureau of Mines aggressively pursued research to find ways to remove methane from coal seams before mining them. By 1971, the Bureau and Amoco Production Company conducted some experimented wells in two of the major basins in US (Warrior Basin and San Juan Basin). After a successful gas production of 1 Mcfd with hydraulic stimulation treatment, the US Department of Energy (GRI) initiated its coalbed methane research program in the early 1980s. Although, the coal seams were not considered as a possible resource of economic gas production because often there was little or no gas show and, the coal seams produce more water than gas. 
It took some time and effort to understand the concept and production system of a CBM reservoir. The technology and completion techniques had to be developed in order to produce gas from coal seams. By the end of 1994, there have been 6,785 drilled wells with gas production of $847 \mathrm{Bcf}$. At the end of 2000, the production of gas has increased more than $35 \%$. The number of wells drilled has risen to 13,936 and the gas production to 1352 Bcf. The coalbed gas accounts for 7 percent of the total annual US dry gas production and 11.7 percent of estimated total gas recoverable US natural gas resource base (GRI, 1996).

Currently, the coal is seen as a reservoir and a source rock in which the methane that is released from the coal is a potential component of the US natural gas supply. Kuuskraa V. and Brandenburg C. affirmed, “...coal mining and gas production science and technology have been combined to form a new energy industry for the economic production of natural gas from coal seams". In other words, one of the major concerns of the miner's has been related to methane storage in the coal since it has made underground coalmines dangerous both from the risk of explosion and from the possibility of an oxygen-poor-atmosphere. The mining and gas industry recognize the advantages of combining efforts to reduce production costs and risks during both operations.

The total estimated gas in U.S. is around 400Tcf (Hunt, A. M., and Steele D. J., 1992). The major coalbed methane resources are located in 13 large basins: Western Washington, Wind River, Greater Green River, Uinta, Piceance, San Juan, Raton Mesa, Arkoma, Warrior, Central Appalachian, Northern Appalachian, Illinois and Power River (Figure 2.2). The two most productive basins are Black Warrior in Alabama and San Juan in northern New Mexico. The estimated gas reserves are $20 \mathrm{Tcf}$ and $88 \mathrm{Tcf}$ respectively. The CBM gas is now estimated to account for some $17 \%$ of total recoverable gas reserves in the country.

The fast growth in coalbed methane production has required significant efforts in improving technology and understanding the difference between gas production from 
conventional sandstone and from coal. Generally, the most relevant physical properties in coalbed methane are briefly described as followed:

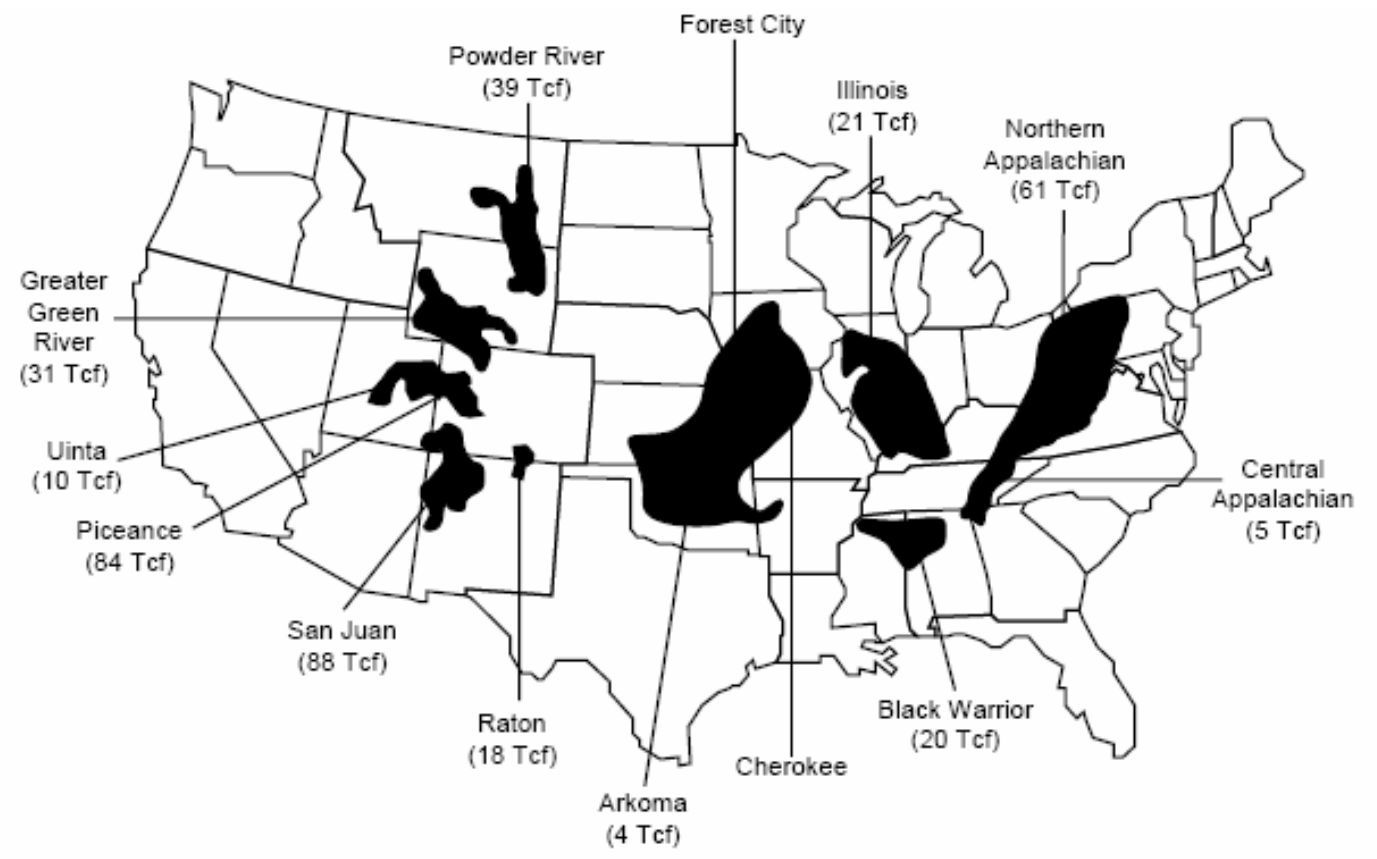

Figure 2.2. Major US Coalbed Methane Resources (adopted from GRI, 1996)

Coal Rank, is deeply associated to CBM reservoirs since the generation of gases in the subsurface occurred during the coalification process. The methane, carbon dioxide and other volatile components of coal are considerate by-products of this process. In this way, there are different levels of coal rank which are (GRI, 1996),

- Lignite, a brownish-black in which the alteration of vegetal material has proceeded further than in peat, but no so far as brown coal.

- Bituminous, a soft coal which burn freely with a flame. It yields volatile matter with heat.

- Anthracite, a hard black lustrous coal with more than 92\% fixed carbon (dry, mineralmatter-free). It is also called hard coal and its permeability is usually very low.

Usually, the rank of coals increases directly proportional with depth because coal is very sensitive to temperature, pressure, and length of burial (Figure 2.3). However there are some other variables that affect the coal rank with depth. So, it is possible that coals at 
the same depth do not have the same rank. Typically the gas content increases with the hardness of the coal, but the natural permeability also decreases. As a result, the most commercial coal ranks are in a range between sub-bituminous to semi-anthracite because they usually provide optimum gas content and sufficient permeability for gas production.

Maceral Composition is defined as the organic microscopic constituents of coals, analogous to minerals for rocks. There are three major groups of macerals: (a) the vitrinite group, which is derived form various decomposed woody tissues, (b) the exinite group from spore and pollen coats, cuticles, resins and other fatty secretions and (c) the inertinite group derived mainly from partial carbonization of the various plant tissues in the peat swamp stage (Rightmire C., et al., 1984).

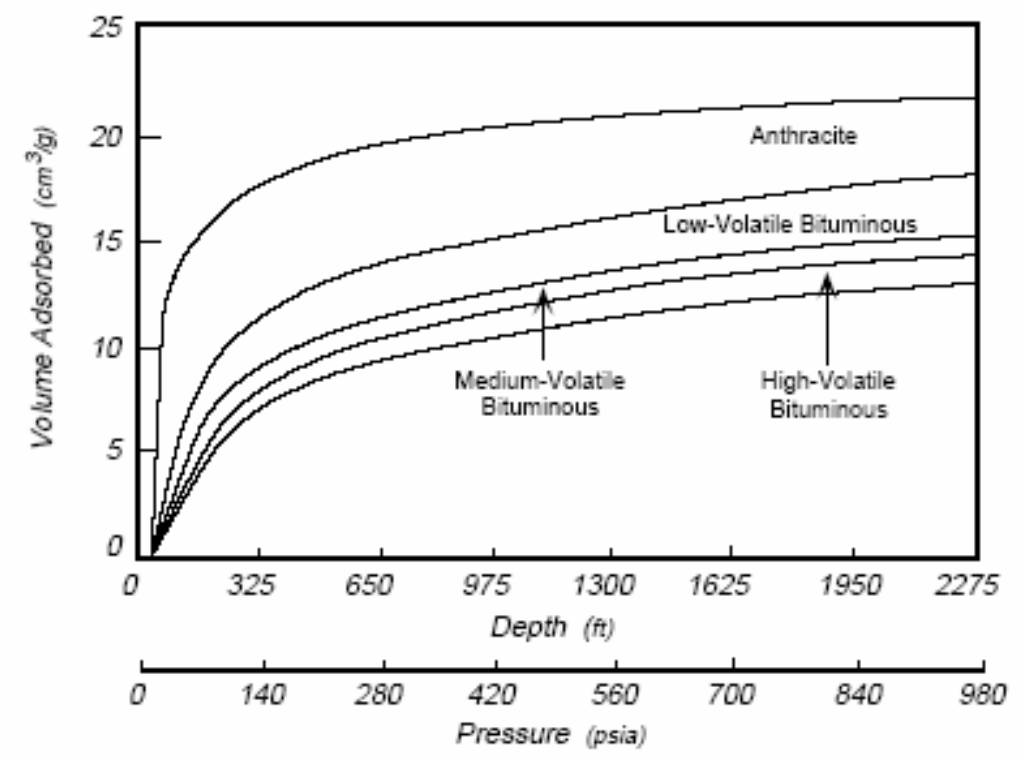

\section{Figure 2.3. Typical Desorption Isotherms as a Function of Coal Rank (adopted from CBM in US)}

Vitrinite Reflectance indicates the degree of metamorphism or coalification. It is mostly performed on vitrinites. It could be highly affected by the mineral matter content of the coal which tends to depress the virtrinite reflectance. Vitrinites exhibit a wide range of reflectance in the coalification series. (Rightmire C., et al., 1984) 
Adsorption Isotherm is a plot that shows the ability of the coal to adsorb the gas with respect to pressure (Figure 2.4). The adsorptive capacity of coal depends on various parameters as surface area, gas pressure, temperature and, moisture level. Nevertheless, pressure represents one of the most critical variables for producing gas. Figure 2.3 also shows that increasing the pressure implicates the decreasing of the ability of coal to continue adsorbing gas. In other words, while the pressure decreases the coal will desorbs more volume of gas. Moreover, higher coal ranks with larger surface areas have the highest adsorption capacity.

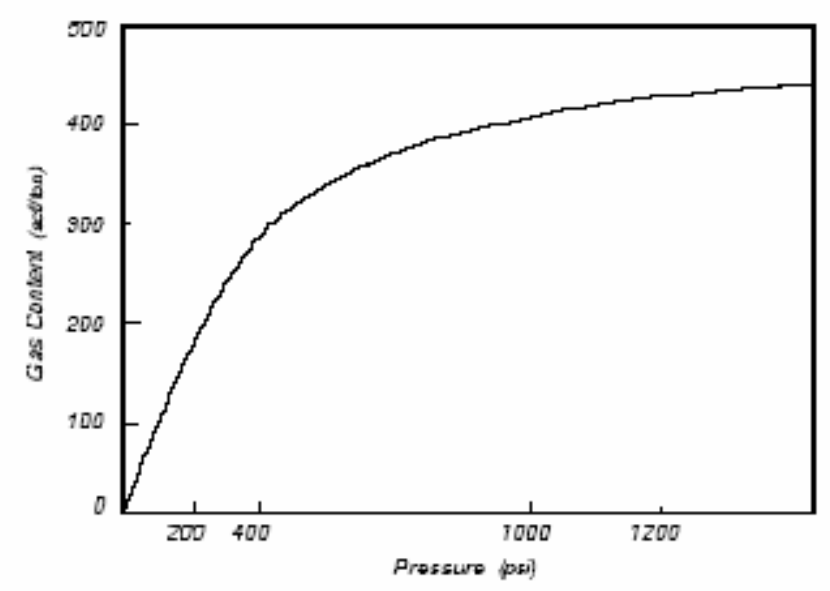

Figure 2.4. Langmuir Isotherm (adopted and modified from CBM in USA, 1984)

Porosity is referred as the portion of the total coal volume that can be occupied by water, helium, or a similar molecule (GRI, 1996). Coal pores are classified by size in macropores $(>500 \AA)$, mesopores $(20$ to $500 \AA)$ and micropores (8 to $20 \AA)$. Macroporosity includes cracks, cleats, fissures, voids in fusinite, etc. Pore volume and pore size both decrease with rank through low-volatile bituminous coals. The macropore spaces (fractures) in the coal are occupied mostly by water and some "free gas". Also, some gas can be solved in the water moving within the porosity of the coal. The micropore structure usually has a very low flow capacity with less permeability (in microdarcy range), whereas coal cleats have a much greater flow capacity with higher 
permeability (millidarcy range). Therefore, coals are considered as materials with dualporosity system.

Permeability is known as the ability of a material (generally an earth material) to transmit fluids through a porous medium when subjected to pressure. It represents one of the most important and crucial properties to produce gas at an economical rate. In US absolute permeabilities can range from 0.1 to 250 millidarcies. In coalbed methane, there are two major fluids flowing in the interconnected cleat network which result in a two phase flow regimen. In this case, effective and absolute permeability take place in order to differentiate two fluid flows in the porous media. The effective permeability is referred to each individual fluid. The effective permeability of individual flowing phase is always less than the absolute permeability of the porous media, and the sum of the effective permeabilities of all flowing phases is less than or equal to the absolute permeability (GRI, 1996). Relative permeability is defined as the ratio between effective and absolute permeability. After gas production starts, (long-time production of $\mathrm{CBM}$ ) a two-phase condition is initiated. At that point relative permeability controls the behavior of the reservoir. Permeability is affected by several parameters such as time-depth burial, fracture spacing, cleat system, effective stress in coals and, coal shrinkage.

The fluids in the coals (water and gases) flow through the coal cleat system and other fractures. The cleat is referred to as the natural system of vertical fractures that were formed during the coalification process. Their orientation is controlled by tectonic stresses at the time of fracture formation. The cleat system typically is formed for two or more sets of sub-parallel fractures oriented nearly perpendicular to the bedding (GRI, 1996). The face cleat is related to the dominant set of fractures. The orientation of the face cleats is a result of the tectonic forces. They are formed parallel to the maximum compressive stress. Butt cleats are more discontinuous and non-planar than face cleats. Butt cleats are usually perpendicular to the face cleats. The cleat system usually creates permeability anisotropic with greater permeability, which often is in the face cleat direction. 
In coals, permeability is very pronounced and stress-dependent. Horizontal stress perpendicular to the face cleat can close the face cleat openings and cause low permeability. When the stress conditions are low, natural fractures can be opened and provide permeability for flow through rock strata. Folding and faulting cam enhance coal permeability through formation of natural fractures. The tensional forces often cause fractures more intense along the axis a fold which produces fractures and keeps them open. In this way, the identification of faulting previous to drilling the coal will contribute to recognize those areas with lower stress near a fault or in a fault block. These areas represent possible locations of increased permeability. Lower permeability occurs at greater depth of burial and the higher values are found near geologic structures.

Cleat spacing also influences coalbed permeability greatly. The spacing of face cleat fractures may range from one tenth of an inch to several inches. It is influenced by coal rank, petrographic composition, mineral matter content, bed thickness, and tectonic history. Permeability can be higher in Medium-Volatile Bituminous than in semianthracite. In anthracite and semi-anthracite coals the permeability can be low to nonexistent because of the destruction of the cleat (GRI, 1996).

Furthermore, mineral fillings in cleat may also affect the permeability in the coals. Common minerals like calcite, pyrite, gypsum, kaolinite, and illite can fill the cleats, thus lowering the permeability values of the coals. If a large proportion of the cleats are filled, absolute permeability may be extremely low.

Therefore, knowing the major properties and its effects in coalbed methane reservoirs, is an important procedure in describing how the methane is stored in the coal, released and the flowing characteristics. Basically there are two basic concepts in the understanding of $\mathrm{CBM}$, these are the methane storage and the methane flow. 


\subsubsection{Gas Storage in Coal Reservoirs}

Methane is held in the coals in one of the following three stages: (a) as adsorbed molecules on the organic surfaces, (b) as free gas within the pores or fractures and (c) dissolved in solution within the coalbed (Rightmire, C. T. et al., 1984). However, the mainly amount of methane in coal exists as a monomolecular layer adsorbed on the internal surfaces of the coal surface and there is just a small amount of free gas in the cleat system of a coal seam. Since coals have a very large internal surface area and the methane's molecules are tightly packed in the monomolecular layer, the total quantity of gas can be adsorbed. Adsorption process is directly influenced by pressure, temperature

and coal rank. As pressure and coal rank increase (larger burial depth) and temperature decreases, the methane capacity of coal increases. So deeper coal seams will generally store larger amounts of methane than shallower coals seams of similar rank (Figure 2.3). In addition, as coal rank increases the coal's capacity of adsorption also increases.

The quantity of methane generated as coal progresses from peat to anthracite is greater than the capacity of the coal seams ability to absorb it. Boyer and others said "...the amount of methane (and other gases) produced during coalification generally exceeds the retention capacity of the coal, and the excess methane often migrates into the surrounding strata. For example, the highest gas content measured for anthracite coal in the US is 21.6 cubic meters per metric ton, only 12 percent of the total theoretical amount of methane generated during coalification". This fact can be explained mainly because the pressure holding the methane is much less today than the pressure when the gas was generated and, the amount of gas generated usually exceeds the capacity of adsorption of the coal seam.

The relationship between pressure and adsorbed capacity of coals is best described using a Langmuir isotherm (Figure 2.4). Generally, the coal's capacity of adsorption gas varies non-linearly as a function of pressure. Desorption isotherm shows the adsorbed gas concentration in the coal matrix changes as a function of the free gas pressure in the coal cleat system. Therefore, it represents the association between the flow in the matrix 
system and the flow in the cleat system. This non-linear relationship is defined by the Langmuir Equation which is,

$$
C_{m}=\frac{V_{L} p}{p_{L}+p}\left(0.031 \rho_{B}\right)
$$

The other byproduct of coalification process that takes an important place in analyzing coalbed methane is water. It can be stored in coals in two ways: (a) as bound water in the coal matrix and (b) as free water in the coal cleat system. Matrix bound water is not mobile and has not shown any significant influence in methane recovery from coal. However, the free water hold in the cleat system represents one of the critical parameter in methane production. The free water is mobile at high water saturations (greater than 30 percent). Many coal deposits are active aquifer systems and are 100 percent water saturated in the cleat system. Those that are not aquifers may not be totally water saturated. Typical irreducible water saturation for a well cleated coal is in the range of 20 to 50 percent of the interconnected cleat volume (GRI, 1996).

\subsubsection{Gas Transport Mechanisms in Coal Reservoirs}

In order to produce gas from coal reservoirs, the flow of methane through coal seams experiences three-stages process which are: (a) gas flows from the natural fractures, (b) gas desorbs from the cleat surfaces and, (c) gas diffuses through the coal matrix to the cleats (GRI, 1996).

The majority amount methane is stored in coal basically by adsorption in the matrix. However, as pressure in the coal is lowered, the main fluid that flows in the cleat system is water and small quantities of free gas and some dissolved gas in the water. After the

coal is dewatering, the methane is released (desorption stages-process) from the surface of the coal. Desorption is the process by which methane molecules detach from the micropore surfaces of the coal matrix and enter the cleat system where they exists as free gas (GRI, 1996). 
After desorbing from the coal surface, the methane flow in the matrix starts moving to the cleat system by different gas concentration gradients in both zones (diffusion). In other words, progressively the cleat system experiments low methane concentration that activates the gas adsorbed in the matrix to move from the higher gas concentration to the lower one. Diffusion is a process in which flow occurs via random molecular motion from an area of high concentration to an area of lower concentration (GRI, 1996). The diffusion process in the micropore system is described by the equation derived from Fick's Law. Using this equation the rate of flow from a matrix element into the cleat system can be calculated. It assumes the matrix elements are perfect cylinders.

$$
q_{g m}=\frac{8 \pi D V_{m}}{s_{f}{ }^{2}}\left(C_{m}-C(p)\right)
$$

The diffusion coefficient (D) is determined by desorbing methane from a core in a laboratory and measuring the rate of desorption as a function of time. It is related to sorption time, $\left(\tau\right.$, days), and cleat spacing $\left(\mathrm{s}_{f}, \mathrm{ft}\right)$. Sorption time is referred as the time required for methane molecules to desorb off of the coal surface and diffuse through the coal into the cleat system. In coals this time can vary from less than one day to over 300 days depending on coal composition, rank, and cleat spacing (Boyer C. M. et al., 1990). Sorption time can be calculated using the following equation,

$$
\tau=\frac{s_{f}{ }^{2}}{8 \pi D}
$$

The methane flow in the coals starts with lowering the pressure in order to produce the free gas and water from the natural system and to desorb methane from the cleat surface. The variation in concentration is compensated by releasing gas from the matrix by diffusion. Desorption is controlled by pressure gradients while diffusion is controlled by concentration gradient. Once the gas reaches a cleat or fracture, the flow of methane through the coal can be describe using Darcy's Law. Darcy's Law is applied to reservoirs with the simultaneous flow of more than one fluid by including the effective permeability 
to each flowing phase (GRI, 1996). The relative permeability of each fluid (gas and water) should be well known in order to get accurate results.

\subsubsection{Coalbed methane production}

Coalbed methane production passes through three phases during the life-time of the reservoir. This behavior differs significantly from the normal decline curve of conventional gas wells. The production profile of coalbed methane well is shown in (Figure 2.5). During phase I, CBM wells experiment a constant water production with a very low or negligible incline in gas production and decline in flowing bottomhole pressure. Initially, most CBM wells are naturally water saturated because water liberation occurs during the coalification process. The water is occupying the principal cleat network. There is the need of removing the water from the major fractures system in order to produce gas. Ideally, water production will relieve the hydraulic pressure on the coal in order to start the production by desorption of the gas from the coal. This process is known as Dewatering. The number of days of this dewatering process and the amount of produced water can vary widely. Their impact deals with the economics of gas production. In this sense, they are very difficult to estimate and their influence in the economics very hard to predict. However, it seams that they are controlled by the physical properties of the coal. The major physical properties that affect the efficiency of the dewatering process are (GRI, 1996): (a) permeability, (b) adsorbed gas content, (c) relative permeability and capillary pressure curves, (d) diffusion coefficient and, (e) desorption isotherm. At the end of this first phase, the well has reached its minimum flowing bottomhole pressure.

Phase II is described by a dramatically decrease in the water production and increase of the gas production rate. The water relative permeability decrease and the gas relative permeability increase. Outer boundary effects become significant and gas desorption rates change dynamically (GRI, 1996). The limit between phase II and III is determined by the peak gas rate is reached. The gas production has stabilized and starts to experiment a typical decline trend. During phase III, the well is considered to be dewatered, so the 
water production is in the low level or negligible. The water and gas relative permeabilities do not change extensively. The pseudo-steady state exists for the rest of producing life.



Figure 2.5. Typical Coalbed Methane Production Profiles for Gas and Water Rates: Three Phases of Producing Life (adopted from GRI, 1996)

\subsection{Northern Appalachian Basin Coal Bed Methane}

Coalbed Methane development and production began in the Appalachian basin nearly 60 years ago. The best known coalbed methane project in the Northern Appalachian was discovered in 1905. As early as 1932, it began producing from the Pittsburgh Seam in Big Run Field in Wetzel County, West Virginia. Since that time, some studies were undertaken in order to assess and improve understanding of the geologic characterization and production mechanisms. Today, the Northern Appalachian represents one of the most important and attractive sources for natural gas. It contains an estimated $61 \mathrm{TCF}$ of gas in place. (GRI, 1992). 
The most important geologic characteristics that has been found is referred to the location, coal group ages, and geological and reservoir properties. The Northern Appalachian Basin encompasses parts of Pennsylvania, West Virginia, Ohio, Kentuky and Maryland. The Appalachian Basin in general is a poli-historic basin developed through different tectonic events. The coal bearing formations were deposited through the Pennsylvanian ( $\approx 323-270$ millions of years ago), during the closing of the paleo-ocean Iapetus and the assemblage of the supercontinent Pangea. It is a northeast-southwest trending basin that covers approximately 30,300 square miles. The basin is bounded by the major graben structure called Rome Trough. The outcrop of Pennsylvanian age sediments defines the northeastern, northern, and western boundaries of the basin. It is conformed by six regional cross sections called The Brookville/Clarion, Kittanning, Freeport, Pittsburgh, Sewickley, and Waynesburg (GRI, 1992). The stratigraphic column is presented following,

\begin{tabular}{|c|c|c|c|c|c|}
\hline Age & System & Group & Lithology & Coal Group & Environment \\
\hline $\begin{array}{c}290-275 \\
\text { MY }\end{array}$ & $\begin{array}{l}\text { Lower } \\
\text { Permian }\end{array}$ & Dunkard & Red beds & & $\begin{array}{l}\text { Shallow water } \\
\text { lake, swamps }\end{array}$ \\
\hline \multirow{5}{*}{$\begin{array}{c}\text { 323-2290 } \\
\text { MY }\end{array}$} & \multirow{5}{*}{ Pennsylvanian } & Monongahela & \multirow{5}{*}{$\begin{array}{l}\text { Fine-to- } \\
\text { coarse- } \\
\text { grained } \\
\text { siliciclastic } \\
\quad \text { rocks }\end{array}$} & $\begin{array}{c}\text { Waynesburg } \\
(1.5 \mathrm{TCF})\end{array}$ & \multirow{5}{*}{$\begin{array}{l}\text { Shallow shelf, } \\
\text { Estuarine, } \\
\text { Swamps, Delta, } \\
\text { Strand plain }\end{array}$} \\
\hline & & Conemaugh & & $\begin{array}{l}\text { Sewickley } \\
(1.8 \mathrm{TCF})\end{array}$ & \\
\hline & & Allegheny & & $\begin{array}{l}\text { Pittsburgh } \\
(7 \mathrm{TCF})\end{array}$ & \\
\hline & & Pottsville & & $\begin{array}{c}\text { Freeport } \\
(15.5 \mathrm{TCF})\end{array}$ & \\
\hline & & & & $\begin{array}{c}\text { Brookville/Clarion } \\
(10.8 \mathrm{TCF})\end{array}$ & \\
\hline
\end{tabular}

Table 2.1. Generalized stratigraphic column of the coal-bearing formations in the Northern Appalachian Basin (adopted and modified from GRI, 1992)

The total natural gas in place estimated is contained in 350,000 billion tons of coal. Over one third of the gas in place is in the deeper zones. The area of highest potential for methane development is an elliptical area covering 16,500 square miles in southwest Pennsylvania and northwestern West Virginia and contains nearly 51 Tcf of gas in place. Each target coal group contains an estimated gas in place of Kittanning (24 Tcf), Freeport 
(15 Tcf), The Brookville/Clarion (11 Tcf), Pittsburgh (7 Tcf), Sewickley (2 Tcf) and Waynesburg (1.5 Tcf) (Kelafant, J. R., 1988).

High-volatile A and B bituminous coals are on the west and in the basin interior. It is flanked on the east by medium to low-volatile bituminous coals and eventually anthracite. The USBM has reported more than 400 desorption gas-content measurements in the basin. The highest reported gas content was $440 \mathrm{SCF} / \mathrm{T}$ and came from medium to low-volatile coal on the eastern margin of the basin. Correlations of gas content with depth indicate that 150 to 200 SCFT may be expected at target depths of 800 to 1,200 feet. Moreover, the coal-gas reservoirs tend to be underpressured with hydrostatic gradient averages of $0.30 \mathrm{psi} / \mathrm{ft}$. It also appears to have a longer sorption time (60 to 600 days) than those of other basins.

The total moisture content varies widely, depending on exposure to extraneous superficial water. It mainly ranges from 0.5 to $6 \%$ and, most coals have inherent moisture content from 2 to $4 \%$. The moisture usually decreases as rank increases. Ash content is about $90 \%$ of the total mineral matter (Kelafant, J. R., 1988). Sulfur content is commonly between 0.35 and $1 \%$ and rarely exceeds $1.5 \%$. Most of the remaining sulfur contained in the Northern Appalachian Basin bituminous coal occurs as iron sulfide in form of lenses, nodules, flakes, or fine particles.

Some gas chemical composition studies have been conducted as a function of time and burial depth. The samples were collected and analyzed from both vertical and horizontal boreholes in the Pittsburgh and Upper Kittanning coalbeds. Pittsburgh coalbed gas samples ranged from 84 to $96 \%$ methane, and the principal contaminant was carbon dioxide $\left(\mathrm{CO}_{2}\right)$. Upper Kittanning coalbed gas samples ranged from 95 to $99 \%$ methane, and nitrogen $\left(\mathrm{N}_{2}\right)$ is the principal contaminant. In general, this basin contains a number of the gassiest mines in the US with cumulative methane emissions measured to be more than 180 MMcfd. Desorption data indicate the presence of highly gassy coals where high coal rank, significant depth of burial, and tectonic stresses indicate a high potential for 
coalbed methane production. Some of the major reservoir and geologic characteristics are presented in the following table:

\begin{tabular}{|c|c|}
\hline $\begin{array}{c}\text { Reservoir and geologic } \\
\text { characteristics }\end{array}$ & $\begin{array}{c}\text { Northern Appalachian } \\
\text { Basin }\end{array}$ \\
\hline Gas Content (SCF/T) & $100-400$ \\
\hline Permeability (md) & $0.1-26$ \\
\hline Sorption time (days) & $60-600$ \\
\hline Coal rank & Bituminous - High Vol. \\
\hline Gas in place (TCF) & Above Pottsville \\
\hline Stratigraphic position & $800-1200$ \\
\hline Target depth (feet) & $0.18-0.3$ \\
\hline Hydrostatic gradient(psi/foot) & \\
\hline
\end{tabular}

Table 2.2. Major reservoir and geologic characteristics in Northern Appalachian Basin (adopted and modified from GRI, 1992)

Rightmire C. T. et al. defined the high-potential coalbed methane target areas in Northern Appalachian Basin. It covers approximately $4500 \mathrm{sq}$ mi and includes a significant part of north-central West Virginia. The target is slightly to the west of some of the highest rank coals. The coals have been extensively mined. The identification of this potential area for CBM production was done based on the following parameters:

- Numerous, relatively thick coalbed

- High or potentially high gas contents

- High-rank coal

- Significant overburden thickness

- High methane mine emission rates

- Significant distance from outcrop

- Producing coalbed methane wells

- Areas of extensive mining 
Furthermore, some of the major problems that have been found for CBM production are,

- The Coalbed Methane Produced Water treatment and disposal.

- The slow sorption rate of the Northern Appalachian Basin coals and the amount of residual gas.

- The need for standardization of testing procedures.

- The difficulties of maintaining quality control measures.

- The questionable nature of laboratory tests (desorption, adsorption isotherm, relative permeability) that do not accurately reflect in-situ conditions.

1. Significant errors (up to $100 \mathrm{pct}$ ) found in determining the gas content using the direct-method test (DM).

2. Inaccurate total gas content calculations due to the effect of topography on depth as well as coal rank.

3. Inaccurate results given by using the mass balance equation form in two-phase system in coalbed methane reservoirs.

4. Inaccurate estimates of permeability given by oversimplifying or neglecting desorption of methane in conventional analytical methods and pseudopressure method.

- The problems of methane emissions in underground coal mines.

- The lack of fundamental geologic and reservoir data for characterization and prediction of production.

- The Appalachian Basin has not achieved a commercial production of CBM due, in part, for the very limited data available for coal seams lying at deeper horizons.

\subsection{CMG Simulator}

CMG (Computer Modelling Group) model is a computer software for reservoir simulation capable to determine reservoir capacities in order to maximize potential recovery. CMG is conformed by six basic applications. They are (a) BUILDER, Preprocessing Applications, (b) IMEX, Black Oil Simulator, (c) STARS, Steam Thermal 
Advanced Processes, (d) GEM, Generalized Equation-of-State Model Compositional Reservoir Simulator, (e) WINPROP, Phase Behavior Analysis, and (f) RESULTS, Postprocessing Applications. For this study, it was used a part of these applications adjusted for coalbed methane production. The applications used were BUIDER, GEM, and RESULTS.

BUILDER is an application used in the preparation of reservoir simulation models. It makes the design and preparation of reservoir models faster and more efficient. It does this by helping engineers navigate the often complex processes involved in preparing a model. BUILDER provides a Windows interface which organizes data in an easy way for engineers. For engineers with little previous experience in modeling, it can be an excellent training tool by guiding them through the process of preparing a simulation model and enabling them to concentrate on the reservoir recovery process and not in the keyword syntax.

BUILDER presents two modules which are: (a) Gridbuilder, and (b) ModelBuilder. The Gridbuilder is used to create simulation grids and rock property data for IMEX, GEM, and STARs. It allows the user to easily create and edit grids, positioning them with respect to geological maps and then interpolating geological structures and rock properties. The grid can be displayed in a variety of $2 \mathrm{D}$ and $3 \mathrm{D}$ views to allow quick checking of the grid correctness and conformance. The ModelBuilder is also a Windowsbased software that helps the user to prepare input data for the simulators. It presents an easy-to-use visual interfaces as wells as support for direct editing of the data set information within the program itself. It has an automatic error checking and data validation options.

GEM is CMG's fully compositional simulator used to model any type of reservoir where the importance of the fluid composition and their interactions are essential to the understanding of the recovery process. It is an essential engineering tool for modeling very complex reservoirs with complicated phase behavior interactions which impact directly on the recovery mechanisms employed to optimize the recovery. Specifically, 
CMG has made some modification to the code in order to be able to use it for coalbed methane reservoirs. In this study, this modified version of GEM was the simulator used to modeling the CBM performance.

RESULTS, the post-processing application, is a CMG's set designed for visualizing and reporting simulator output. This application is able to prepare $2 \mathrm{D}$ and $3 \mathrm{D}$ plots, generate various informative graphs, and prepare tables of required information to be included in a study report. It can generate quick and easy export to spreadsheets for economic analysis, and specialized software. RESULTS is currently compose of two modules: (a) Results Graph and 3D, and (b) Result Report.

Results Graph is a 2D graph of well production and injection data from simulator runs and from common historical production data sources. It is controlled and defined by the user to provide all the options that the user needs to better understand the reservoir. Results $3 \mathrm{D}$ is a module that produces high quality scaled 2D and 3D views of all gridbased simulator data and links the displayed wells directly to the graphing capabilities of Results Graph. It allows the user control over the display both in location and time. It can be accessed directly through Results Graph and vice versa by opening different windows at the same time. In this way, the user has the complete vision of the plots to better understanding the performance of the reservoir. Results Report produces user-definable tabular reports of virtually any type of data generated during a reservoir simulation run, including well data, reservoir or sector totals and averages, and reservoir grid property data. It also can be used to compare data from different simulation runs and to generate ASCII files to input to economic analysis applications or spreadsheets of the user choice. 


\section{CHAPTER III}

\section{OBJECTIVE AND METHODOLOGY}

The objective of this research was to develop a simple and reliable tool to predict the performance of CBM wells in order to evaluate the economic feasibility and to maximize

potential recovery. To achieve the objective, a methodology consisting of the following four steps was employed:

1. Development of a base model for coalbed methane production in Northern Appalachian Basin.

2. Development and verification of the dimensionless groups for type curve generation.

3. Generation of the CBM production type curve.

4. Validation of the CBM production type curve.

\subsection{Development of a base model for coalbed methane production in Northern Appalachian}

The study started with an intensive literature review about CBM geological and reservoir characteristics in Northern Appalachian Basin. Information and wide range of data was compiled in order to use reliable and more accurate parameters for the construction of CBM base model. CMG software was used to build the CBM base model for the Northern Appalachian coals seams characteristics.

A large set of models were run to visualize, analyze, and understand the influence of each parameter on the performance of CBM wells. The main inputs that were estimated and evaluated were:

1. Cleat permeability

2. Thickness

3. Cleat porosity 
4. Initial matrix pressure

5. Initial fracture pressure

6. Flowing bottomhole pressure

7. Sorption time

8. Rock compressibility

9. Reservoir temperature

10. Gas and water relative permeability curve

11. Water and gas saturation

12. Area

13. Period of production

As a result, a two-dimensional, two-phase, Cartesian CBM base model was built for an under-saturated reservoir with a well located at the center of the drainage area. Table 3.1 summarizes the selected inputs for the base case.

\subsection{Development and verification of the dimensionless groups for type curve generation}

The second stage was performed based on the application of two sets of dimensionless equations. These two sets of equations have been published in literature (Aminian, K. et al., 1988; Mohaghegh S., and Ertekin T., 1991). The dimensionless groups are essentials for generating the production type curve to analyze and predict CBM performance. These dimensionless variables represent the values for the ordinate and abscissa of the type curve. Knowing the effect of two phase flow through the porous media in CBM, it is required to carefully analyze the impact of each variable of the equation in the behavior of the gas production type curve.

The first set of dimensionless equations used included some reservoir and geological properties such as viscosity, z-factor, temperature, permeability, thickness, pressure difference, compressibility, viscosity, and area. Some of these properties can be 
measured or estimated before starting or during gas production. They are presented as followed,

$$
\begin{gathered}
q_{D}=\frac{141.2 \mu z T}{k h\left(P_{i}^{2}-P_{w f}{ }^{2}\right)} \\
t_{D}=\frac{0.000267 k}{\phi \mu_{i} C_{t i} A}
\end{gathered}
$$

For this study, the viscosity, z-factor, and total compressibility were calculated. The initial pressure $\left(P_{i}\right)$ is considered as initial matrix pressure since it represents the pressure when the gas production starts.

The generation of the type curve was conducted together with the development of the dimensionless group was performed, and using a feedback from the results obtained from the validation process. A large number of simulations were run using the base model and the dimensionless equations 4 and 5. Eight parameters were analyzed and evaluated in order to verify the definition of each one in the dimensionless group and their impact in the gas production behavior. These variables are:

1. Cleat permeability

2. Cleat porosity

3. Area

4. Thickness

5. Initial matrix pressure

6. Initial fracture pressure

7. Sorption time

8. Flowing bottomhole pressure

Each of these inputs was varied in a realistic range between typical limits in Northern Appalachian basin leaving the rest of the inputs constant. These ranges were also 
extended in order to verify the accuracy of the model for other locations. The ranges used for each variable are shown in Table 3.2.

Table 3.1. Values for the CBM base model in CMG

\begin{tabular}{|c|c|c|}
\hline \multirow[t]{2}{*}{ INPUT PARAMETERS } & \multicolumn{2}{|c|}{ CMB BASE MODEL } \\
\hline & & VALUE \\
\hline Period of Production & & 20 years \\
\hline Porosity Model & Dual Porosity Model & - \\
\hline Shape Factor Calculations & $\begin{array}{l}\text { Gilman and Kazemi Style } \\
\text { Formulations }\end{array}$ & - \\
\hline $\begin{array}{l}\text { Matrix-Fracture Transfer } \\
\text { Calculations }\end{array}$ & $\begin{array}{l}\text { Pseudo-capillary pressure } \\
\text { model with corrections }\end{array}$ & - \\
\hline \multirow{2}{*}{ Grid } & Cartesian & $13 \times 1 \times 1$ \\
\hline & $\mathrm{K}$ direction & Down \\
\hline Grid's Size & & $100 \mathrm{ft} \times 100 \mathrm{ft}$ \\
\hline Reservoir Area & & $40 \mathrm{ac}$ \\
\hline \multirow{7}{*}{ Grid Properties } & Grid top & $1200 \mathrm{ft}$ \\
\hline & Grid thickness & $10 \mathrm{ft}$ \\
\hline & Porosity Matrix & $0.5 \%$ \\
\hline & Porosity Fracture & $2 \%$ \\
\hline & Permeability Matrix & $0.01 \mathrm{md}$ \\
\hline & Permeability Fracture & $10 \mathrm{md}$ \\
\hline & Fracture spacing & $0.2 \mathrm{ft}$ \\
\hline \multirow[t]{2}{*}{ Rock Compressibility } & $\begin{array}{l}\text { Matrix and Fracture: } \\
\text { Reference Pressure }\end{array}$ & 1100 psi \\
\hline & Rock Compressibility & $1 \times 10^{-6} 1 / \mathrm{psia}$ \\
\hline EOS Model & Peng - Robinson & \\
\hline Library Components & Methane & $\mathrm{CH}_{4}$ \\
\hline Constant reservoir temperature & & $113 \mathrm{~F}$ \\
\hline \multirow{4}{*}{$\begin{array}{l}\text { Rock-Fluid Data - Grid } \\
\text { Properties }\end{array}$} & $\begin{array}{l}\text { Maximal Adsorbed mass } \\
\left(\mathrm{CH}_{4}\right)\end{array}$ & $\begin{array}{l}\text { Matrix: } 0.2845 \\
\text { Fracture: } 0\end{array}$ \\
\hline & $\begin{array}{l}\text { Langmuir Adsorption } \\
\text { Constant }\left(\mathrm{CH}_{4}\right) \\
\end{array}$ & $\begin{array}{l}\text { Matrix: } 1.48 \text { e-3 } \\
\text { Fracture: } 0\end{array}$ \\
\hline & Rock Density & $\begin{array}{l}\text { Matrix: } 89.63 \mathrm{lb} / \mathrm{ft} 3 \\
\text { Fracture: } 89.63 \mathrm{lb} / \mathrm{ft} 3\end{array}$ \\
\hline & Coal Sorption Time (CH4) & $\begin{array}{l}\text { Matrix: } 50 \text { days } \\
\text { Fracture: } 50 \text { days }\end{array}$ \\
\hline \multirow[t]{3}{*}{$\begin{array}{l}\text { Initial Conditions - Grid } \\
\text { Properties }\end{array}$} & Water Saturation & $\begin{array}{l}\text { Matrix: } 0.005 \\
\text { Fracture: } 1\end{array}$ \\
\hline & Pressure & $\begin{array}{l}\text { Matrix: } 300 \text { psia } \\
\text { Fracture: } 600 \text { psia }\end{array}$ \\
\hline & Gas Composition (CH4) & Matrix: $1 \quad$ Fracture: 1 \\
\hline \multirow[t]{2}{*}{ Constrains } & $\begin{array}{l}\text { Operate Min Bottom Hole } \\
\text { Pressure }\end{array}$ & 50 psia \\
\hline & Operate Gas Rate Maximum & $350,000 \mathrm{ft} 3 /$ day \\
\hline
\end{tabular}


Then, having the gas production for each run, the outputs (time and gas rate) were converted to dimensionless values using the first set of equations. These dimensionless groups ( $t_{D}$ vs $q_{D}$ ) were plotted as Cartesian and log-log curves. This will allow studying the effect of each variable in the behavior of the curves generated more precisely. Different combinations and conditions were tested. Figure 3.1 shows an example of the gas production vs. time in a Cartesian scale varying permeability.

Table 3.2. Parameters range varied during simulations

\begin{tabular}{|c|c|c|}
\hline Variable & Range & Values used \\
\hline Cleat permeability (md) & $5-20$ & $5,10,15,20$ \\
\hline Cleat porosity (\%) & $1-4$ & $1,1.5,2,2.5,3,3.5,4$ \\
\hline Area (ac) & $40-160$ & $40,80,160$ \\
\hline Thickness (ft) & $5-15$ & $5,10,15$ \\
\hline Initial Matrix Pressure (psi) & $300-900$ & $\begin{array}{c}300,400,450,500, \\
600,900\end{array}$ \\
\hline Initial Fracture Pressure (psi) & $1100-300$ & $400,500,600,1100$ \\
\hline Sorption time (days) & $10-300$ & $10,50,100,200,300$ \\
\hline Flowing Bottomhole Pressure (psi) & $50-200$ & $50,75,100,200$ \\
\hline
\end{tabular}




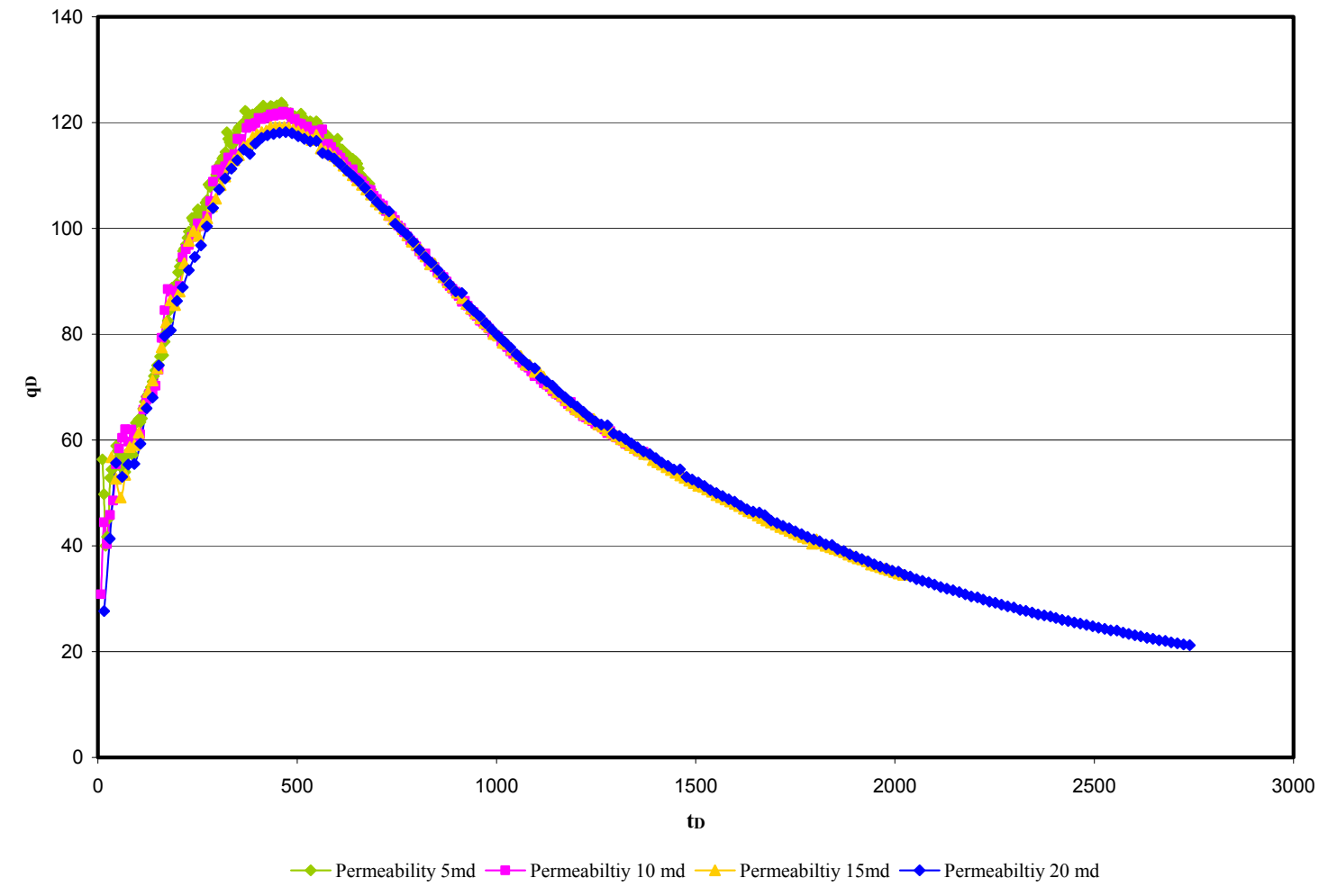

Figure 3.1. Dimensionless Time vs Dimensionless Gas Rate: Permeability Variation

A second set of equations for dimensionless time and gas rate was also applied. In this case, the equations incorporate maximum gas rate and initial gas in place. They do not require reservoir properties and they are presented as followed.

$$
\begin{gathered}
q_{D}=\frac{q}{q_{\text {peak }}} \\
t_{D}=\frac{t q_{\text {peak }}}{G_{i}}
\end{gathered}
$$

The same procedure was applied with the second group of equations. Similar runs were used and the outputs were converted to dimensionless values using the second set of dimensionless terms. The gas in place was calculated based on gas content (Equation 8). Gas content was estimated from Langmuir isotherm at the specific initial matrix pressure for each case. 


$$
G_{i}=43560 A h \rho G C
$$

The Langmuir isotherm was constructed based on values of $P_{L}$ and $V_{L}$ adapted to Northern Appalachian Basin. These values were also varied in order to evaluate the behavior of the gas production curve. Figure 3.2 shows one of the Langmuir isotherm used in this study.

\subsection{Generation of the CBM production type curve}

The generation of the CBM production type curve was performed while the dimensionless group was been developed and verified. The second set of dimensionless equations resulted to be the best group to generate the production type curve. Figure 3.3 and 3.4 shows an example of simulated outputs of dimensionless gas rates and time curves. Once the conversion of the different curves for the eight properties evaluated was reached, a unique production type curve was generated.

\subsection{Validation of the CBM production type curve}

Finally, the last stage was initiated in order to validate the accuracy of the production type curve that was constructed. The validation process started with the identification of the curve with the largest gap between the dimensionless curves and the average curve for each property analyzed. Then the squares of Pearson and the errors between those curves were computed by selecting the gas rate at similar times. In that way, the maximum difference (error) was measured and evaluated for the eight properties studied. 


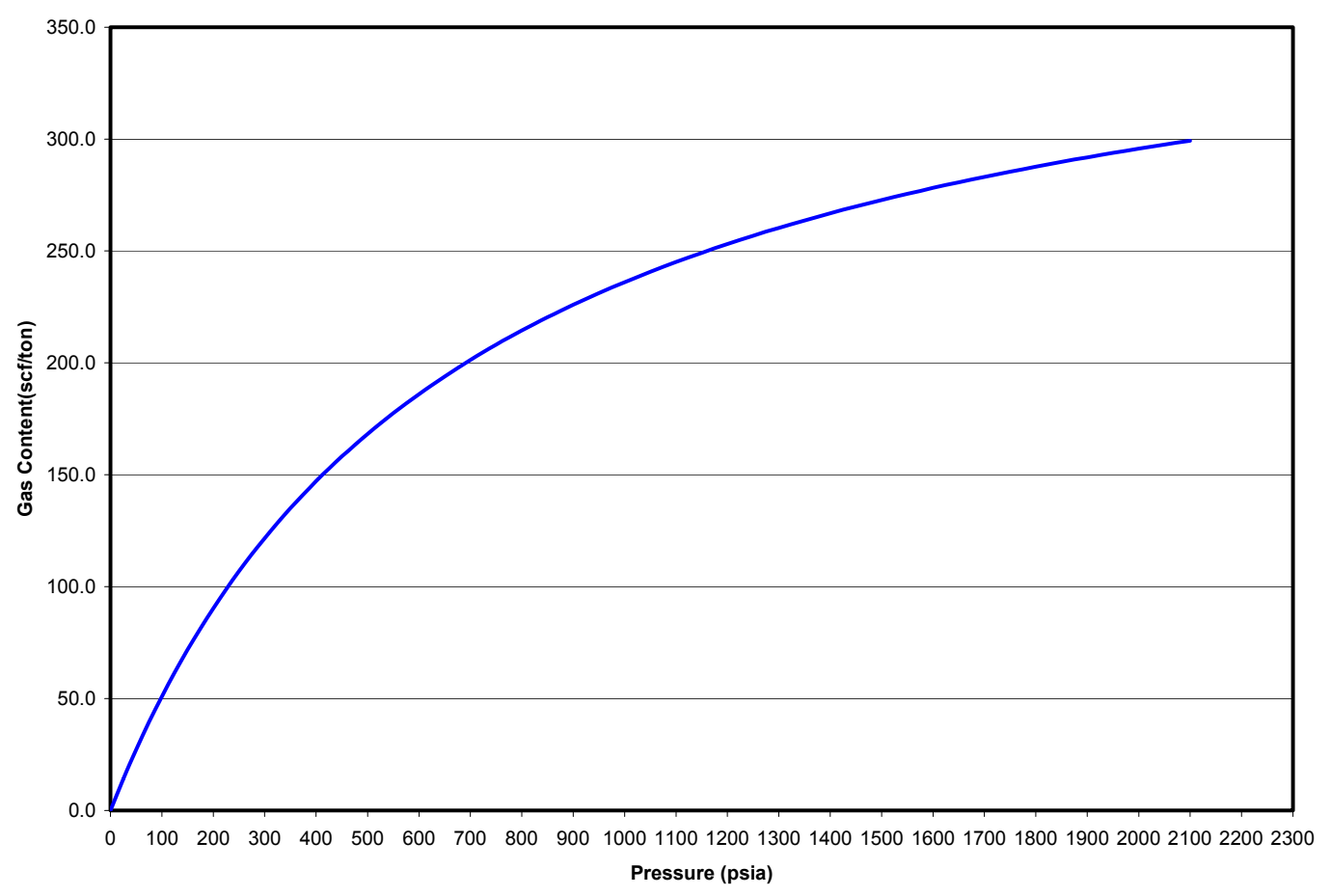

Figure 3.2. Langmuir Isotherm calculated

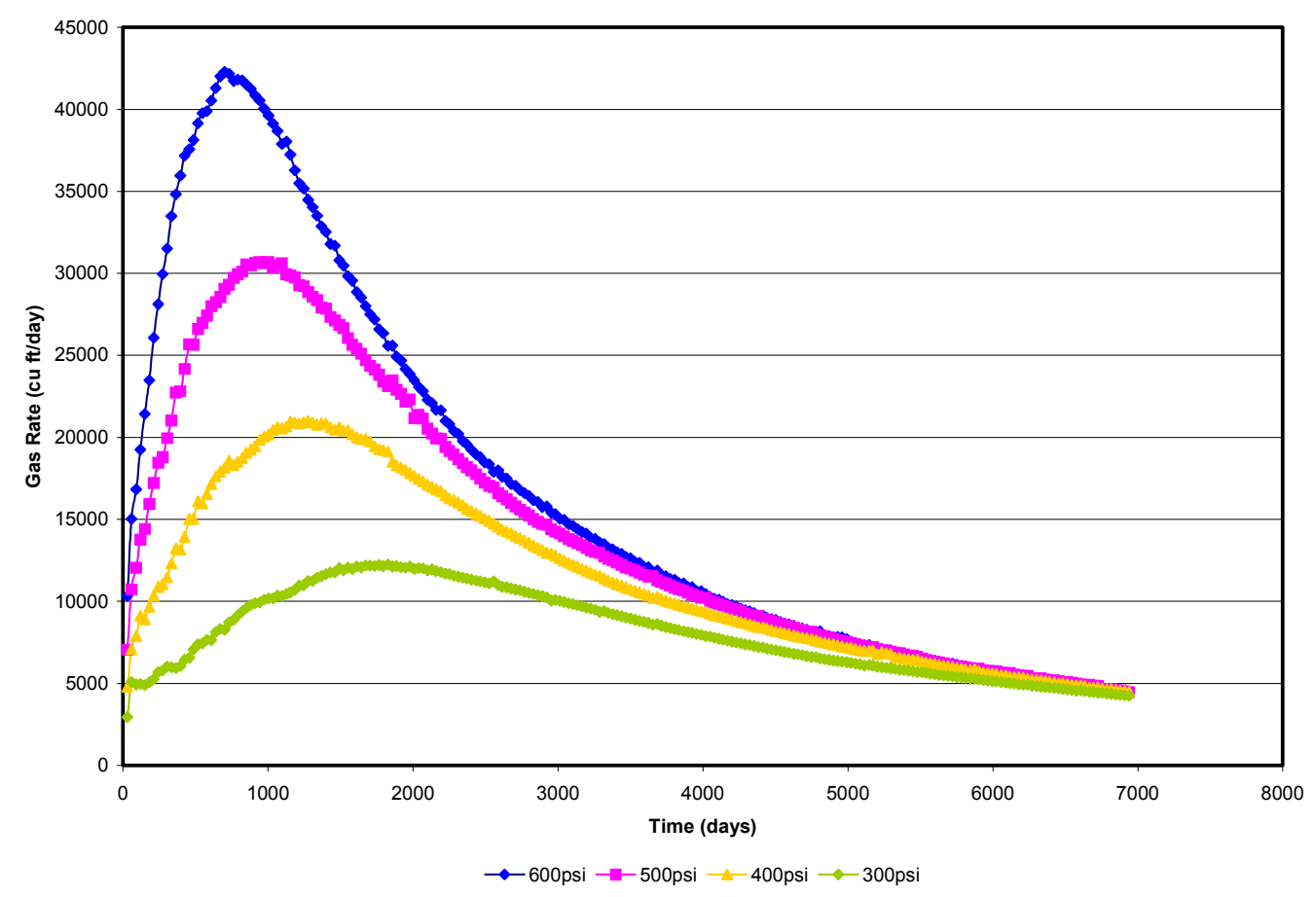

Figure 3.3. Effect of initial matrix pressure on the first set of Type Curves 
In addition, $\mathrm{CMG}$ simulator was used to generate the production history for two cases. The inputs used were values within the range that characterize the Northern Appalachian Basin properties, but using a combination of inputs completely different than the ones used for the runs made before at stages two and three.

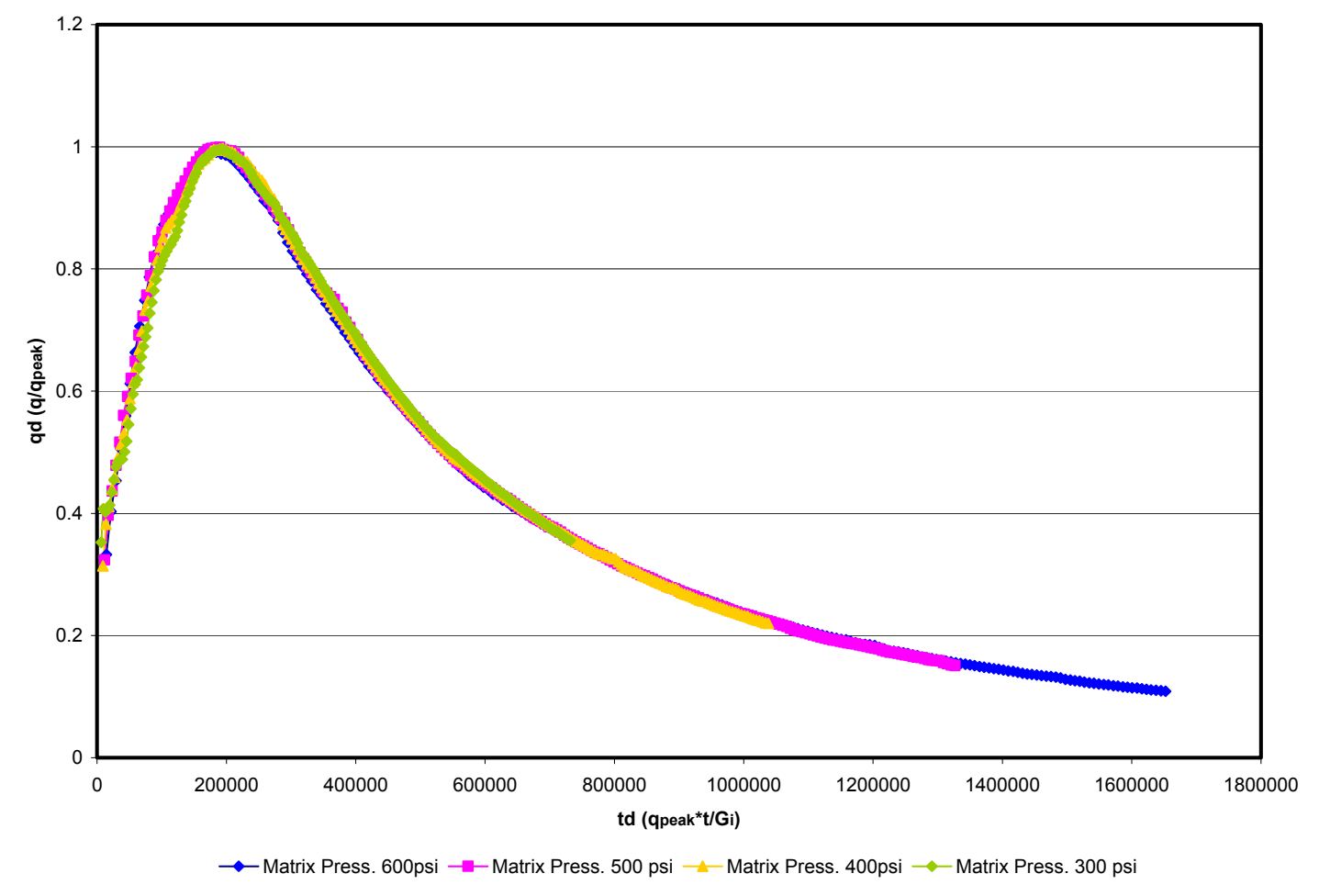

Figure 3.4. Effect of initial matrix pressure on the second set of Type Curves

The data (gas rate and time) generated by the numerical simulator was converted to dimensionless gas rate and time, which was plotted on a log-log scale. To analyze the production history for each case, the log-log plot is placed over the production type curve and it is moved only by shift coordinates. The process is repeated until it has found the closest match between both curves. Therefore, any arbitrary point can be selected and it is called the match point. This point provides two sets of coordinates, one from each plot. In other words, from the match point, it can be known $t_{D}-q_{D}$ from the dimensionless group and, $q-t$ from the simulated data. Knowing those values, peak gas rate $\left(q_{p e a k}\right)$ and the gas in place $\left(G_{i}\right)$ can be computed as followed, 


$$
\begin{aligned}
& q_{\text {peak }}=\left(\frac{q}{q_{D}}\right)_{\text {matchpoint }} \\
& G_{i}=\left(\frac{t q_{\text {peak }}}{t_{D}}\right)_{\text {match point }}
\end{aligned}
$$

Consequently, the production history simulated by CMG for the first years of production was used to obtain dimensionless values in order to employ the type curve. Then, the prediction of future production rate from the type curve and the future rates generated by the numerical simulator were compared. This step was performed in order to guarantee the degree of uniqueness of the dimensionless group used in the construction of the CBM production type curve.

On the other hand, an evaluation of peak gas rate was performed in order to provide an alternative procedure to predict CBM gas production without having any production data. The impact of the reservoir properties (area, permeability, thickness, porosity, initial matrix pressure, initial fracture pressure, sorption time, flowing bottomhole pressure, and differential pressure) on peak gas rate was studied. An alternative dimensionless group was presented (Equation 11) based on Darcy's Law definition. The flow rate basically depends on thickness, permeability and differential pressure. Therefore, these properties and peak gas rate were used as first approach to get the dimensionless group. This dimensionless flow rate was plotted against the reservoir properties studied before in order to analyze the impact of each property. The properties which effect was not taken in account by the dimensionless group were identified. An evaluation of those properties and peak gas rate behavior was performed.

$$
q_{D}=\frac{q_{\text {peak }}}{k h\left(P_{m}-P_{w f}\right)}
$$

This approach was conducted with the purpose of define a correlation to estimate the value of $q_{p e a k}$. Then, knowing some of the reservoir properties $q_{D}$ value can be found from 
the correlation. Then, solving equation 11 for $q_{p e a k}$, the prediction of gas production can be also estimated if there is not production data available. The value of peak gas rate was compared with the maximum gas rate obtained from the numerical simulator to complete the validation process. 


\section{CHAPTER IV}

\section{RESULTS AND DISCUSSION}

The general objective of this study was focused towards providing a simple tool capable of predicting the CBM production with accuracy. In order to develop this research and achieve the goals, a CBM base model was constructed using a numerical simulator (CMG). The model was defined in a Cartesian system for a single unstimulated well located at the center of the drainage area a two phase two dimensional flow in an undersaturated reservoir condition. The base model takes the account of coal reservoir characteristics from the Northern Appalachian Basin. However, the parameters were evaluated in wider ranges with the purpose to guarantee the accuracy and efficiency of the model for different coal seam properties from other locations.

A large number of computer simulations were ran while varying eight basic parameters (cleat permeability, cleat porosity, thickness, sorption time, matrix and initial fracture pressure, area, and flowing bottomhole pressure) and holding the rest of the inputs constant. The gas production and the time from each set of simulations were converted to dimensionless values applying two different sets of dimensionless equations. This procedure was performed in order to identify and analyze the impact of each selected property in the gas production performance. This was also done in order to evaluate the definition of the set of the dimensionless group for the construction of the production type curve.

Each property being tested varied within a range similar to the characteristic for the Northern Appalachian Basin. The dimensionless values were plotted on a Cartesian and $\log -\log$ scale. It was found that using the first set of dimensionless equations, six of the nine properties evaluated (permeability, area, initial fracture pressure, flowing bottomhole pressure, thickness, and sorption time) converge between themselves with a certain level of accuracy. Figures 4.1 to 4.6 show the graphs for the dimensionless group for each case. 


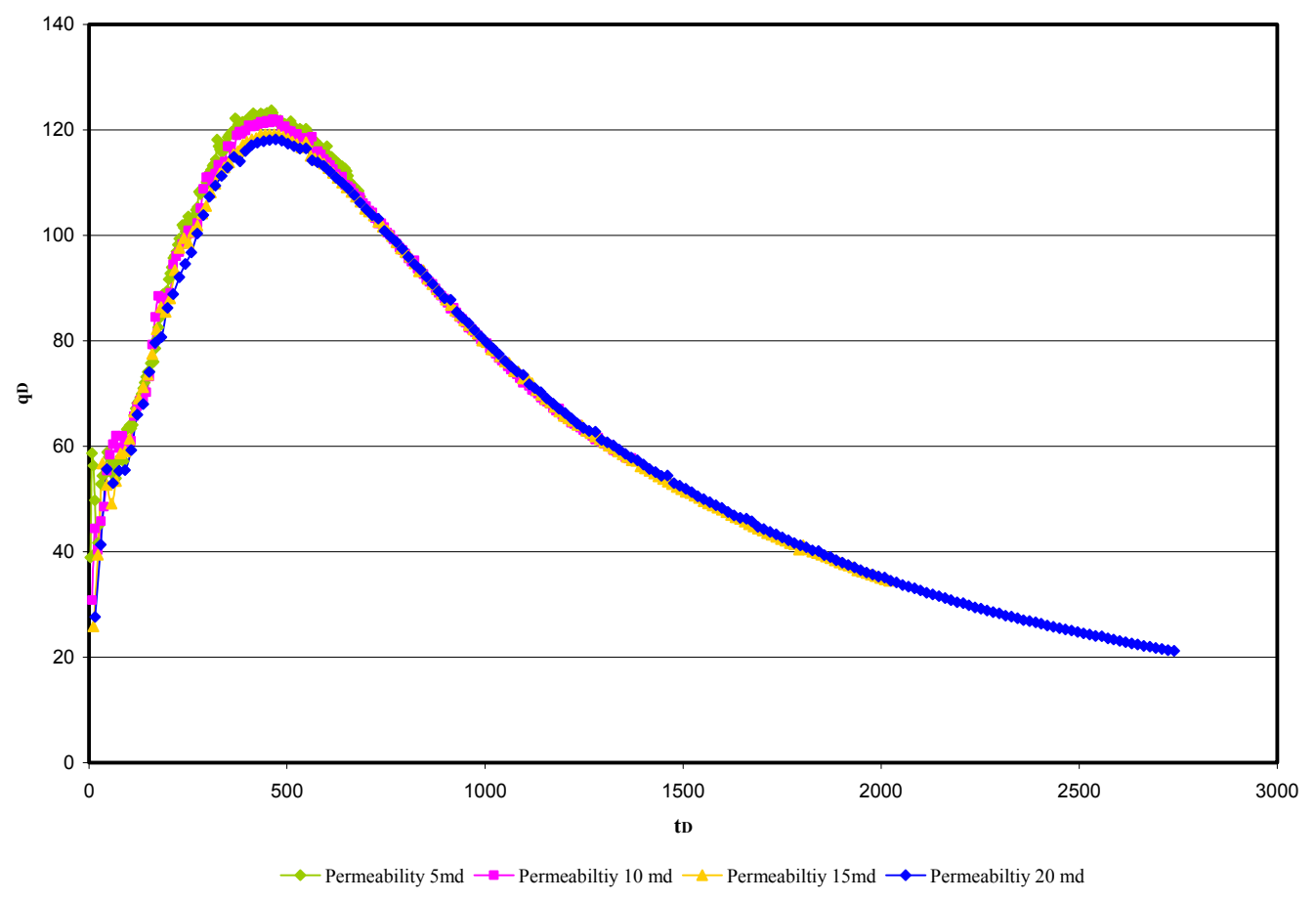

Figure 4.1. Effect of permeability on first set of Type Curves

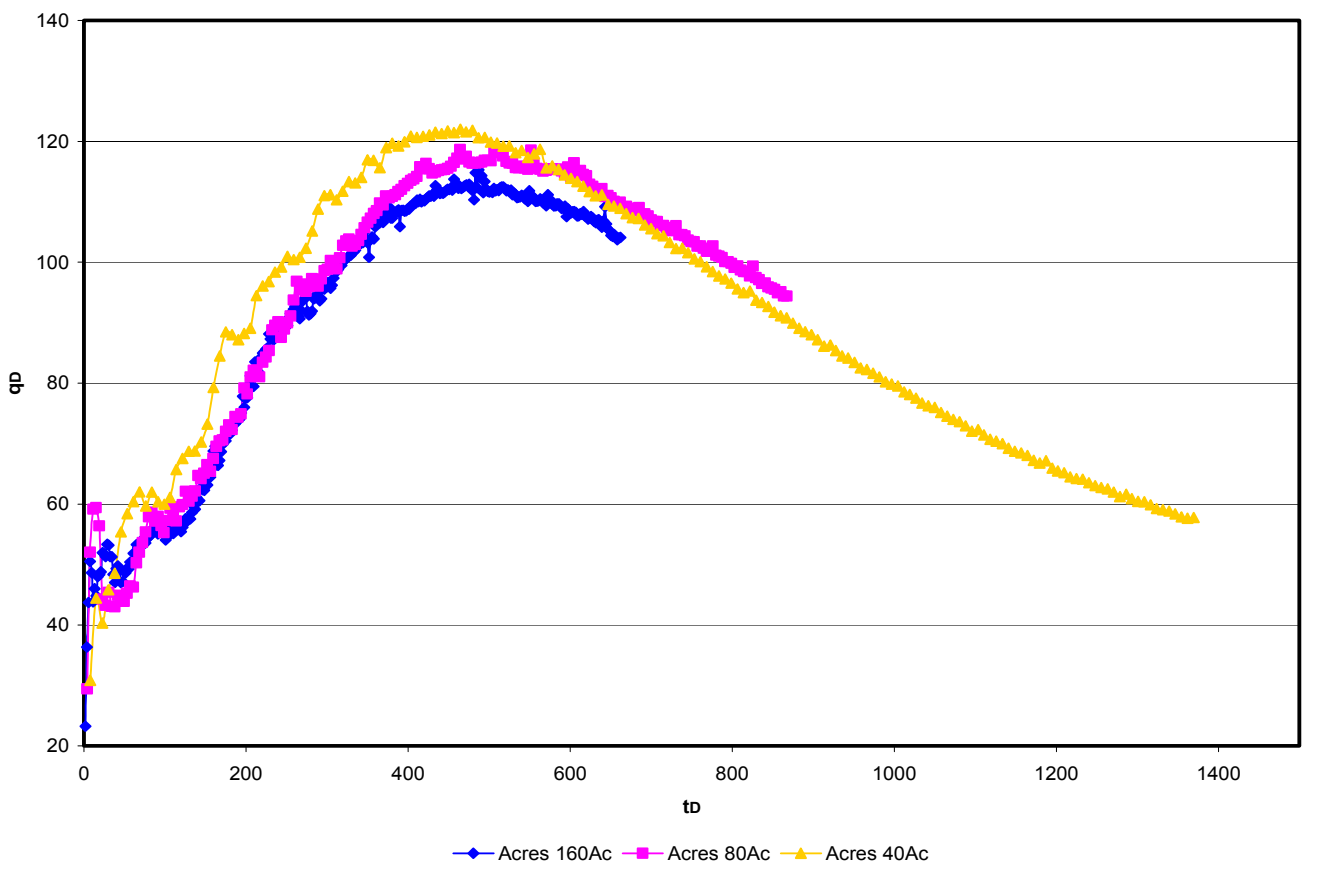

Figure 4.2. Effect of area on the first set of Type Curves 


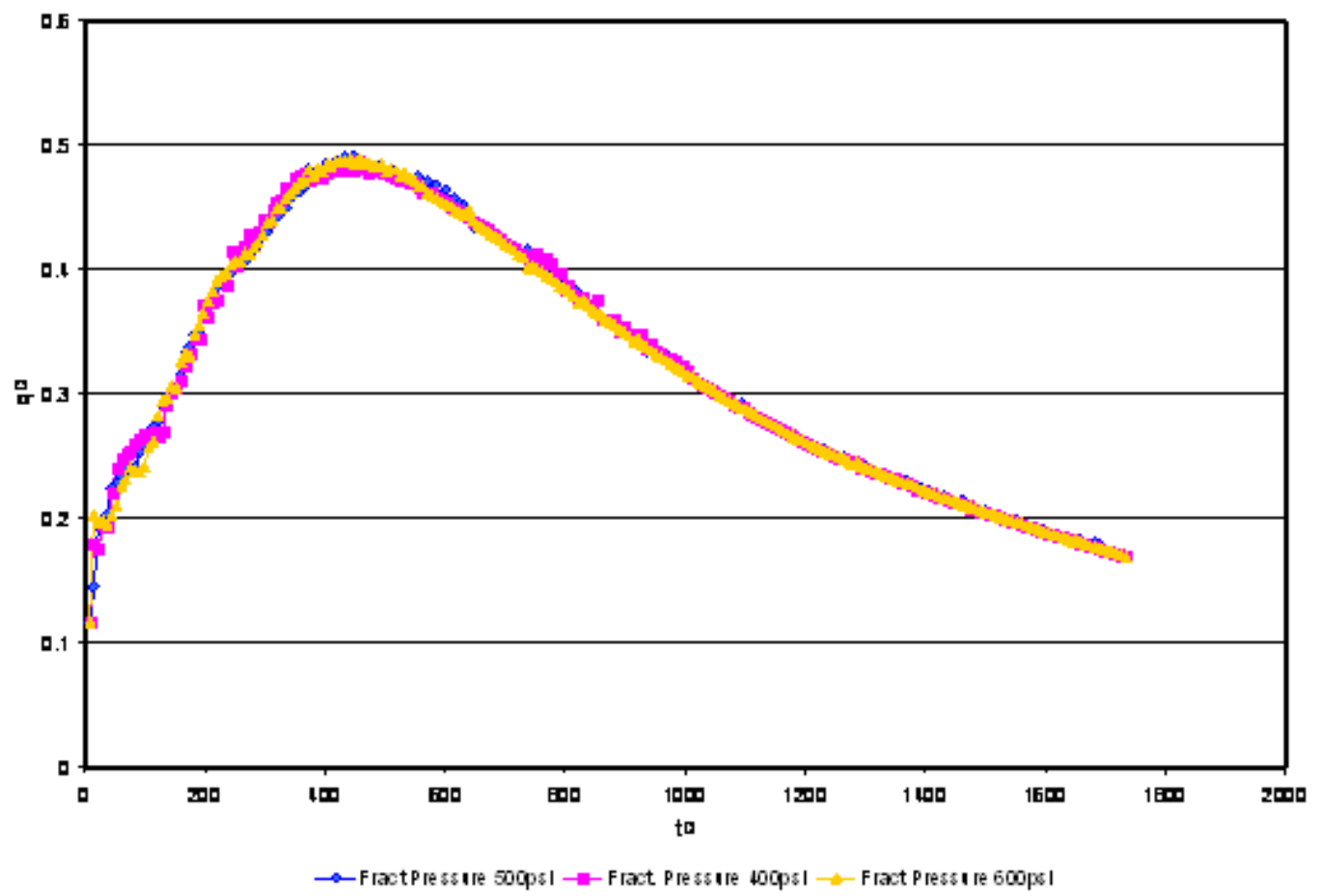

Figure 4.3. Effect of initial fracture pressure on the first set of Type Curves

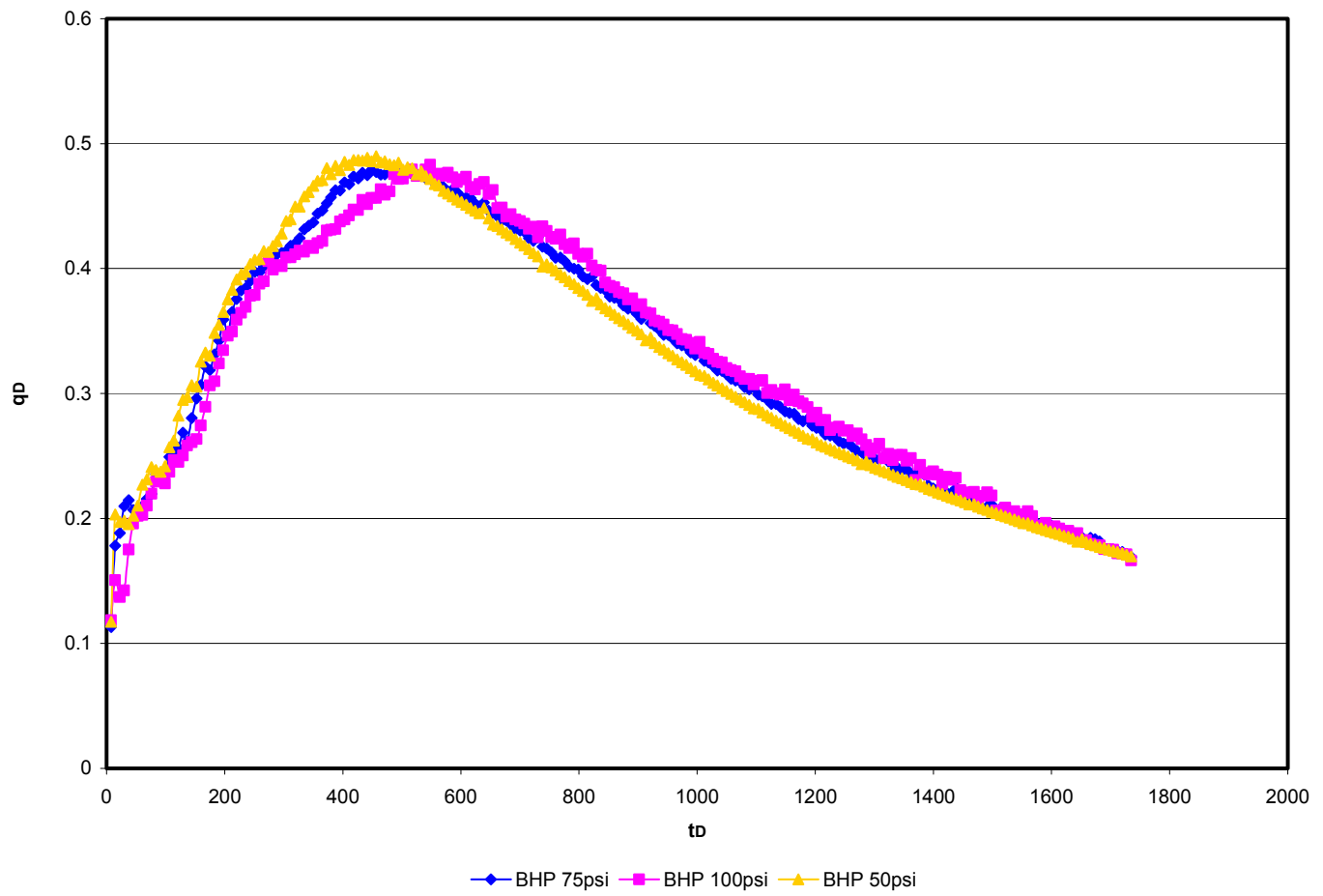

Figure 4.4. Effect of flowing bottomhole pressure on the first set of Type Curves 


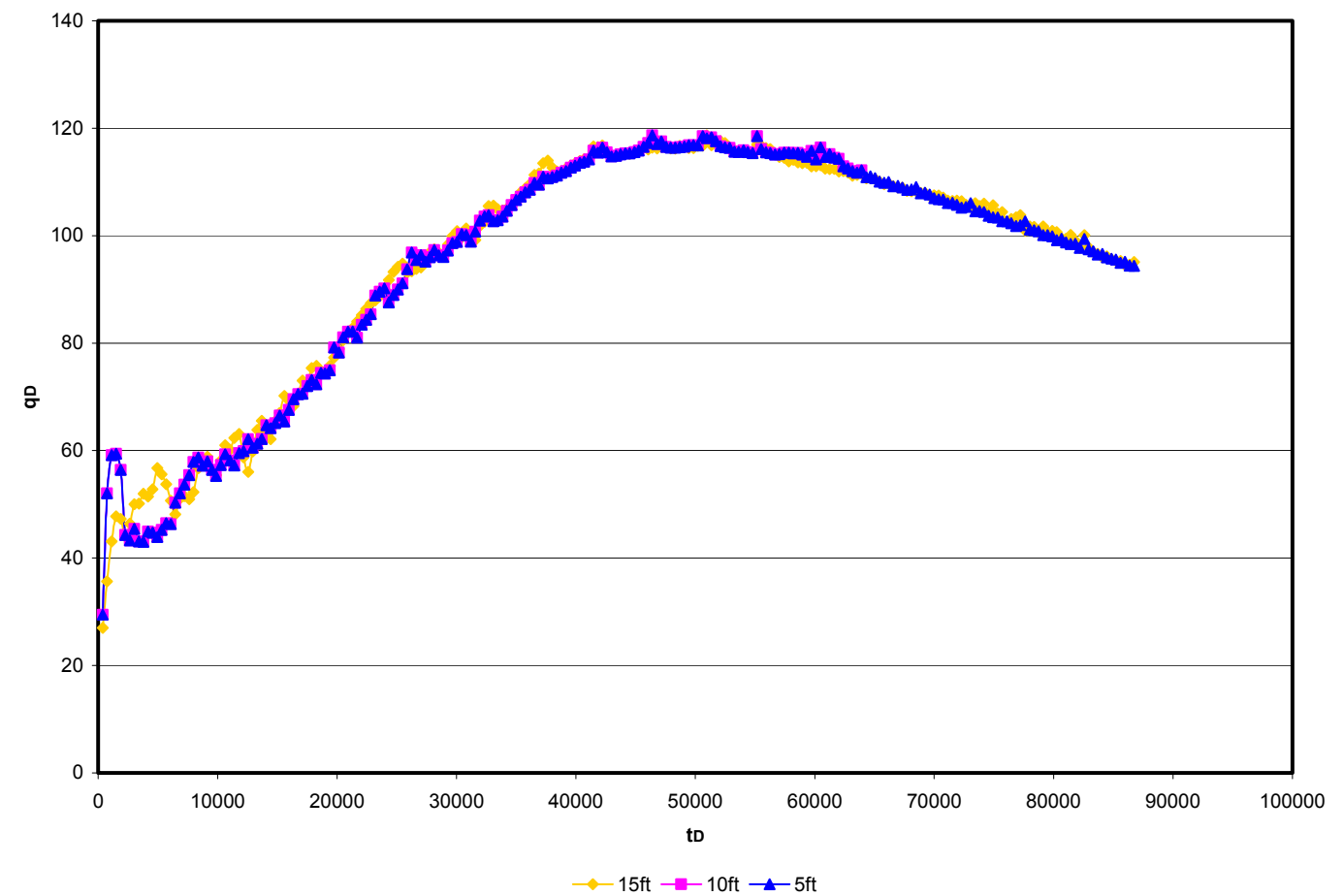

Figure 4.5. Effect of thickness on the first set of Type Curves

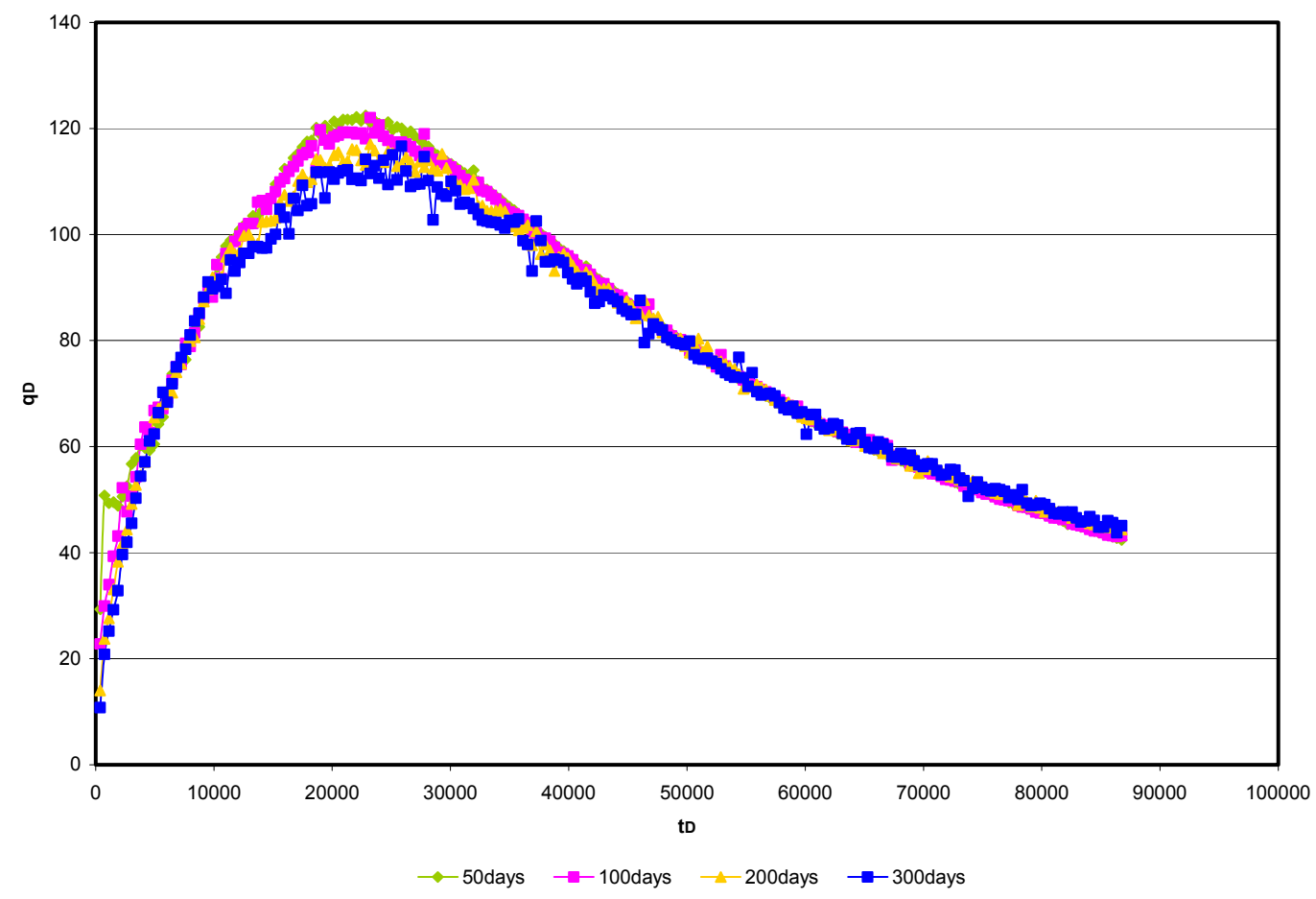

Figure 4.6. Effect of sorption time on the first set of Type Curves 
Porosity and initial matrix pressure appear to have a secondary effect in CBM performance that it is not taken in account by the dimensionless equations. The different values assumed for porosity provided different curves after the conversion of gas production and the time to dimensionless values. In plot 4.7 the curves showed variation of porosity and they do not converge between themselves. The same impact in the gas production behavior appears to have initial matrix pressure (Figure 4.8).



Figure 4.7. Effect of porosity on the first set of Type Curves

Having these results from using the first set of equations for dimensionless time and gas production a second set of dimensionless groups were applied. The second set of dimensionless equations uses the same procedure that was applied in the first set. The eight properties were studied and tested and the curves converged (Figures 4.9, 4.10, $4.12,4.14,4.16,4.18,4.20,4.22$ and 4.24). Knowing that the impact of the eight properties is being taking in account in the dimensionless group, an average model was simulated. The results were converted to dimensionless variables using the second set of dimensionless equations. After that, the eight sets of curves were also compared with the 
average curve in order to guarantee that converting them to dimensionless group moderate their impact on the gas production. The impact of each property will be explained in details as followed.

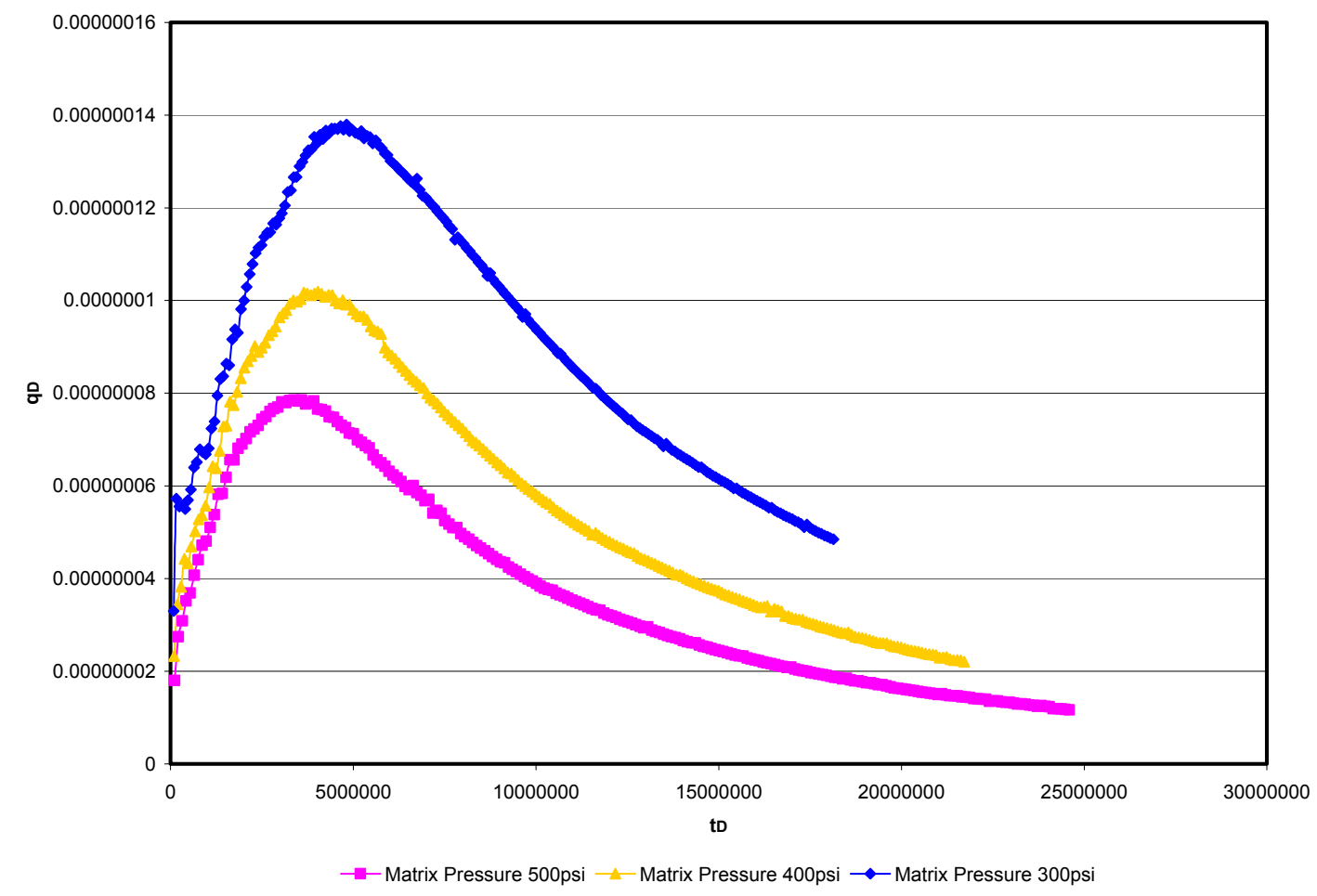

Figure 4.8. Effect of initial matrix pressure on the first set of Type Curves

In the first series of simulations the permeability values varied from 5 to $20 \mathrm{md}$. The top limit $(20 \mathrm{md})$ is considered really high for the Northern Appalachian coal seams; however it was incorporated in order to compare the effect of extreme values to make sure that the effect of this property is diminished when using the dimensionless values. Results from the first series of runs are shown in Figure 4.9. It can be seen that all the curves for different permeability values converge almost perfectly. Moreover, the permeability values were changed for different direction (Ex. $i=10 \mathrm{md}, j=5 \mathrm{md}$ and, $j=$ $10 \mathrm{md}$ ) in order to verify the behavior of the well and the anisotropic permeability impact. Figure 4.10 includes one of the simulations varying permeability in each direction. It shows that this curve also converges with the rest of the cases. Figure 4.11 shows the behavior of the curves varying permeability in $\log$-log scale. In addition, the error 
generated between the curves with different permeabilities and the average curve was calculated. The maximum error between the curve with the largest gap and the average curve corresponded to $9 \%$ with a square of Pearson of $91 \%$ (Appendix A). Therefore, as far as permeability is concerned, the dimensionless groups $\left(t_{D}\right.$ and $\left.q_{D}\right)$ provide a reasonable unique curve.

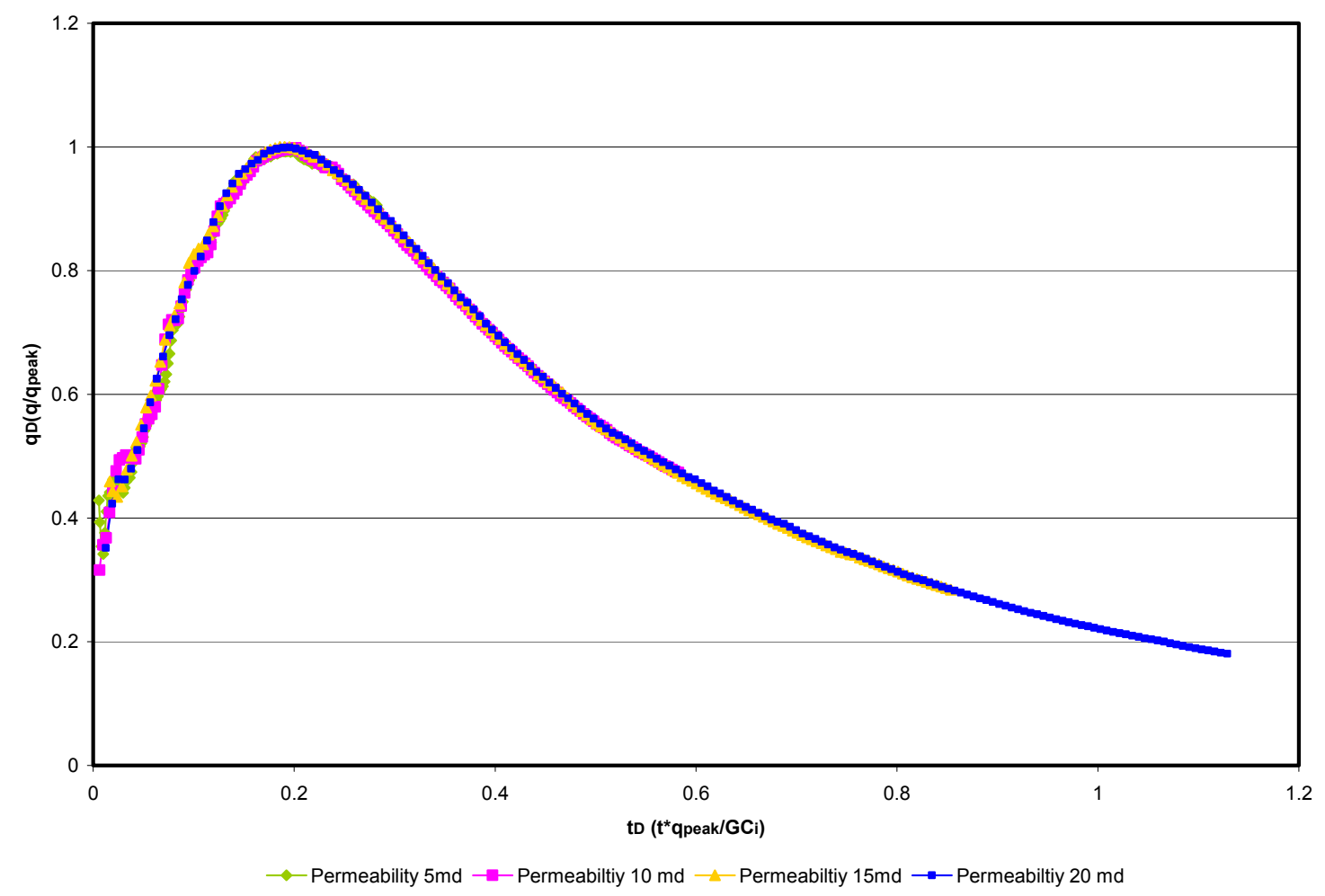

Figure 4.9. Effect of permeability on the second set of Type Curves

The second set of simulations incorporated the effect of porosity into the behavior of CBM production. Porosity varied from 1 to $4 \%$. This range is applicable to Northern Appalachian basin and in fact exceeds the typical values for this location. Figure 4.12 shows the curves for five cases $(1 \%, 1.5 \%, 2 \%, 3 \%$, and $4 \%)$. Figure 4.13 illustrates the effect of different porosity values in log-log scale. The lower porosity experiences a longer period of production because the fracture system has less capacity to flow fluid flowing when compared those coals seams with higher porosity values. This fact can be seen in the plot mentioned above. Additionally, the plot shows that all the cases almost 
meet in one curve. The error calculated between the curve with the largest gap and the average curve was $1 \%$ with a square of Pearson of $99 \%$ (Appendix B). These results confirm that the effect of porosity is perfectly taken in account by converting them in dimensionless values.

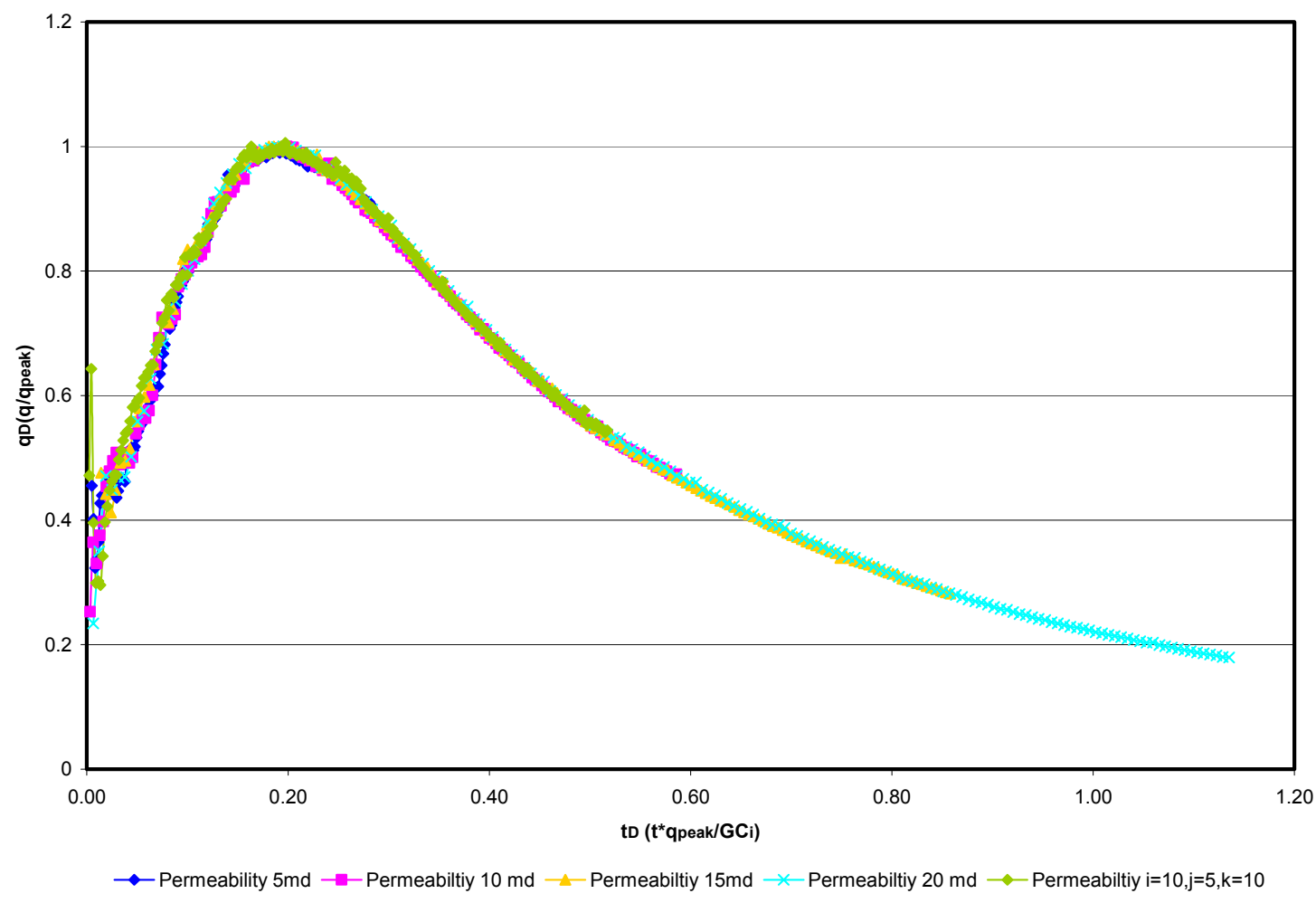

Figure 4.10. Effect of permeability in different directions $(i, j, k)$ on the second set of Type Curves

The third set of simulations used different values for reservoir area. The application of three distinct areas of 40,80, and 160 acres were utilized. Figure 4.14 shows the gas production for each case. By observing the graph, the three cases converge. The smallest area presents longer period of production since the drainage area is not as big as the case for 160 acres. The biggest drainage area presents the same shape of the curve, but the time of production is shorter due to bigger depletion area. The gas production occurs faster for smaller drainage areas. However, the time-gas-peak occurs at the same point for all the cases (Figure 4.14). 
Figure 4.15 illustrates the gas production rate vs. time in dimensionless time using a log$\log$ scale. At very early stages, the gas production diverges for each curve, but the timegas-peak and the production after that point converges with high level of accuracy. In order to evaluate these gaps at early stages, the square Pearson was calculated and the error between the curve with the largest gap and the average curve (Appendix C). The square of Pearson resulted in $91 \%$ and the maximum error in $9 \%$. This margin of error is still considered between the acceptable ranges of errors for prediction calculations. Consequently, the effect of the drainage area can be taken in account by the dimensionless group.

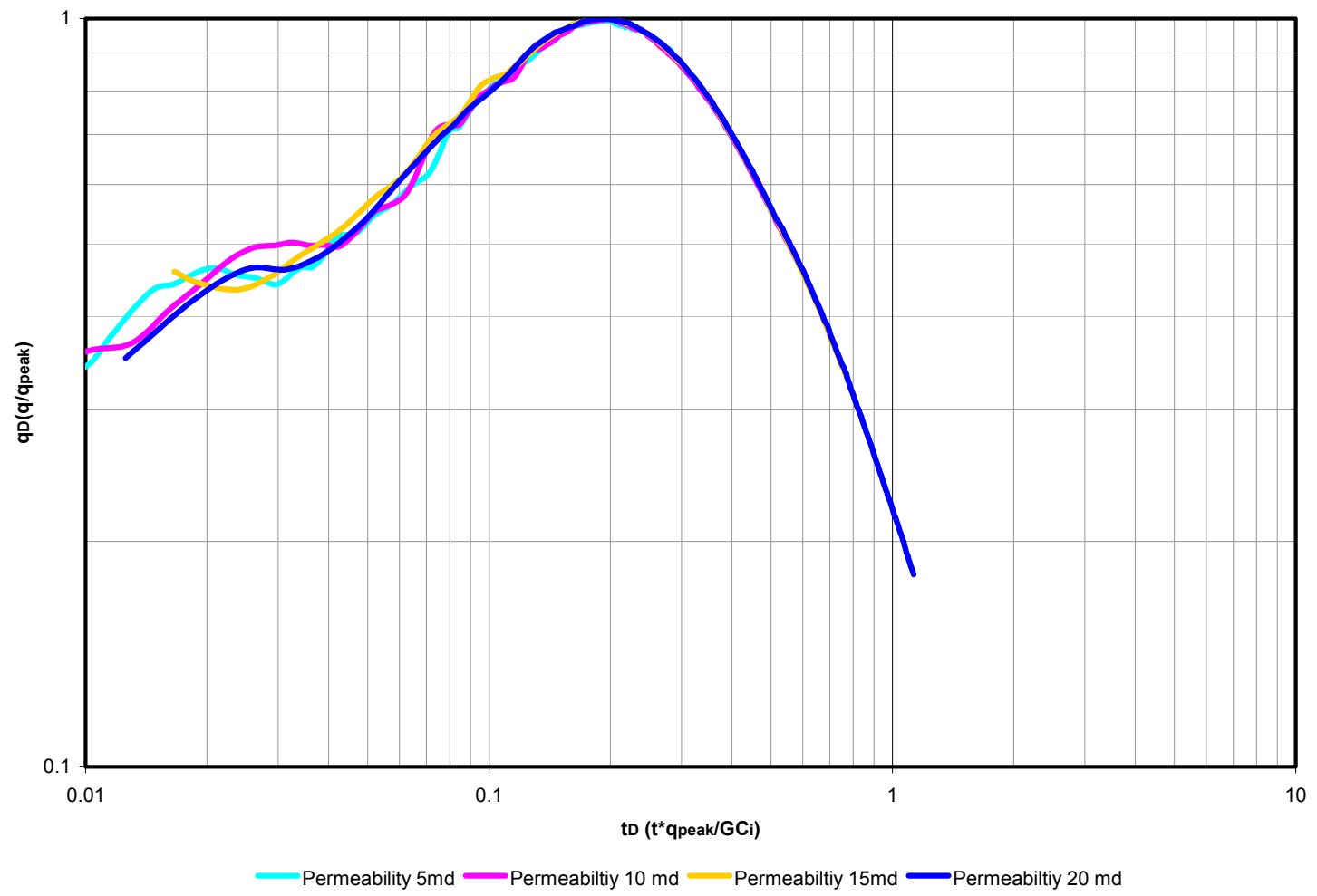

Figure 4.11. Effect of permeability on the second set of Type Curve in log-log scale 


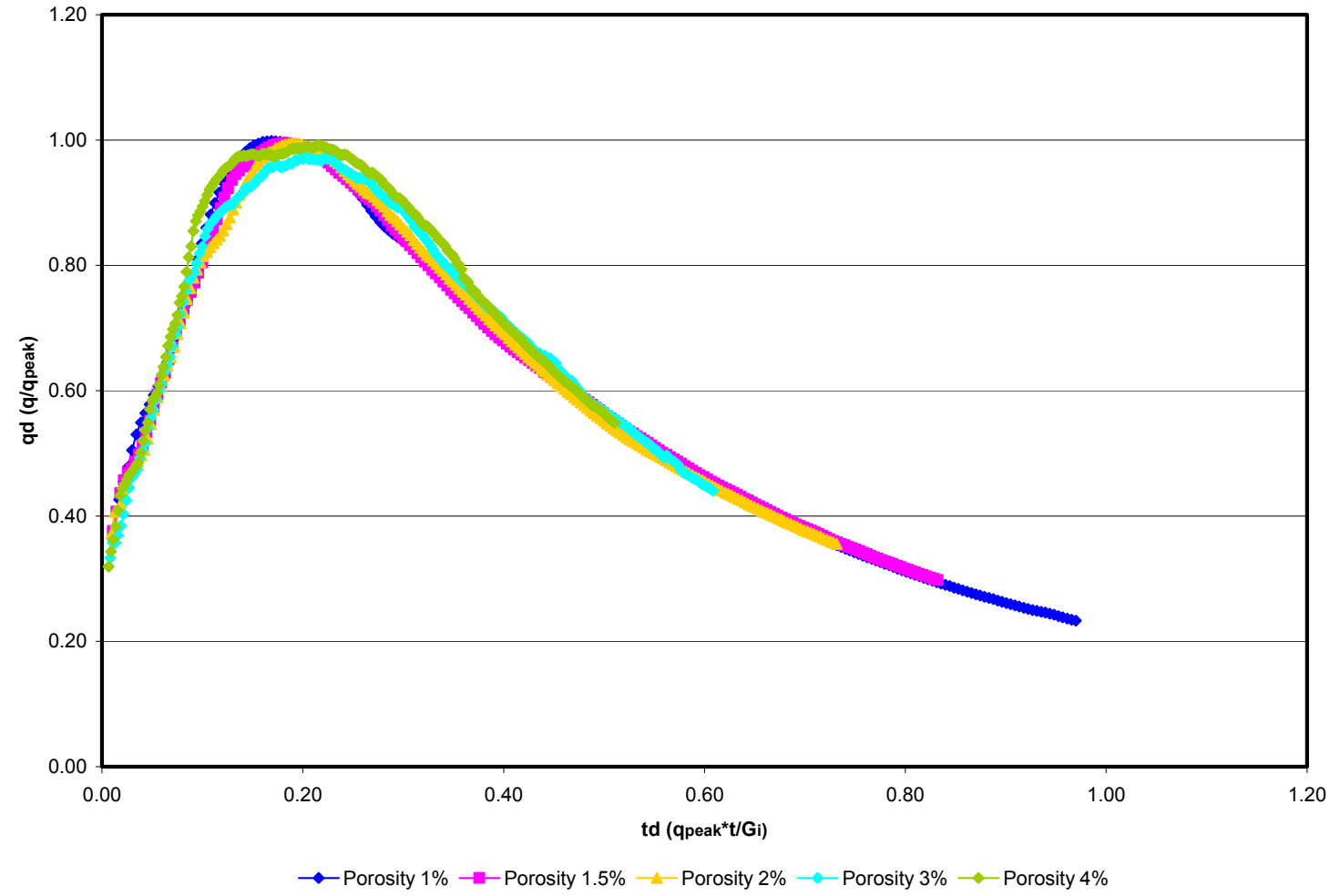

Figure 4.12. Effect of porosity on the second set of Type Curves



Figure 4.13. Effect of the porosity on the second set of Type Curves in $\log$-log scale 


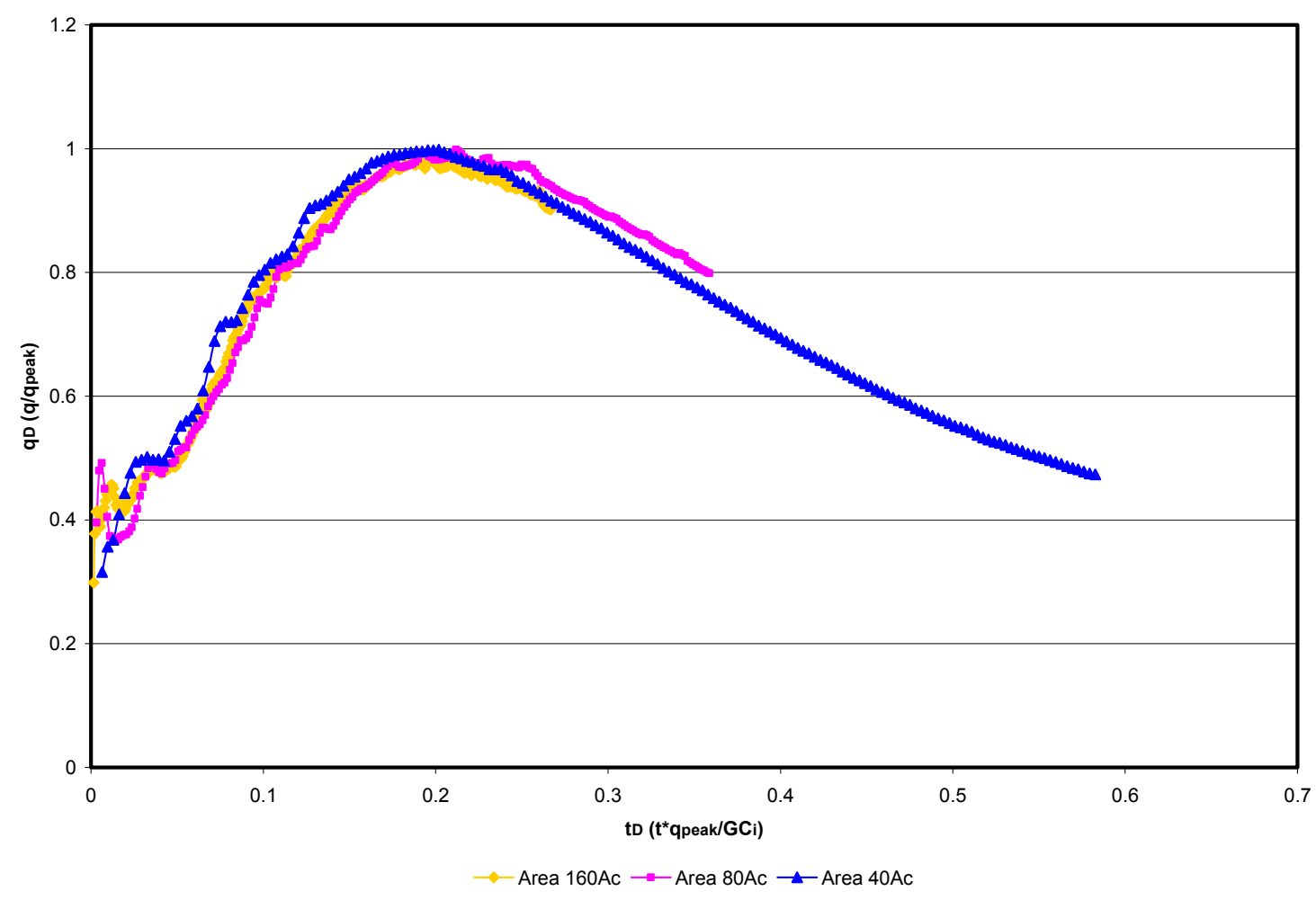

Figure 4.14. Effect of area on the second set of Type Curves

The fourth set of simulations was performed to evaluate the influence of coal thickness in CBM reservoirs performance. Thickness of 5, 10, and 15 feet were used for the simulations. Figure 4.16 illustrates the comparison between these three cases and the average curve. During the early stages they converge in an acceptable manner, but at late time they deviate in a small range from the average curve. Nevertheless, the period for the gas peak occurs almost at the same time for all the curves. The maximum error found for thickness change was $9 \%$ with a square of Pearson of 91\% (Appendix D). The dimensionless group is then providing a reasonable unique curve minimizing the impact of the coal thickness on the CBM production.

The fifth set of simulations includes the variation of initial matrix pressure. The initial matrix pressure is referred as the pressure when the gas production starts. The reservoir pressure has to be decreased until it reaches the initial matrix pressure in order to release the gas from the coal seam. In this sense, the impact of the initial matrix pressure in the 
CBM production is considered critical and it needs to be tested to evaluate the behavior of the gas depletion. The initial matrix pressure varied in a range of 300 to 1000 psi. Figure 4.18 illustrates the comparison between the average curve and different values of initial matrix pressure. Figure 4.19 illustrates the influence of initial matrix pressure on the gas production performance in a log-log scale. The plot reveals almost a perfect match between them. The largest error was about $1 \%$ with and square of Pearson of $99 \%$ (Appendix E). Therefore, the impact of initial matrix pressure can be overlooked using these sets of dimensionless equations.

The sixth set of simulations corresponds to the variation of initial fracture pressure. Simulations were performed testing this property from 300 to $1100 \mathrm{psi}$. The impact of the initial fracture pressure on the gas production behavior is not as high as initial matrix pressure because most of the gas is stored in the coal matrix and it is not flowing as a free gas in the fractures of the coal.

Figure 4.20 shows the behavior of the dimensionless production for several initial fracture pressures. In the plot can be seen the curves shapes between different initial fracture pressures. Appendix F and Figure 4.21 demonstrate the comparison between the average curve and different gas production curves for each initial fracture pressure and the behavior of the production in log-loc scale.

At early stages, a small gap between the curve can be seen it, but after the time-peak-gas and at the late production all the curves meet in one shape. The maximum error computed for initial fracture pressure variation was 3\% with a square of Pearson of $97 \%$. As a result, the effect of initial fracture pressure can also be accounted by the dimensionless group used. 


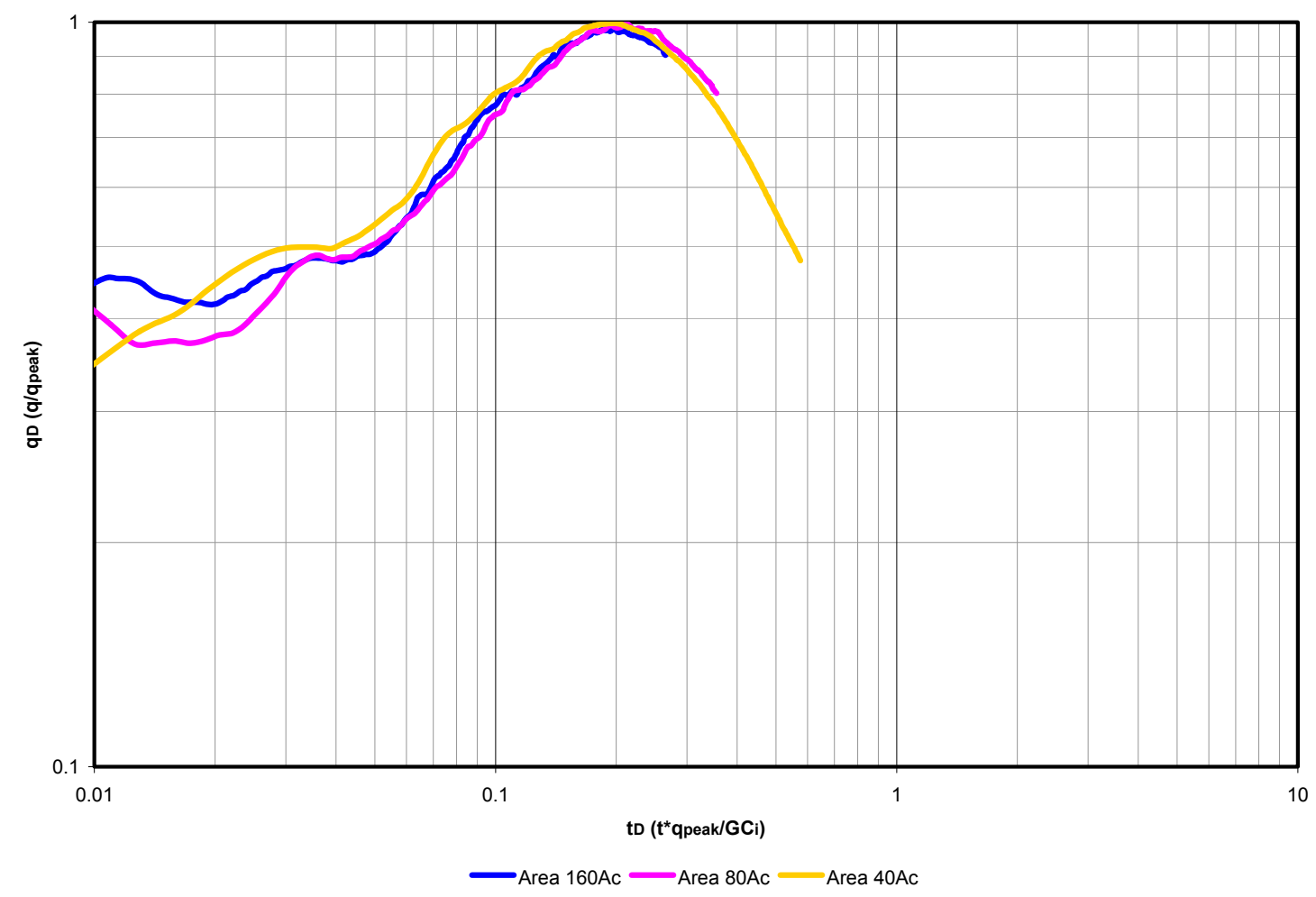

Figure 4.15. Effect of area on the second set of Type Curves in log-log scale

The seventh set of simulations took in account the required time for the coal to release the gas while the pressure decreases, which is controlled by sorption time. Because the sorption time varies from coal to coal and it is influenced also by many other properties as permeability, porosity, moisturize level, pressure, etc., it represents an important parameter to be tested.

Figure 4.22 shows the behavior for 50, 100, 200, and 300 days. In Cartesian scale all of the cases converge with a high level of accuracy. At early stages, the time-gas-peak and the late performance coincide with the average curve (Appendix G). By seeing the production behavior in log-log scale (Figure 4.23), the curves experience a small gap between them at the very early time of depletion. However, the curves converge right before and after the peak occur. The maximum error calculated between the curve with the largest gap and the average curve was 2\% (Appendix G). The square of Pearson computed was 98\%. For this case, the dimensionless groups generate a curve with reasonable results as far as sorption time is concerned. 


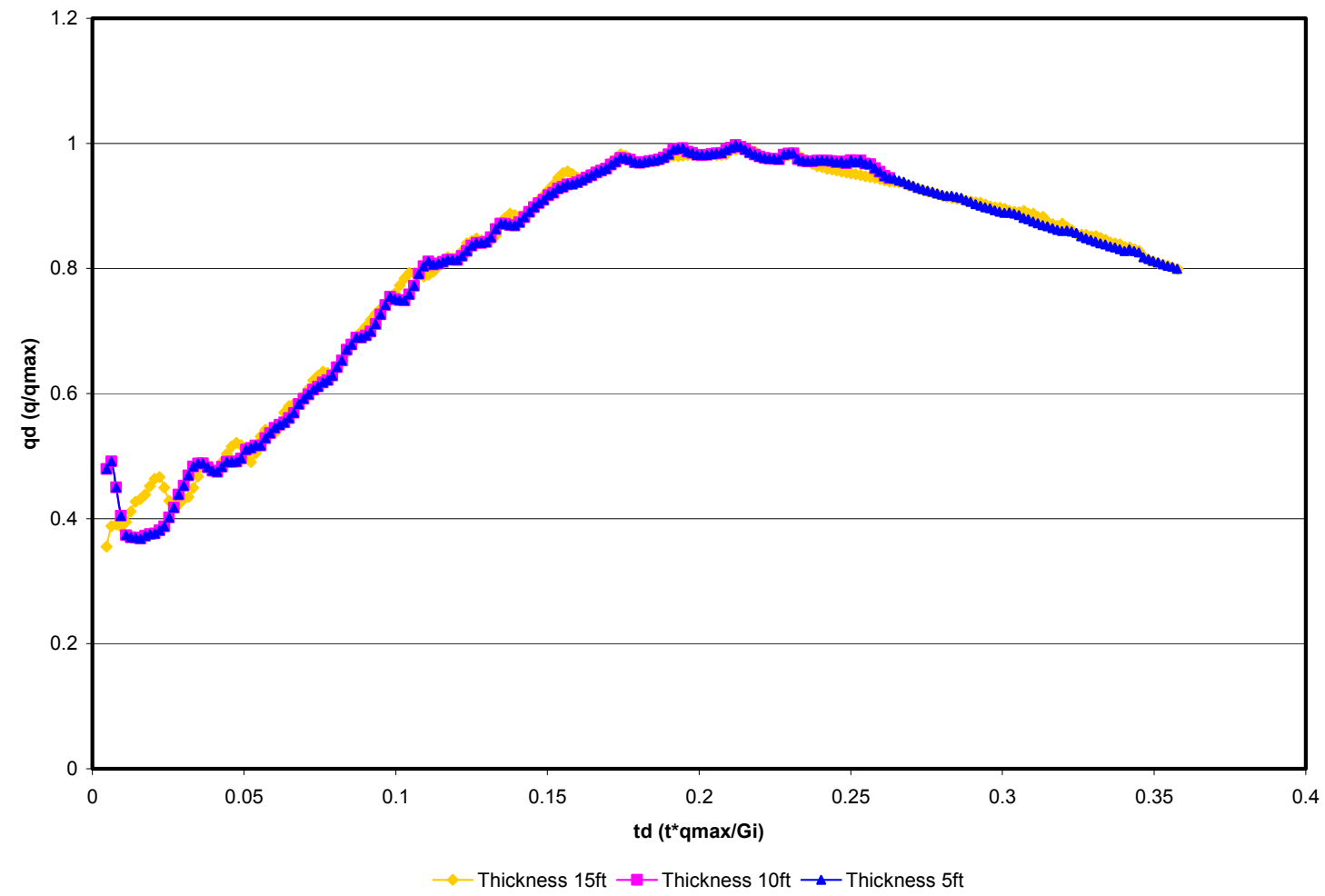

Figure 4.16. Effect of thickness on the second set of Type Curves

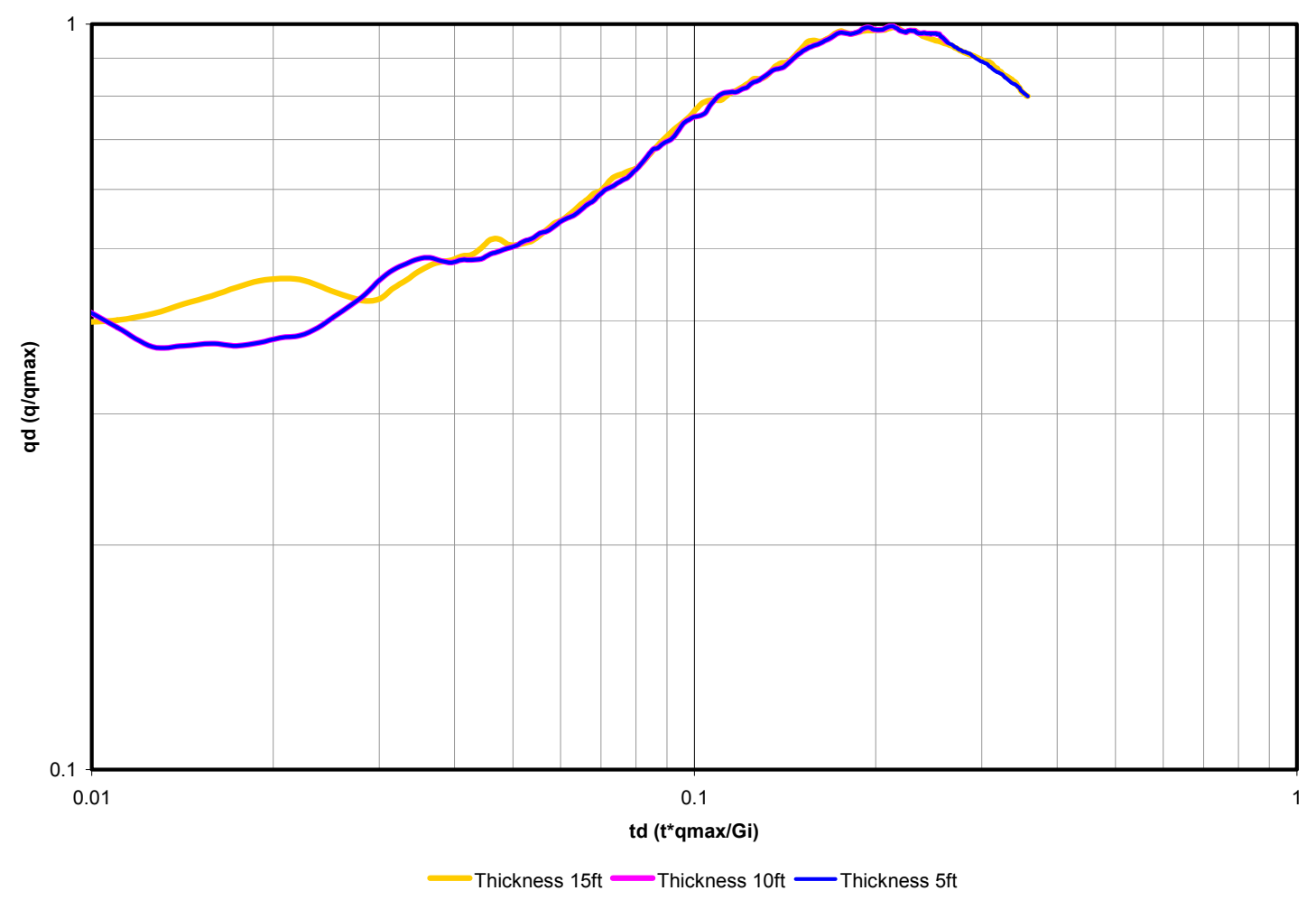

Figure 4.17. Effect of thickness on the second set of Type Curves 


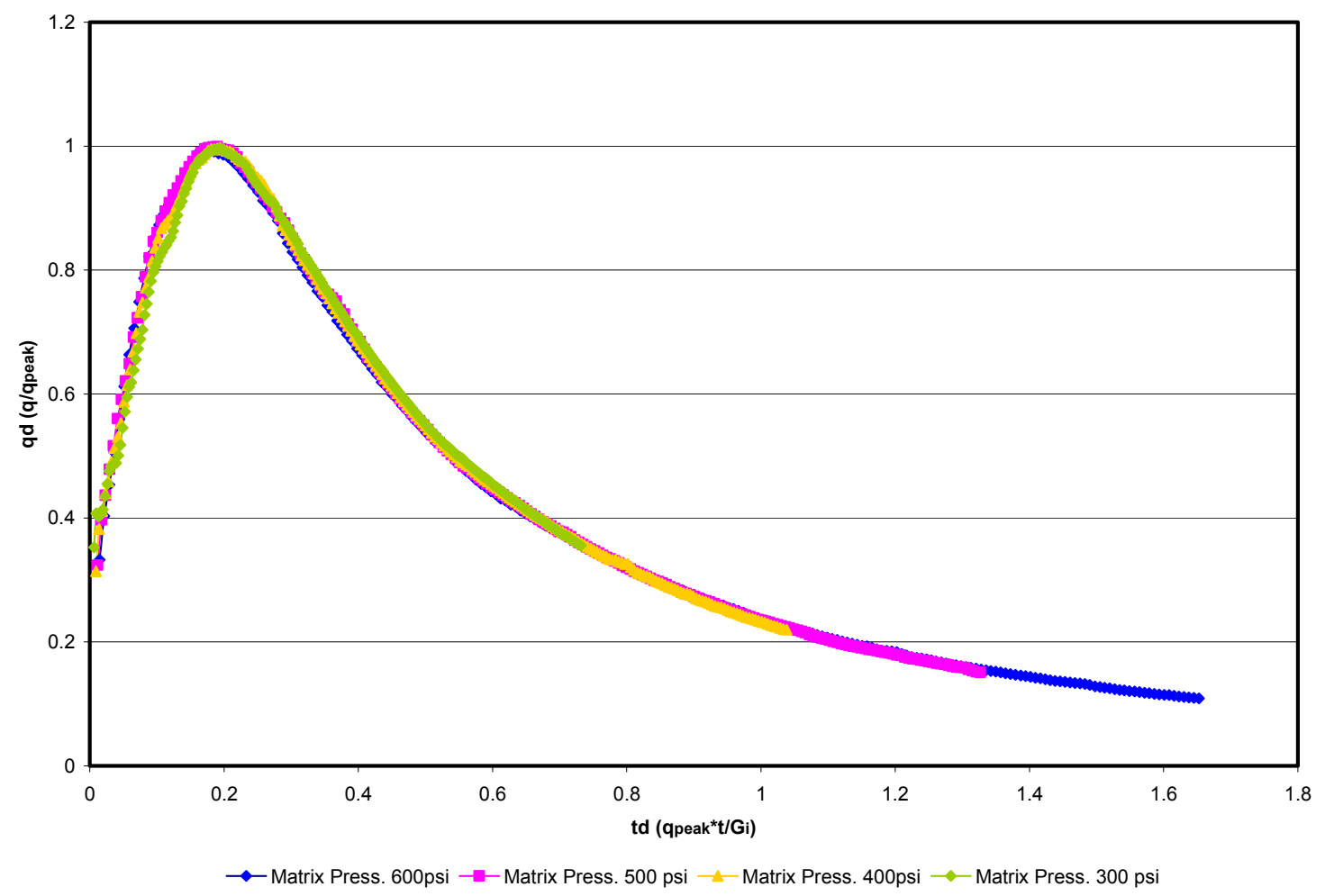

Figure 4.18. Effect of the initial matrix pressure on the second set of Type Curve

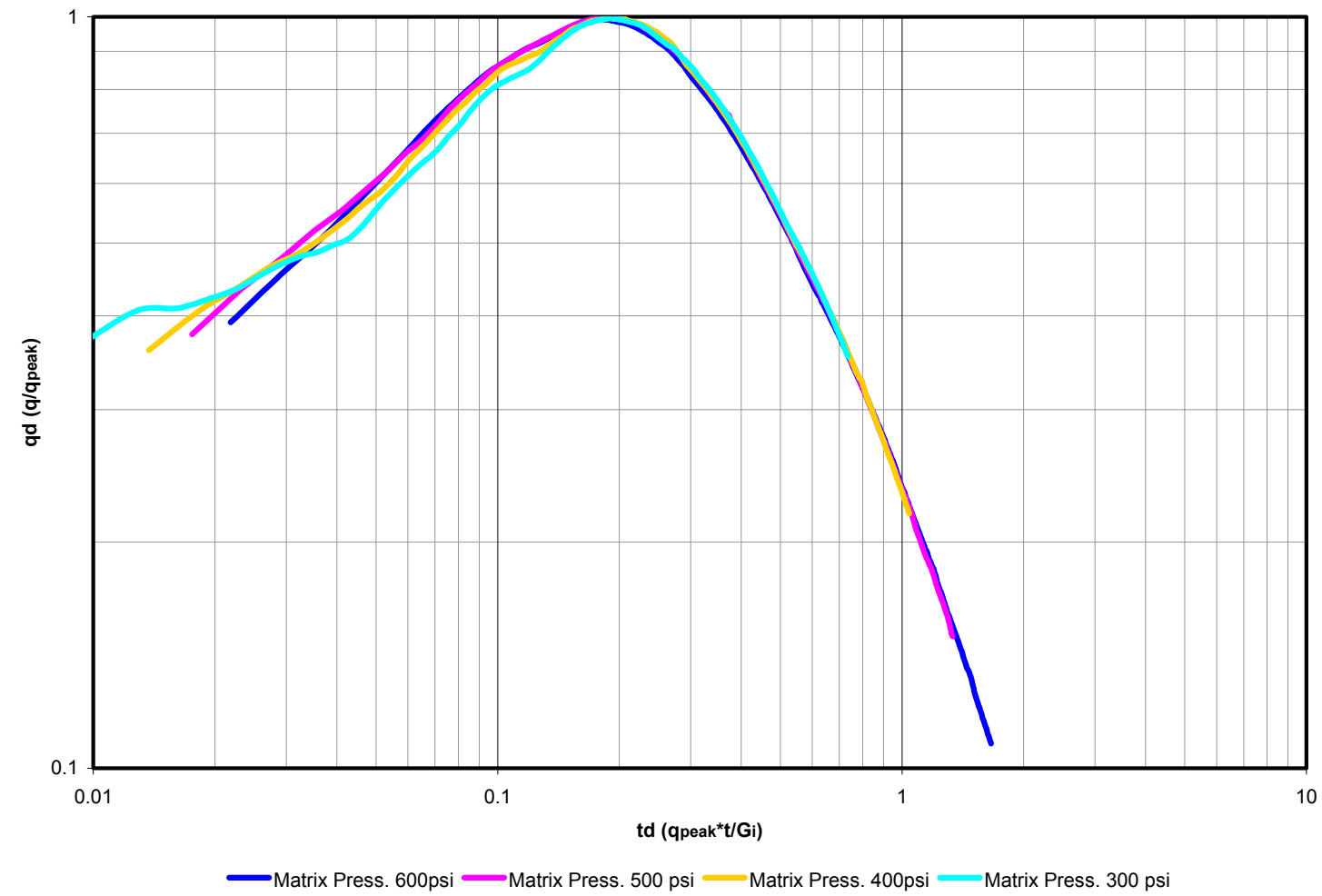

Figure 4.19. Effect of initial matrix pressure on the second set of Type Curve in log-log scale 


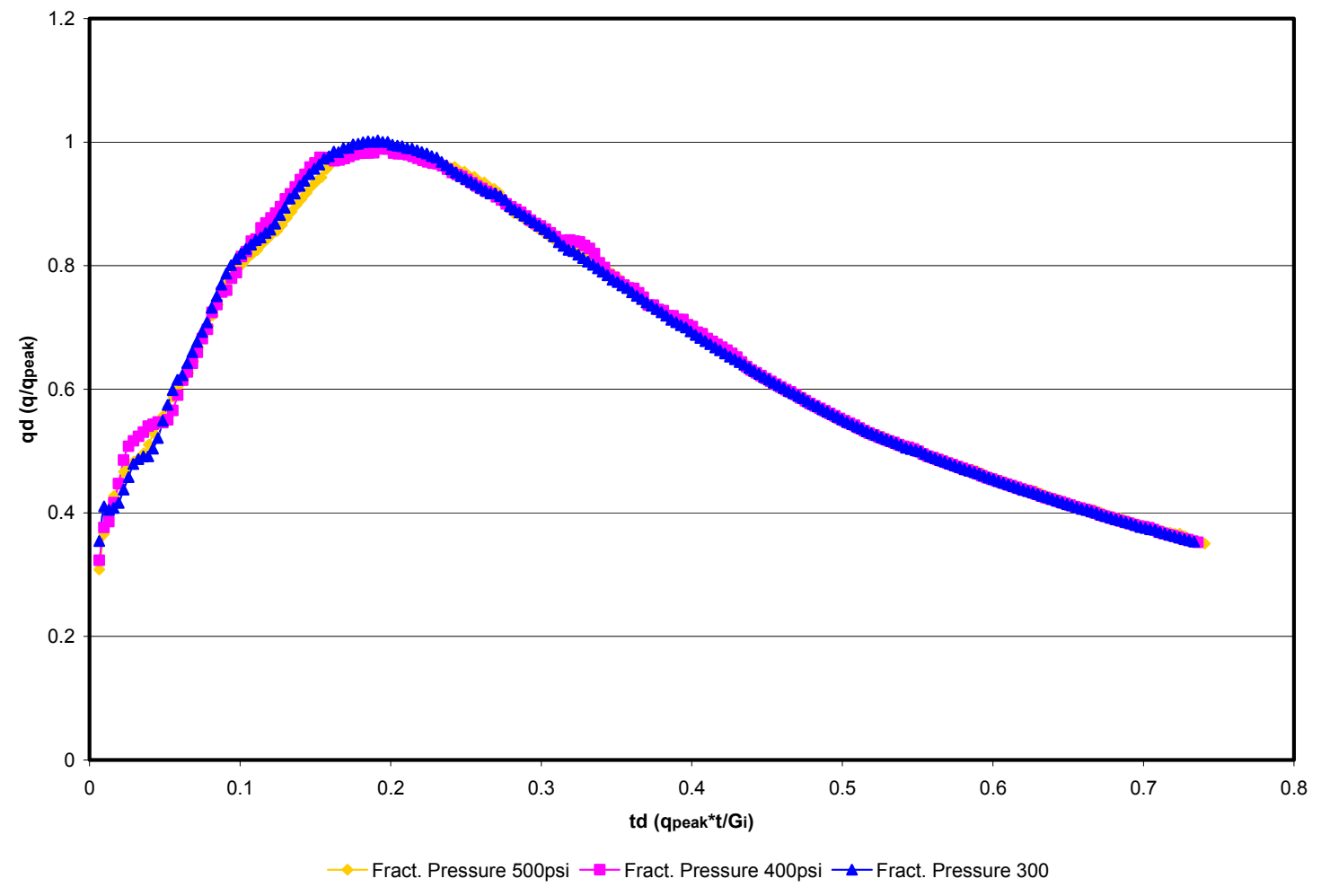

Figure 4.20. Effect of initial fracture pressure on the second set of Type Curves

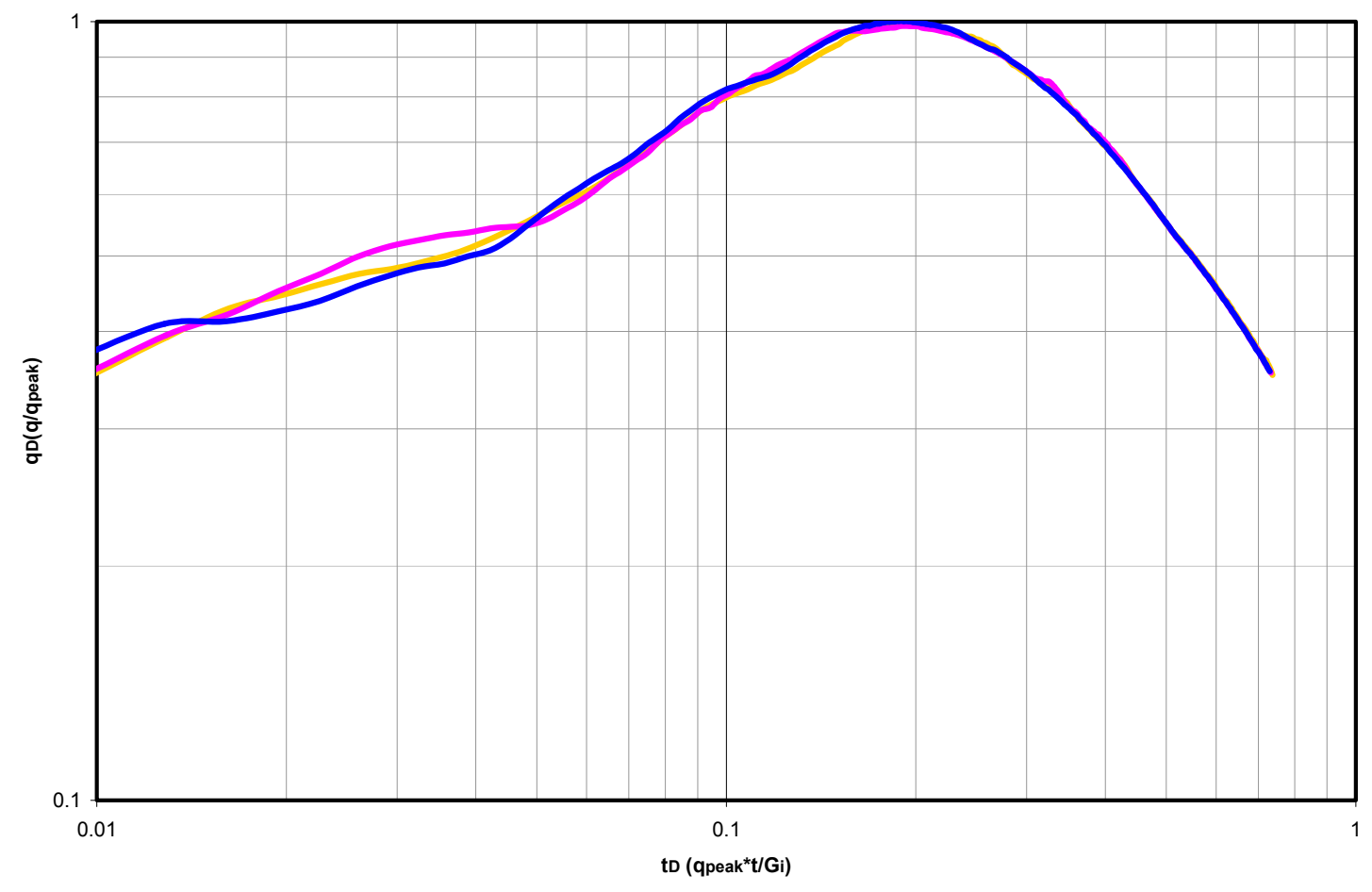

Fract. Pressure 500psi — Fract. Pressure 400psi - Fract. Pressure 300

Figure 4.21. Effect of initial fracture pressure on the second set of Type Curves in $\log -\log$ scale 


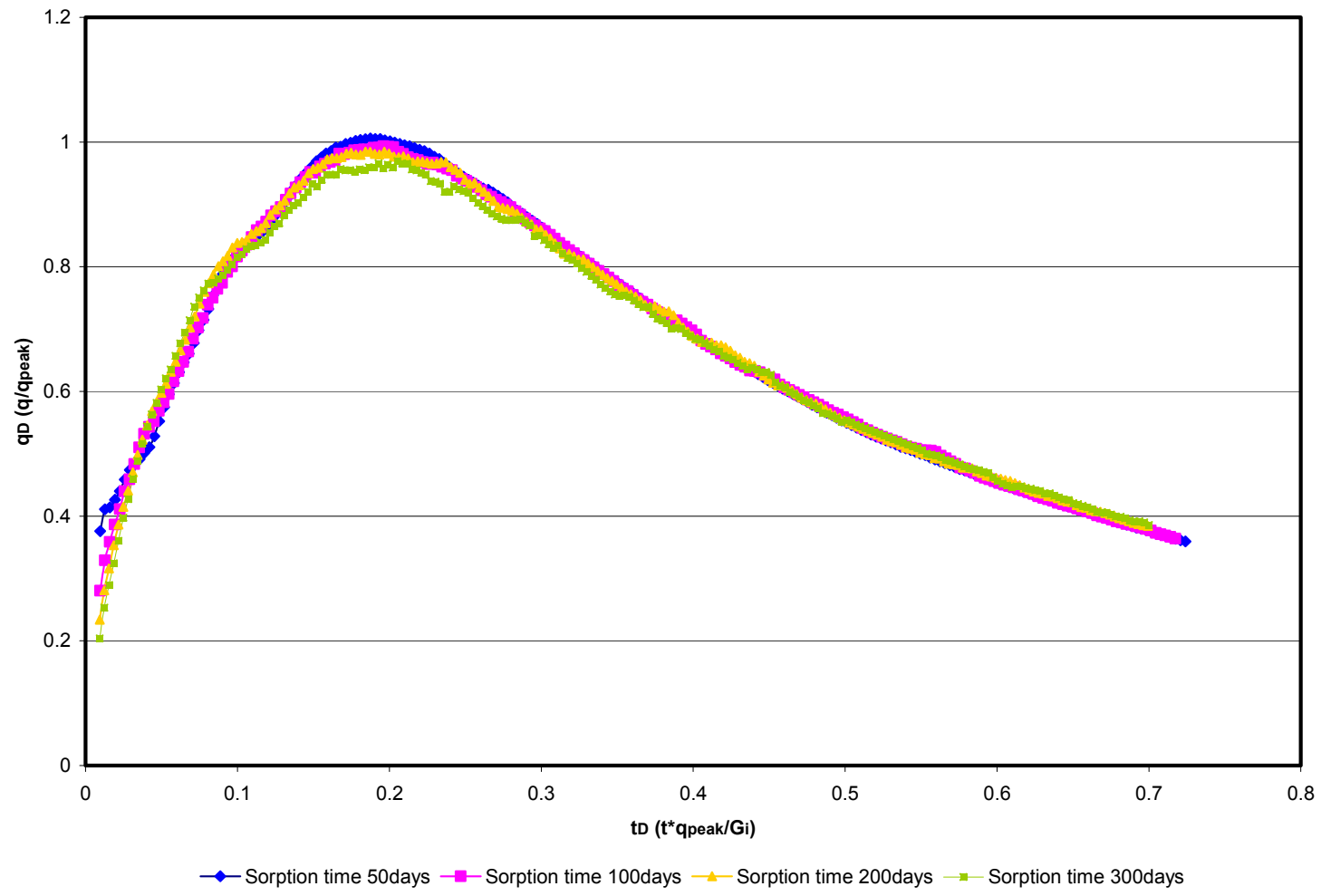

Figure 4.22. Effect of sorption time on the second set of Type Curve

The eighth set of simulations considers the influence of flowing bottomhole pressure in the CBM gas production behavior. In this study, the numerical simulator considers gas production at constant flowing bottomhole pressure. Then BHP was tested in a range of 50 to 150 psi. Figure 4.24 illustrates the three cases (50, 75 and, 100 psi) and Figure 4.25 shows the behavior in log-log scale. At the early stages of the performance and at the time-gas-peak the three plots match with the average curve (Appendix H). However, after the peak occurs, each curve deviates in a small grade from the type curve. This behavior takes place at the late time of the production (pseudo-steady state), which means that the prediction of gas production can also be compared with other conventional techniques.

Different test were run changing initial matrix pressure and leaving the flowing bottomhole pressure constant for each case (50,75, and 100psi). The behavior for each flowing bottomhole pressure was studied separately in order to generate a curve for each 
case. Figure 4.26 to 4.28 (Cartesian) illustrates the behavior of the gas production for the flowing bottomhole pressures of 50, 75, and 100 psi.

From the plots, it can be concluded, that the performance of the reservoir is almost the same for each case. If the initial matrix pressure is varied, the flowing bottomhole pressure controls the behavior of the curve at the late production. The dimensionless group does not take completely in account the impact of this parameter in the behavior of the curve. Therefore, an individual curve is proposed for five different values of flowing bottomhole pressure (Figure 4.29).

Consequently, if one wants to be more accurate in the prediction of gas production, each curve can be used according to the specific flowing bottomhole pressures instead of using the average curve.

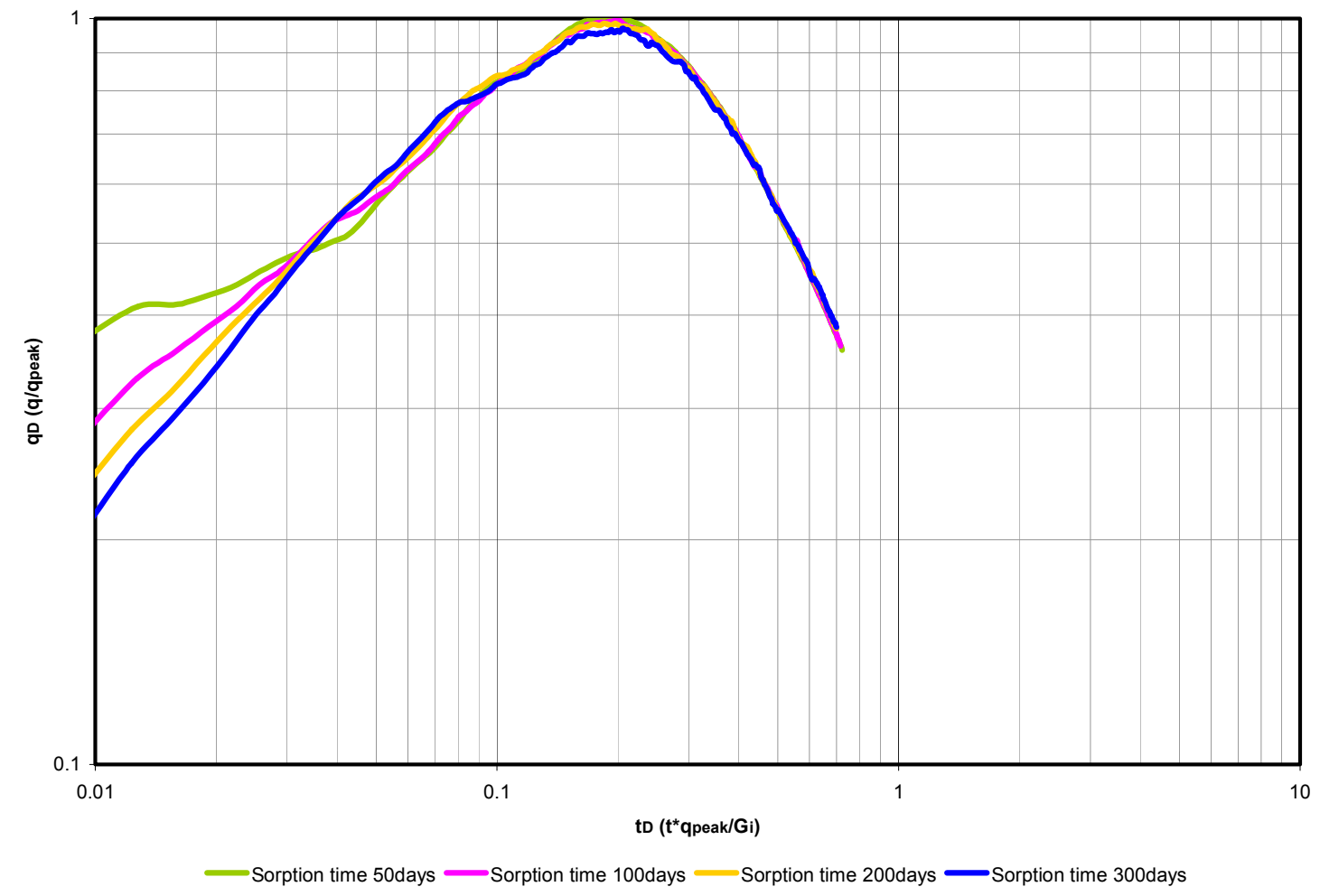

Figure 4.23. Effect of sorption time on the second set of Type Curve in log-log scale 


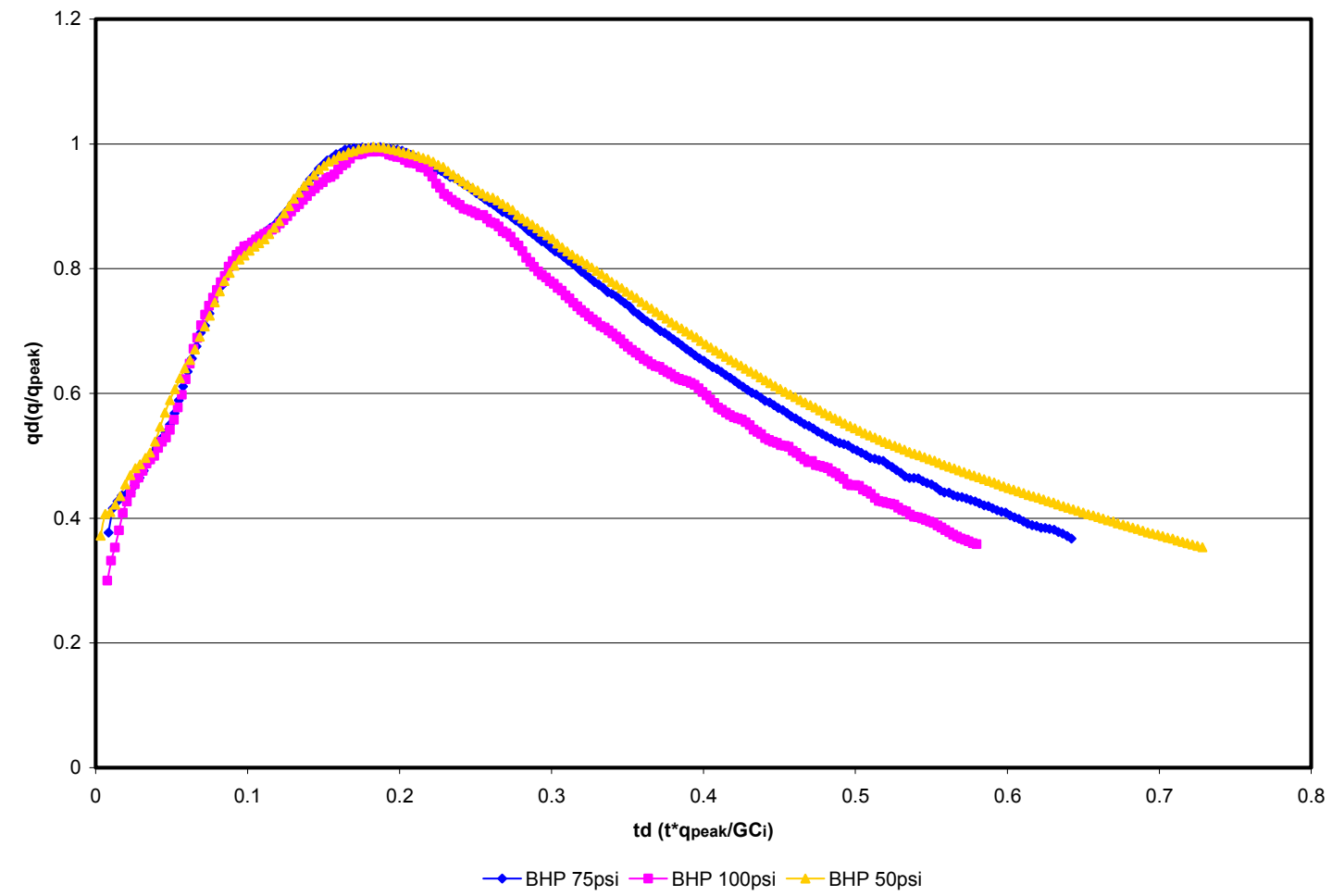

Figure 4.24. Effect of flowing bottomhole pressure on the second set of Type Curves

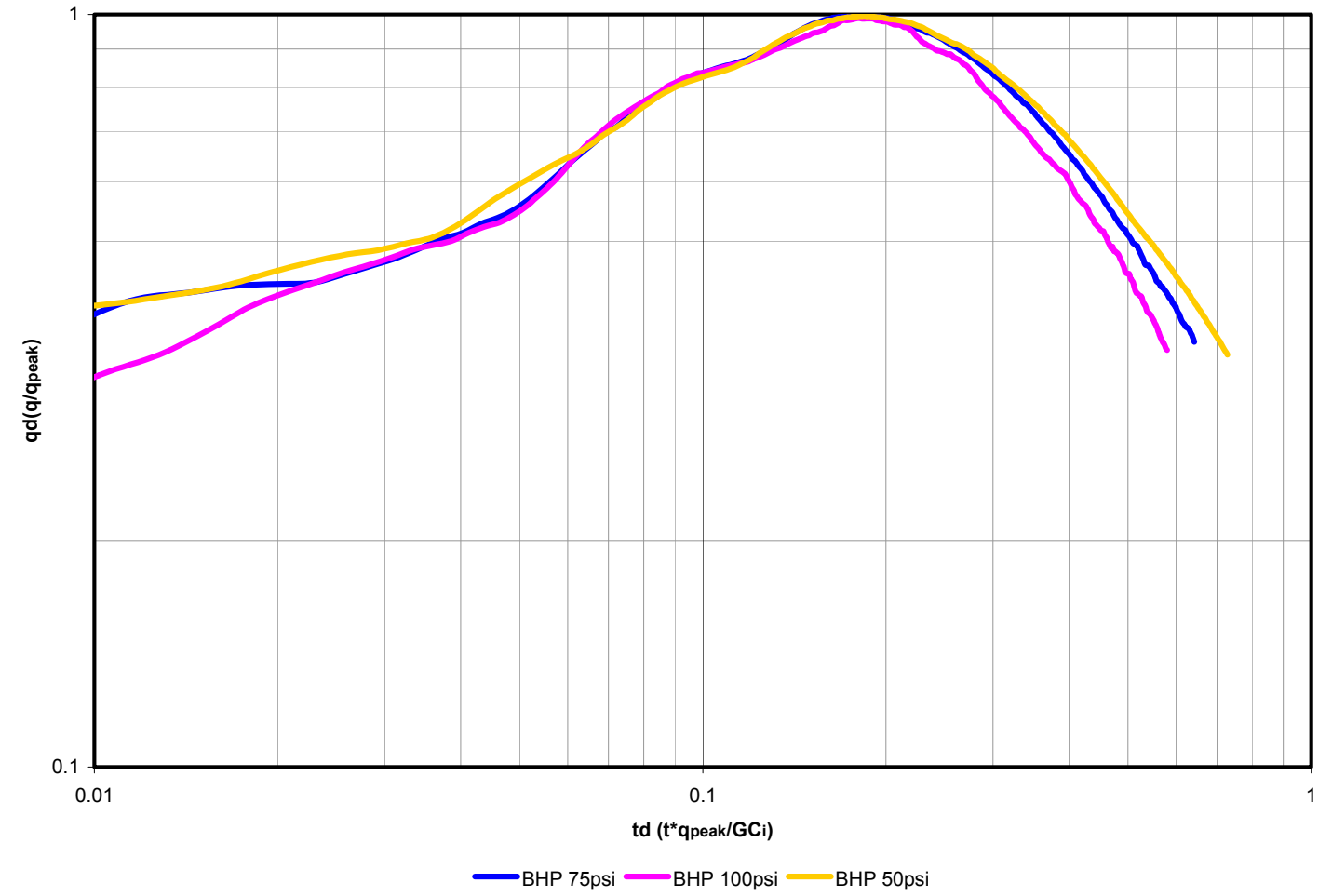

Figure 4.25 Effect of flowing bottomhole pressure on the second set of Type Curves in log-log scale 


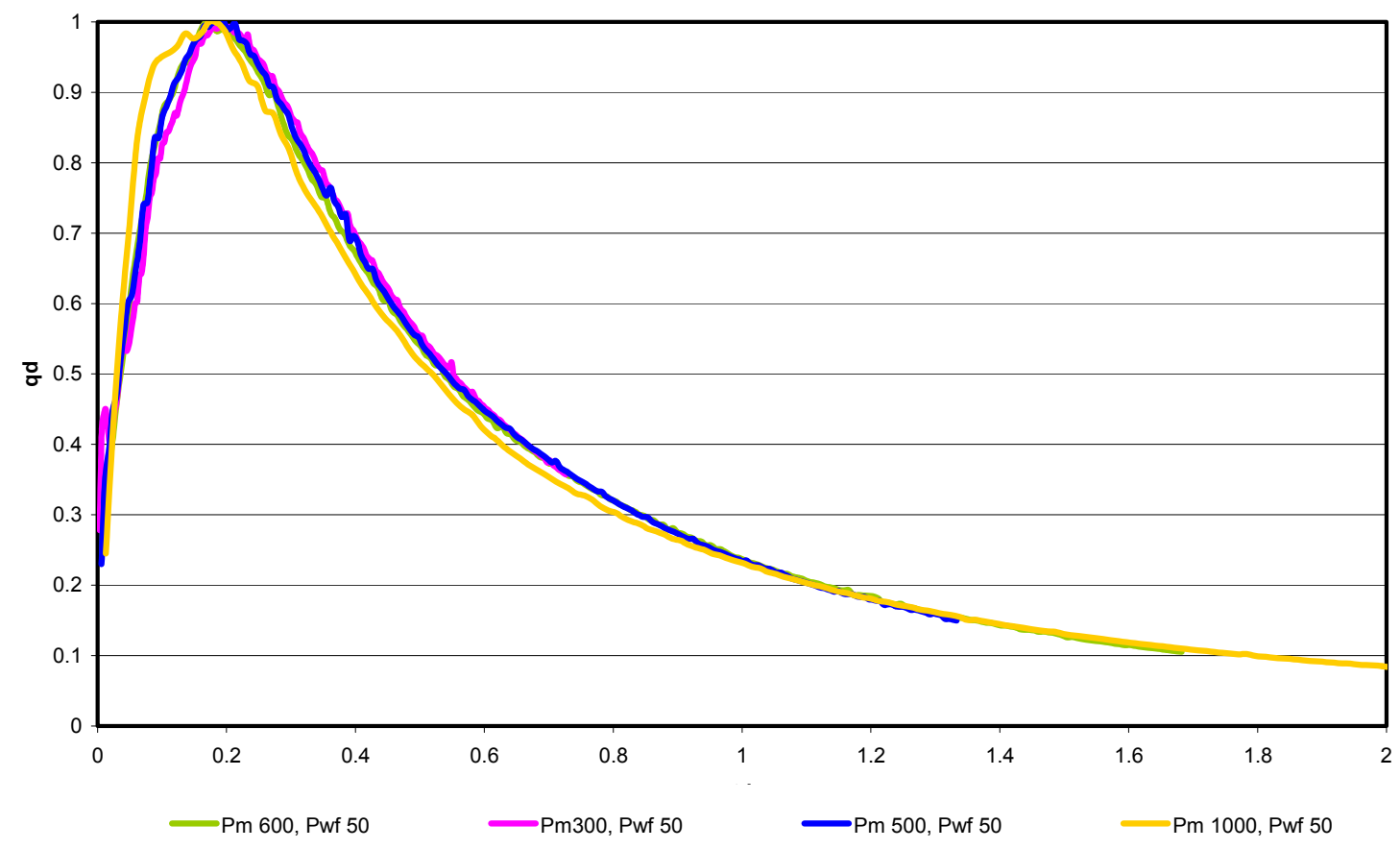

Figure 4.26. Effect of initial matrix pressure on the second set of Type Curves at BHP of 50 psi

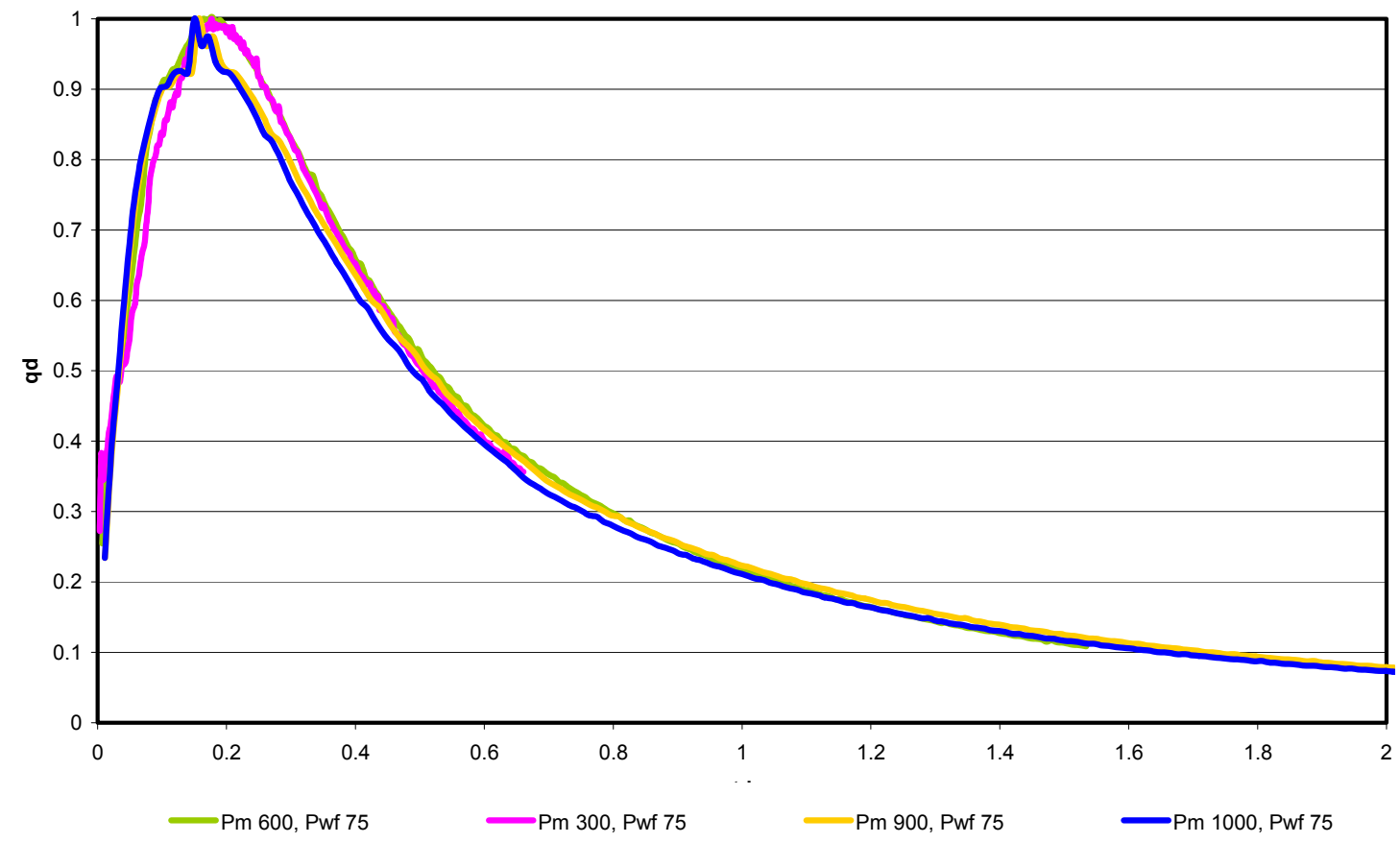

Figure 4.27. Effect of initial matrix pressure on second set of Type Curve at BHP of 75 psi 


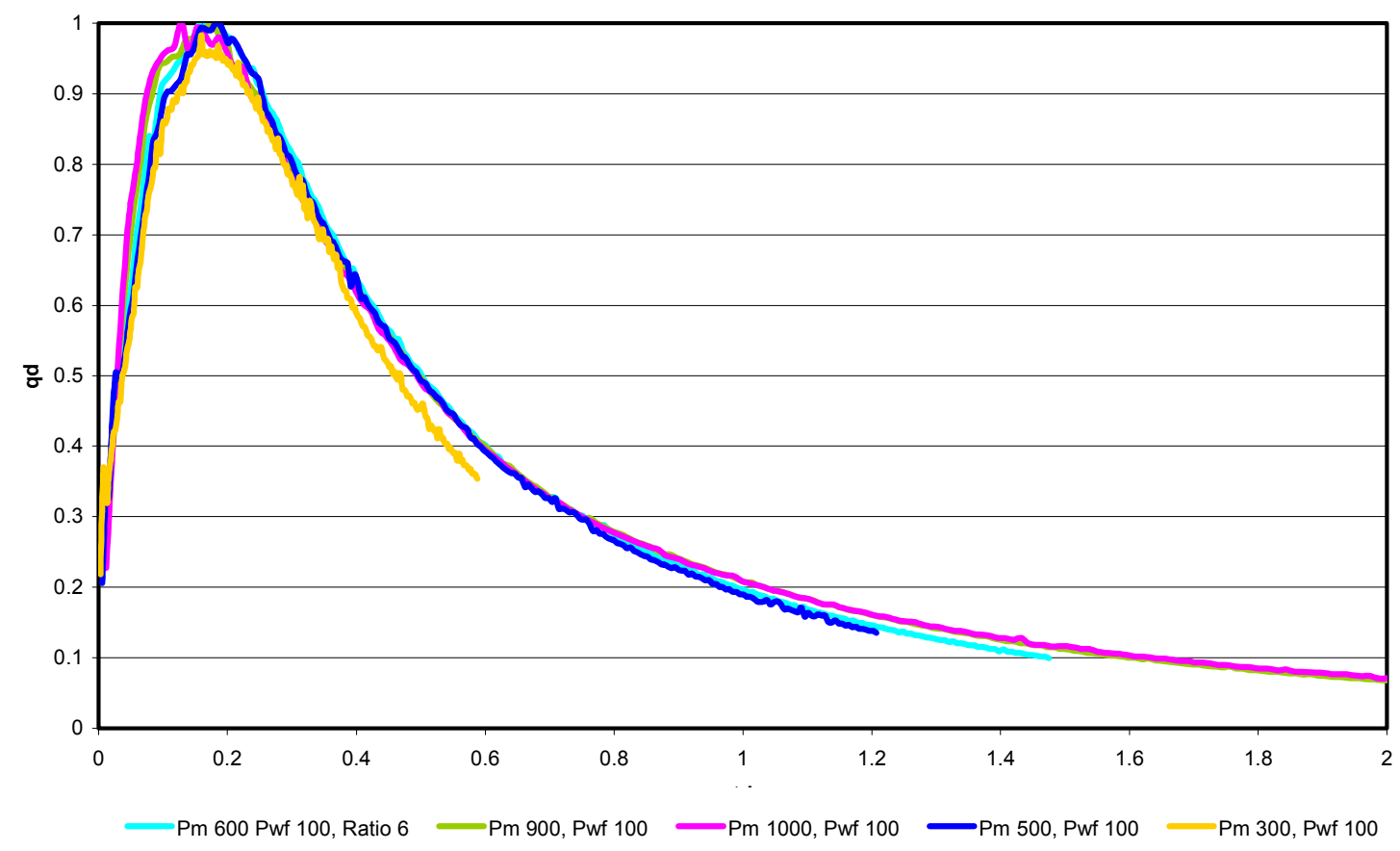

Figure 4.28. Effect of initial matrix pressure on second set of Type Curve at BHP of 100psi

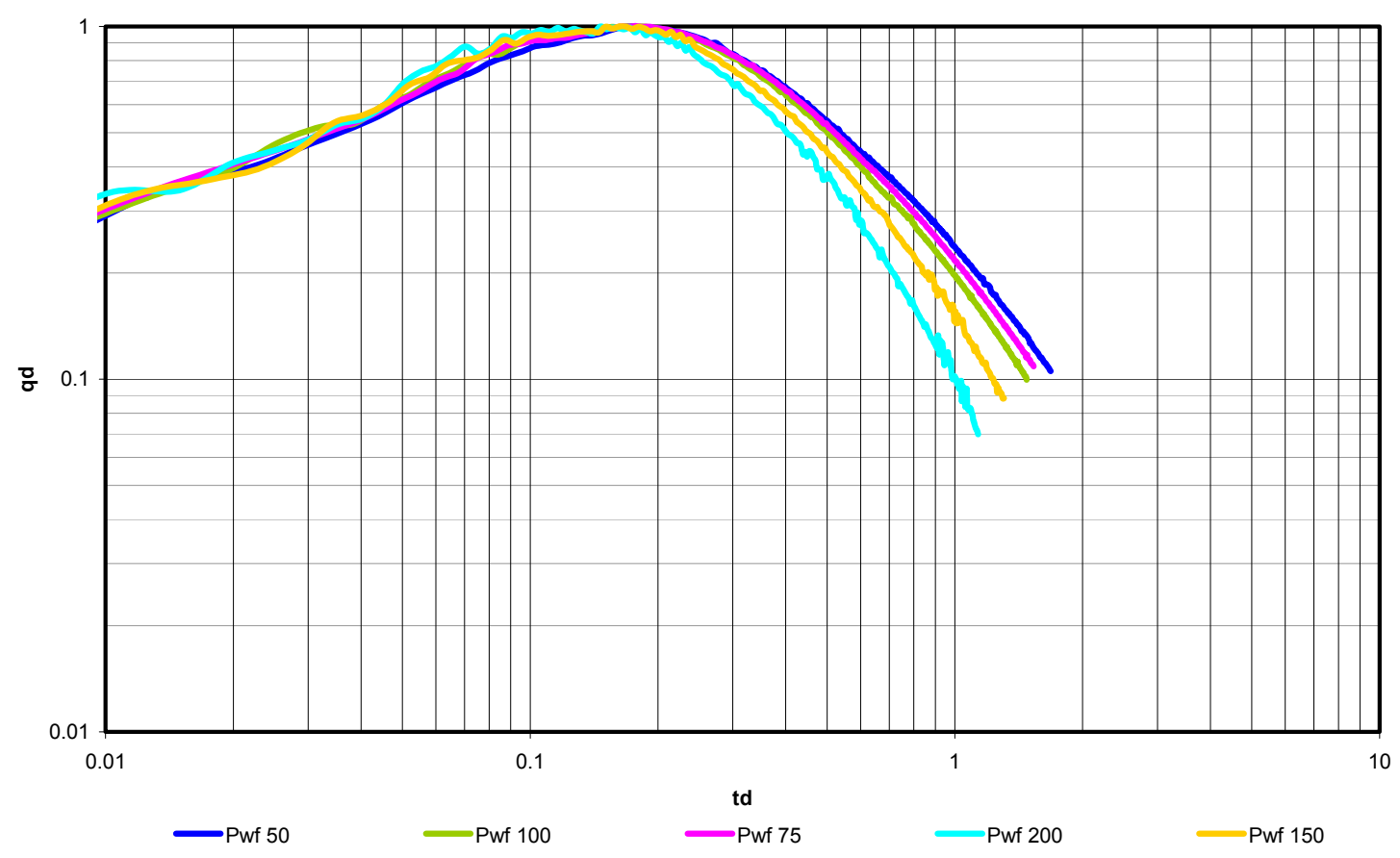

Figure 4.29.Production Type Curve for different flowing bottomhole pressures 
Additionally, a last set of simulations was incorporated in order to test the effect of relative permeability curve in the CBM performance. Different data for relative permeability curves were assessed. This parameter is one of the most significant properties because of the presence of two-phase fluid flow characteristics in CBM production. In this study, three different relative permeability curves were evaluated. The first curve was taken from the CMG tutorial for CBM simulations (Figure 4.30). The other two curves corresponded to data published in previous researches. One is the a simulated relative permeability curve for Rock Creek-Oak Grove (Figure 4.31) and the other one is a result of a laboratory experiment applied to Pittsburgh coals seams (Figure 4.32).

Figure 4.33 shows the shapes for the three relative permeability curves. Figure 4.34 illustrates the production type curve used for all the cases. Figure 4.34 show the comparison of the average curve with the results of each of the relative permeability curves applied. The variation of relative permeability results in an evident impact on the gas production performance. By observing the graph, the shape of the production curve diverges at early stages between the three curves. The time is also shift to the left in a small grade. However, the time-peak-gas occurs almost at the same time because of the use of the maximum gas rate in the dimensionless equation. At the late production, the behavior of the production curve that uses the relative permeability curves from the CMG Model and from the simulated Rock Creek-Oak Grove Model is very similar. In fact, both curves almost converge at the late production.

The gas production curve that uses the data from Pittsburgh coal relative permeability curve experiences the same shape as the rest of the production curves, but it diverges in a slightly from the other ones at the very early and late phase of production. Consequently, it can be concluded that even though the impact of relative permeability is critical; the proposed production type curve provides an average behavior of gas production performance. 
After an intensive analysis and evaluation of the impact of nine of the most important properties on CBM production, a unique production curve was constructed. This curve takes into account the effect of nine properties by converting them to dimensionless group. Therefore, the CBM production type curve is as an alternative tool to easily predict and analyze CBM production data (Figure 4.33). Appendix I shows the type curve in log-log scale.

The validation of the CBM production type curve was performed based on the analysis of two different cases to demonstrate its application and implementation. Moreover, one of the conventional methods of prediction, exponential decline analysis, was also applied to these cases in order to compare the results with the simulated future production data and with the results obtained from the type curve. Two cases were constructed using different input data than what was used in the rest of the simulations run before. Table 4.1 specifies some of the inputs used for case one and two.

Table 4.1. Input Data for cases one and two

\begin{tabular}{|l|c|c|}
\hline \multicolumn{1}{|c|}{ Property } & Case 1 & Case 2 \\
\hline Area (Ac) & 40 & 100 \\
\hline Thickness (ft) & 12 & 6 \\
\hline Cleat Porosity (\%) & 3.5 & 2 \\
\hline Cleat Permeability (md) & $\mathrm{i}=14, \mathrm{j}=7, \mathrm{k}=14$ & $\mathrm{i}=19, \mathrm{j}=10, \mathrm{k}=19$ \\
\hline Initial Matrix Pressure (psi) & 350 & 325 \\
\hline Initial Fracture Pressure (psi) & 850 & 450 \\
\hline Sorption Time (days) & 120 & 110 \\
\hline Flowing Bottomhole Pressure (psi) & 50 & 70 \\
\hline
\end{tabular}




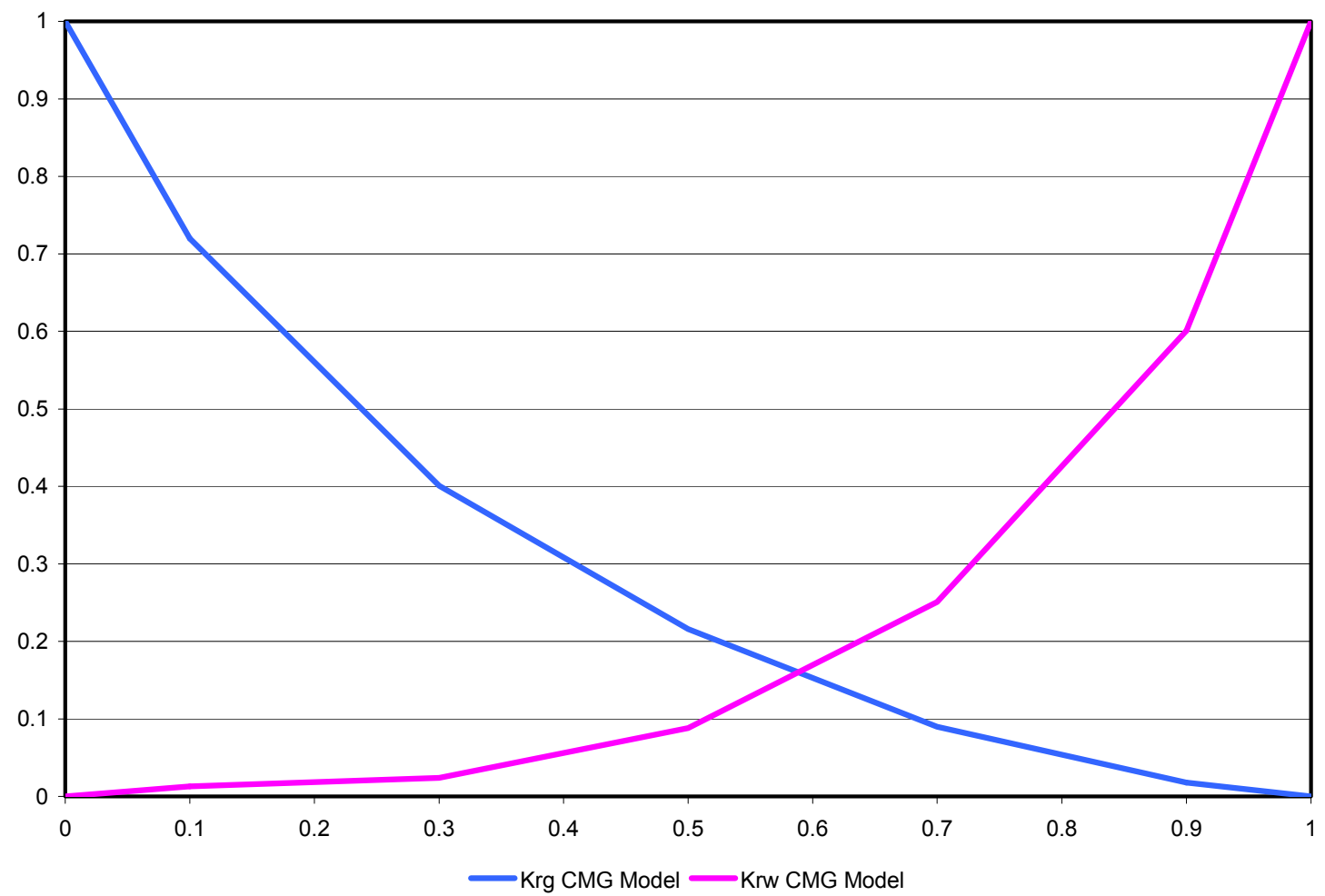

Figure 4.30. CMG Model relative permeability curve (adopted from CMG Model)

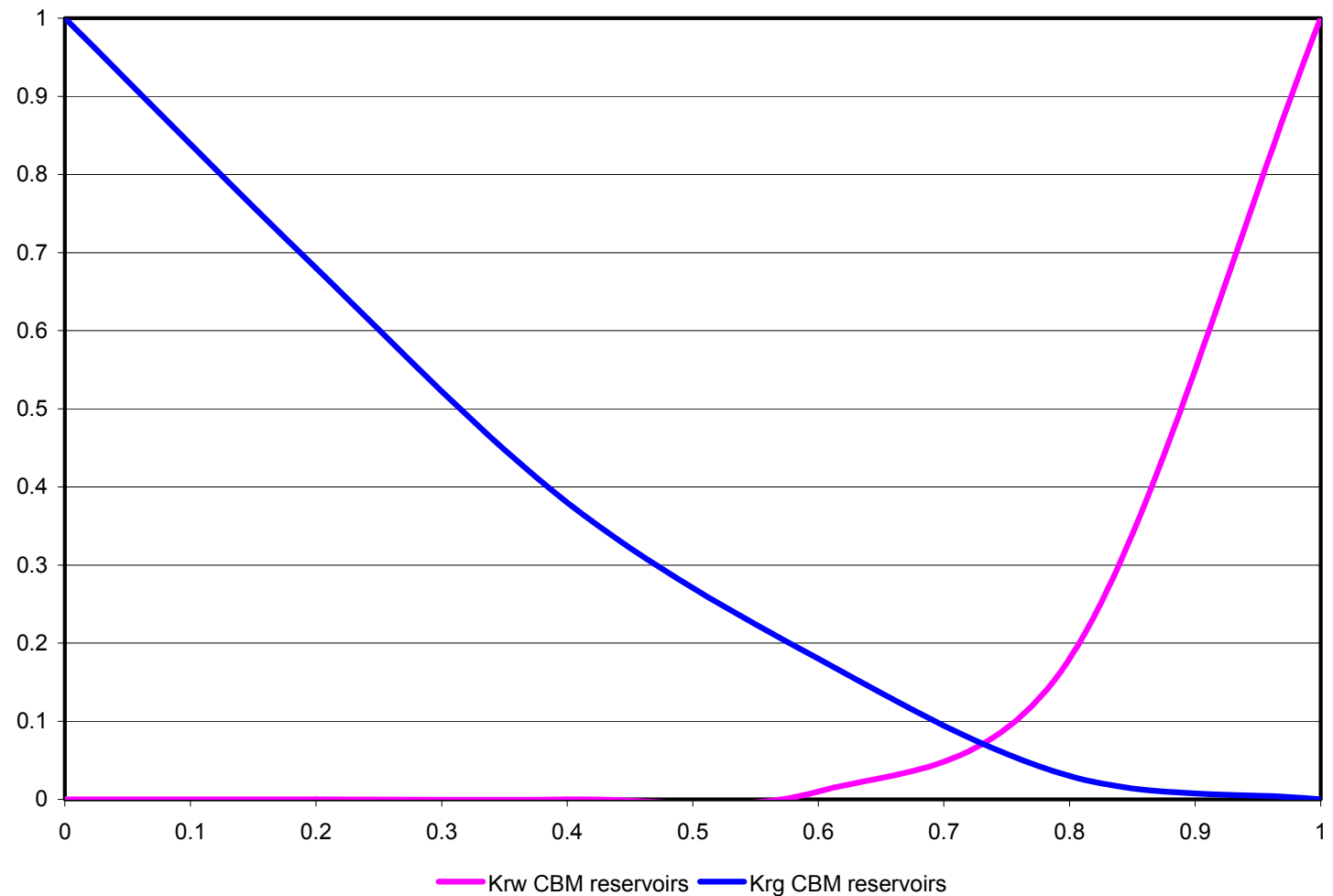

Figure 4.31. Simulated relative permeability curve for Rock Creek-Oak Grove (adopted from the GRI, 1996) 


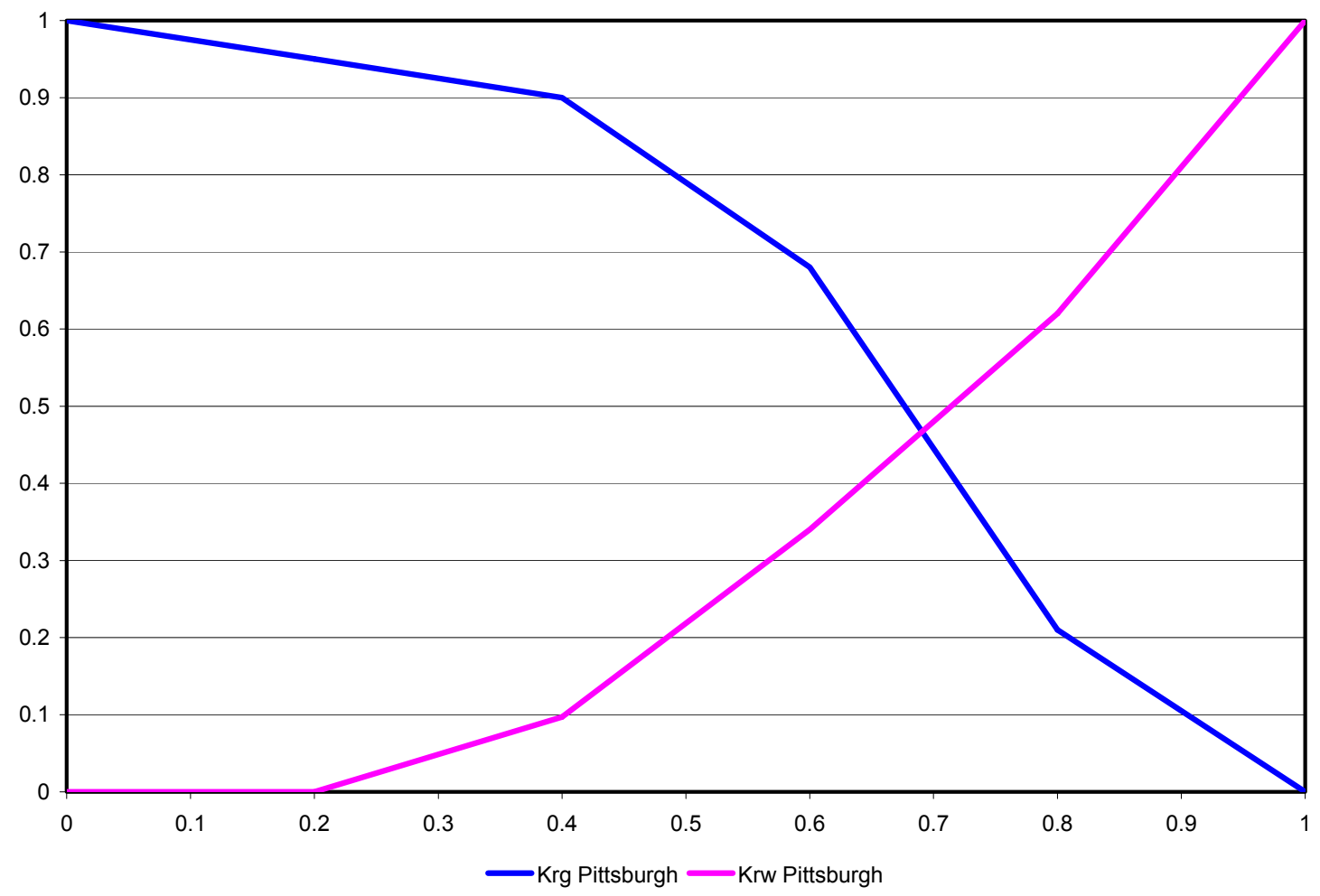

Figure 4.32. Relative permeability curve for Pittsburgh coal samples (adopted from Rightmire C, 1984)

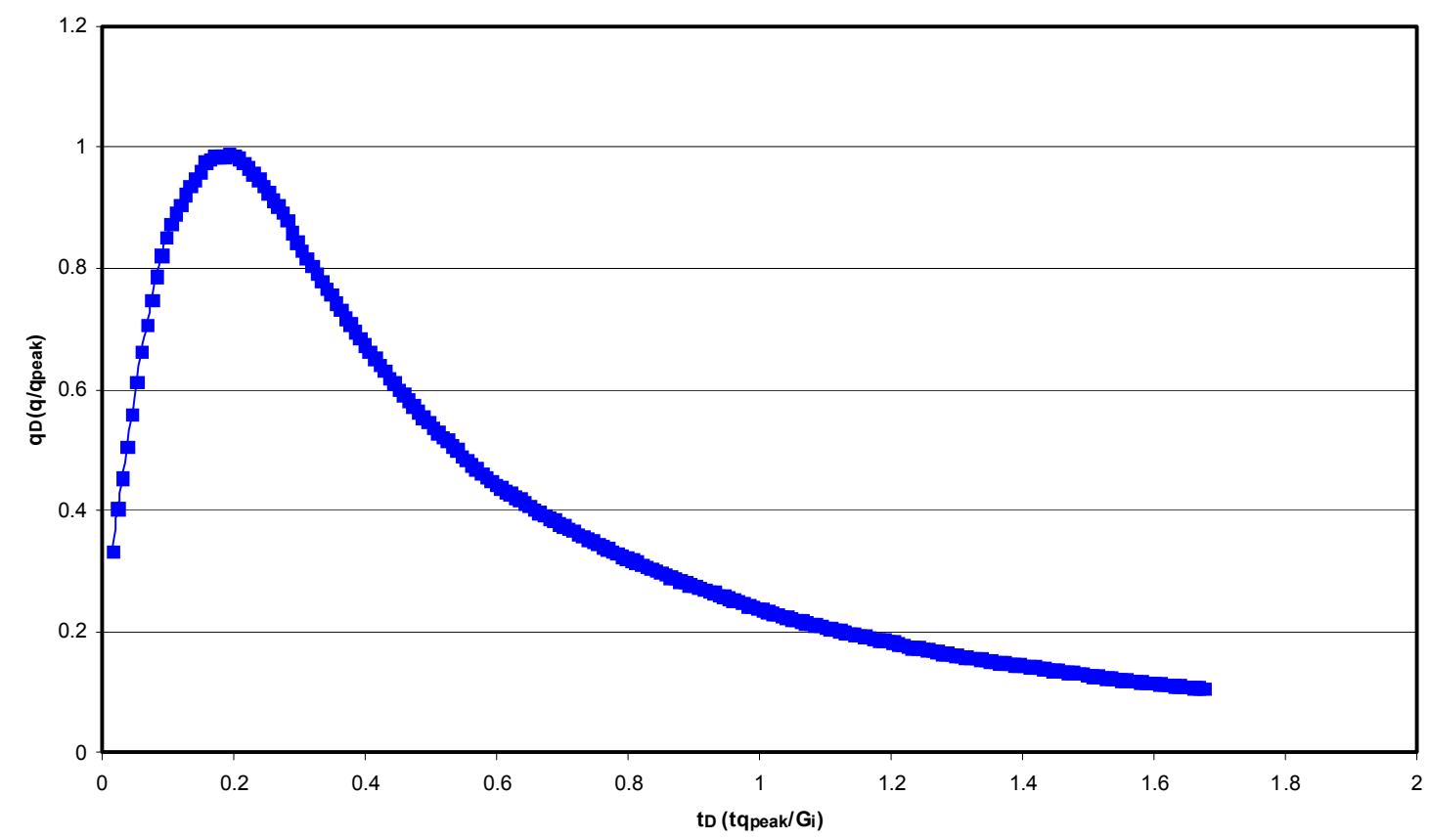

Figure 4.33. Production Type Curve in Cartesian scale 


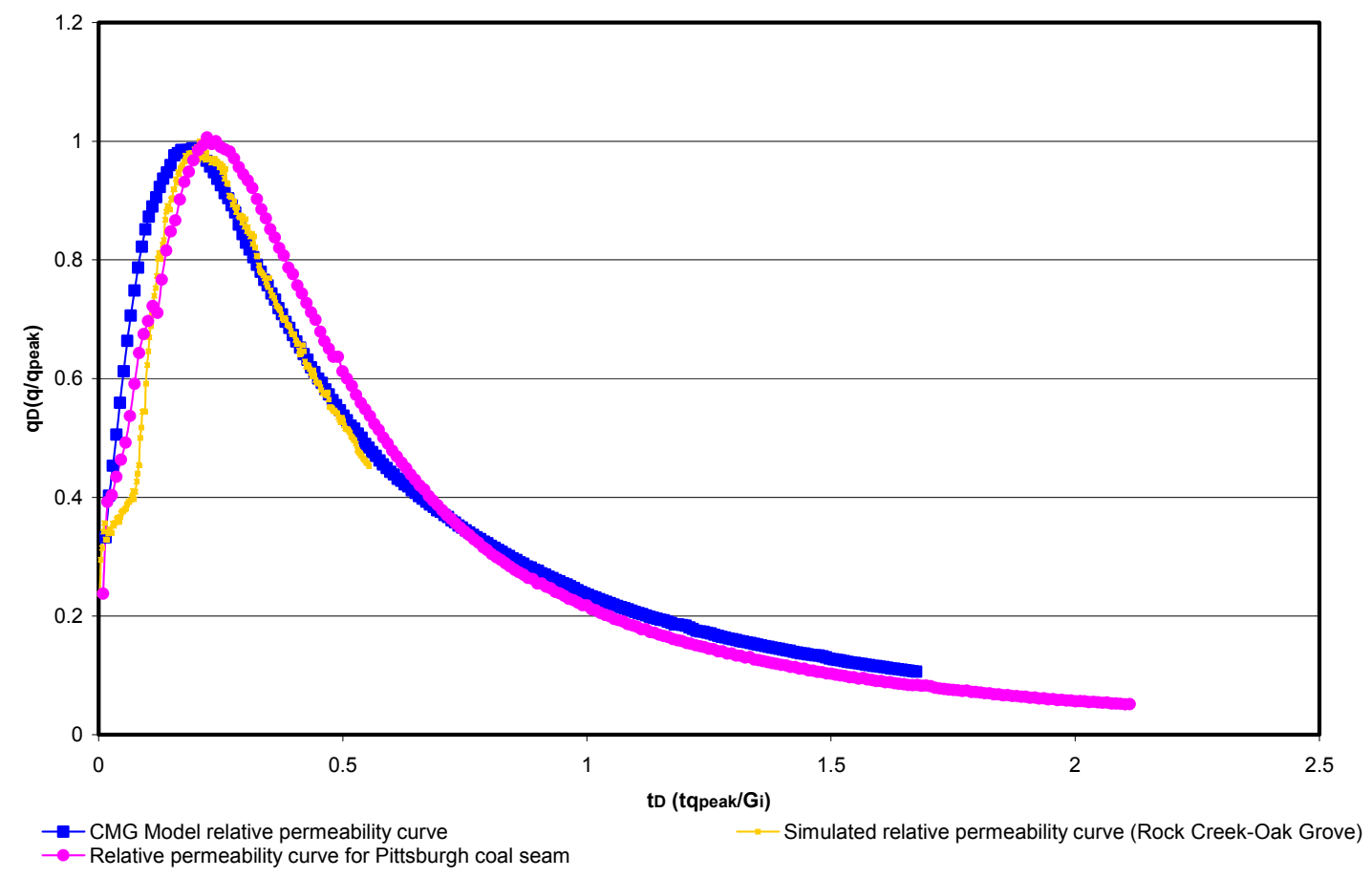

Figure 4.34. Effect of relative permeability curve on the Production Type Curve

Production data from the first few years (after the peak was reached) was selected and plotted in log-log scale for both cases. Figures 4.35 and 4.36 show the simulated production data for case one and two. Having the shape of the production for the first years, the plots were matched with the production type curve in log-log scale.

The matched points were found and the peak rate was determined. The $q_{\text {peak }}$ values calculated from the matched points resulted very similar to the maximum gas rate from the simulated data for both cases. Gas in place was calculated based on $q_{\text {peak }}$ found from the matched points and compared with the gas in place computed using equation 8 .

For the first case, the gas in place calculated based on $q_{\text {peak }}$ was 144 MMcfd and using the referred equation was 151 MMcfd. There was a difference of 8 MMcfd which means an error of 5\%. For the second case, the gas in place computed using $q_{p e a k}$ was 193 MMcfd and the value obtained from the equation was 243 MMcfd. The difference is equivalent an underestimation of $50 \mathrm{MMcfd}$ with $20 \%$ of error. It is important to address, that for the 
second case, a flowing bottomhole pressure of 70 psi was applied. As it was discussed earlier, this property has high effect on the CBM performance and impact is demonstrated in the gas in place obtained in the second case. For this case, the specific production type curve for a flowing bottomhole pressure of 75 psi was also tested. A gas in place of 241MMscf was found. The difference between the gas in place calculated from the equation and from the type curve (75psi) was 2 MMcfd with an error less than $1 \%$ $(0.82 \%)$. Table 4.2 summarizes the gas in place calculations and shows the comparison between the results obtained for gas in place using different methods of calculations.

Table 4.2. Summary of gas in place calculations for cases one and two

\begin{tabular}{|l|c|c|c|c|c|}
\hline \multicolumn{1}{|c|}{ Results } & \multicolumn{2}{|c|}{ Case 1 } & \multicolumn{4}{c|}{ Case 2 } \\
\hline & Eq. 8 & $\begin{array}{c}\text { CBM Type } \\
\text { Curve }\end{array}$ & Eq. 8 & $\begin{array}{c}\text { CBM Type } \\
\text { Curve }\end{array}$ & $\begin{array}{c}\text { CBM Type Curve } \\
\text { (BHP 75psi) }\end{array}$ \\
\hline Gas in place & 151 & 144 & 243 & 193 & 240 \\
\hline Error & \multicolumn{2}{|c|}{$5 \%$} & \multicolumn{2}{|c|}{$20 \%$} & $1 \%$ \\
\hline
\end{tabular}

Moreover, the prediction of future gas production rate was calculated using the production type curve and the exponential decline analysis. Figure 4.35 summarizes the results and compares them with the actual production data for case one. This plot clearly evidences that the predicted results based on the CBM production type curve is almost on the top of the actual values. It appears that the exponential decline prediction tends to shift the gas production toward to the right as the gas rate decline, causing a deviation from the actual values.

For case two, figure 4.36 shows the comparison between the gas rate prediction using exponential decline and production type curve. It can be seen that the prediction based on the type curve matches much more with the actual values than the exponential decline prediction. The type curve prediction presents a very small deviation from the actual values. This deviation can be explained by the effect of bottomhole pressure cause in CBM performance. 
The type curve applied was built with average values for each property and for bottomhole pressure was recommended to use specific type curves according to the value of each reservoir. In case two, the flowing bottomhole pressure (70psi) is different than the average value used for the average type curve (50psi). This difference impacts the shape of the curve and shifts it in a small grade to the left. However, the average type curve gives reasonable and quite accurate prediction. The exponential decline curve prediction experiences a big gap.

This deviation is increasing as the gas production decreases. At the late stages, this difference is extremely high. The conventional prediction method seams not to be taking in account the effect of some of the geological and reservoir properties that characterize CBM reservoirs and production.

Finally, the evaluation of the effect of the reservoir properties on the peak gas rate was performed in order to be able to use the CBM production type curve without having production data. By using the numerical simulation results, the dimensionless peak gas rate was plotted with different values for each property. Evaluating the behavior of the plots, the effect of permeability, initial matrix pressure, initial fracture pressure, thickness, sorption time, fracture spacing, and area appears to be taken in account by using the dimensionless group (Equation 11). They seam to experience almost a constant behavior with the variation of those properties. However, initial matrix pressure and porosity were identified to have a high impact. This effect is showed by large changes of peak gas rate when different values of those properties were tested.

The dimensionless group was plotted vs. porosity and initial matrix pressure. A correlation was found between porosity, initial matrix pressure, and peak gas rate (Figure 4.37). Therefore, having an approximation of reservoir porosity and initial matrix pressure, this plot can be used to get $q_{\text {peak }}$ estimation. This correlation represents a way to estimate the value of peak gas rate in case the production data is not available or has not reached the peak yet. 


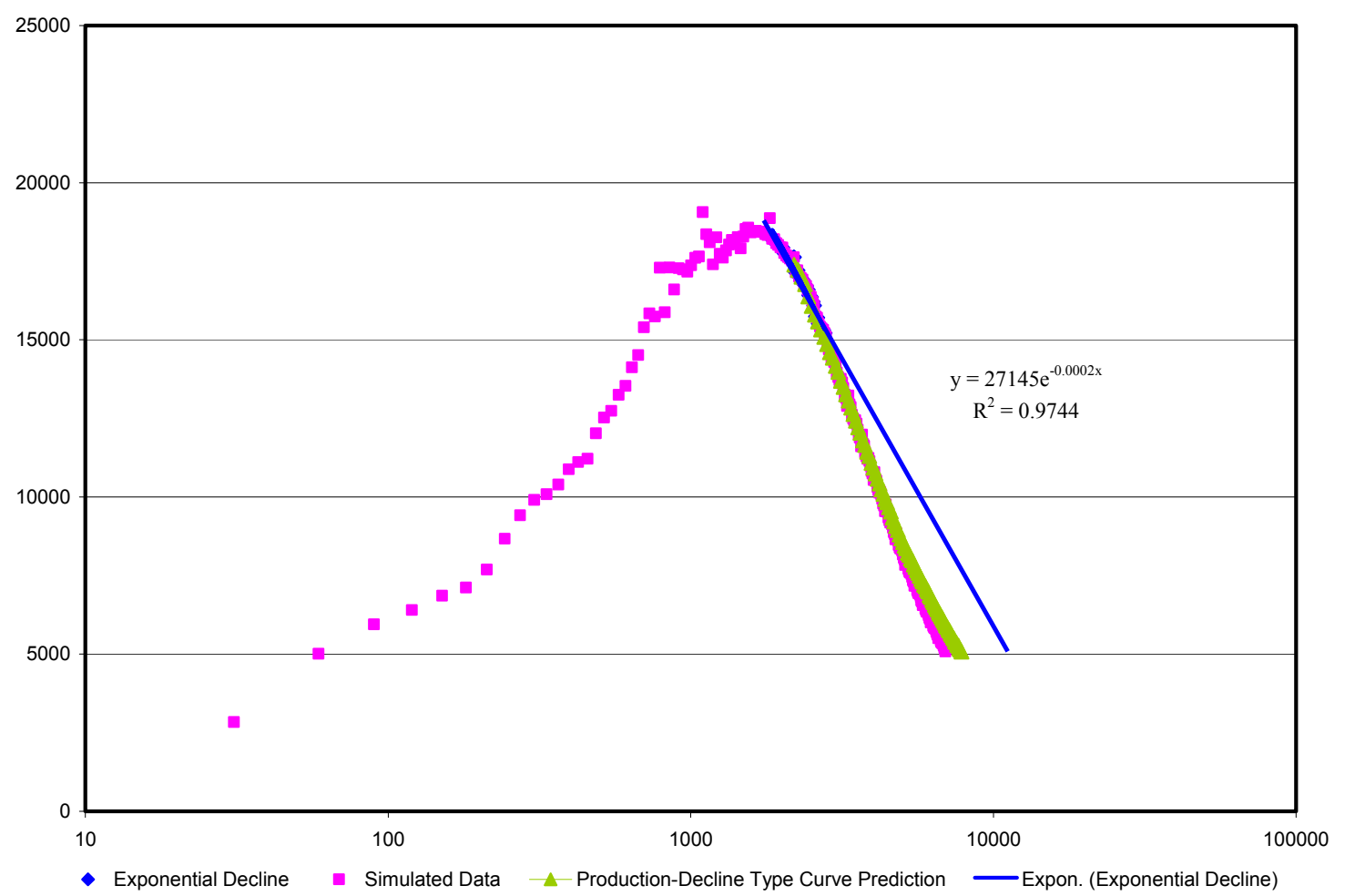

Figure 4.35. Comparison of gas production prediction: case one

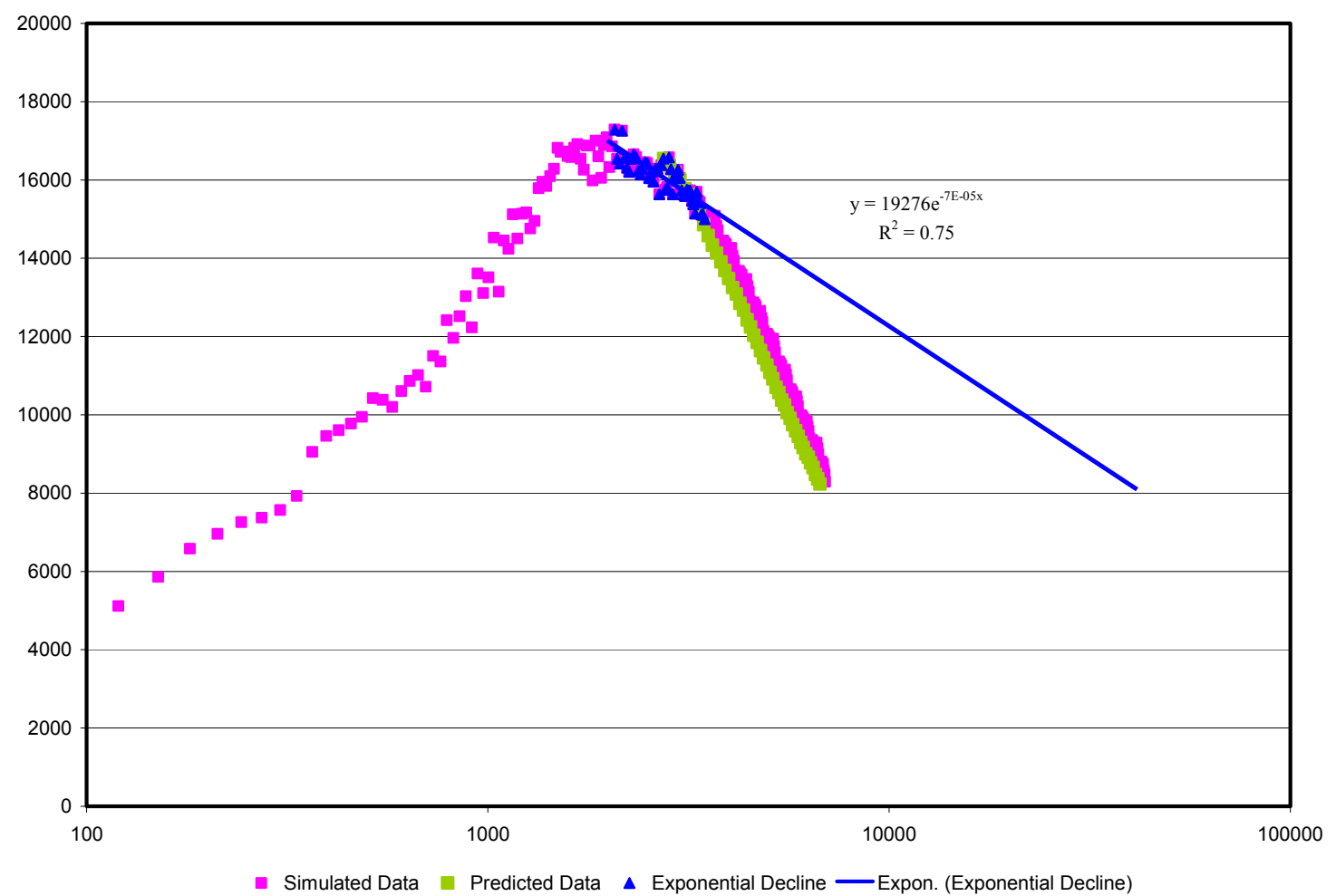

Figure 4.36. Comparison of gas production prediction: case two 


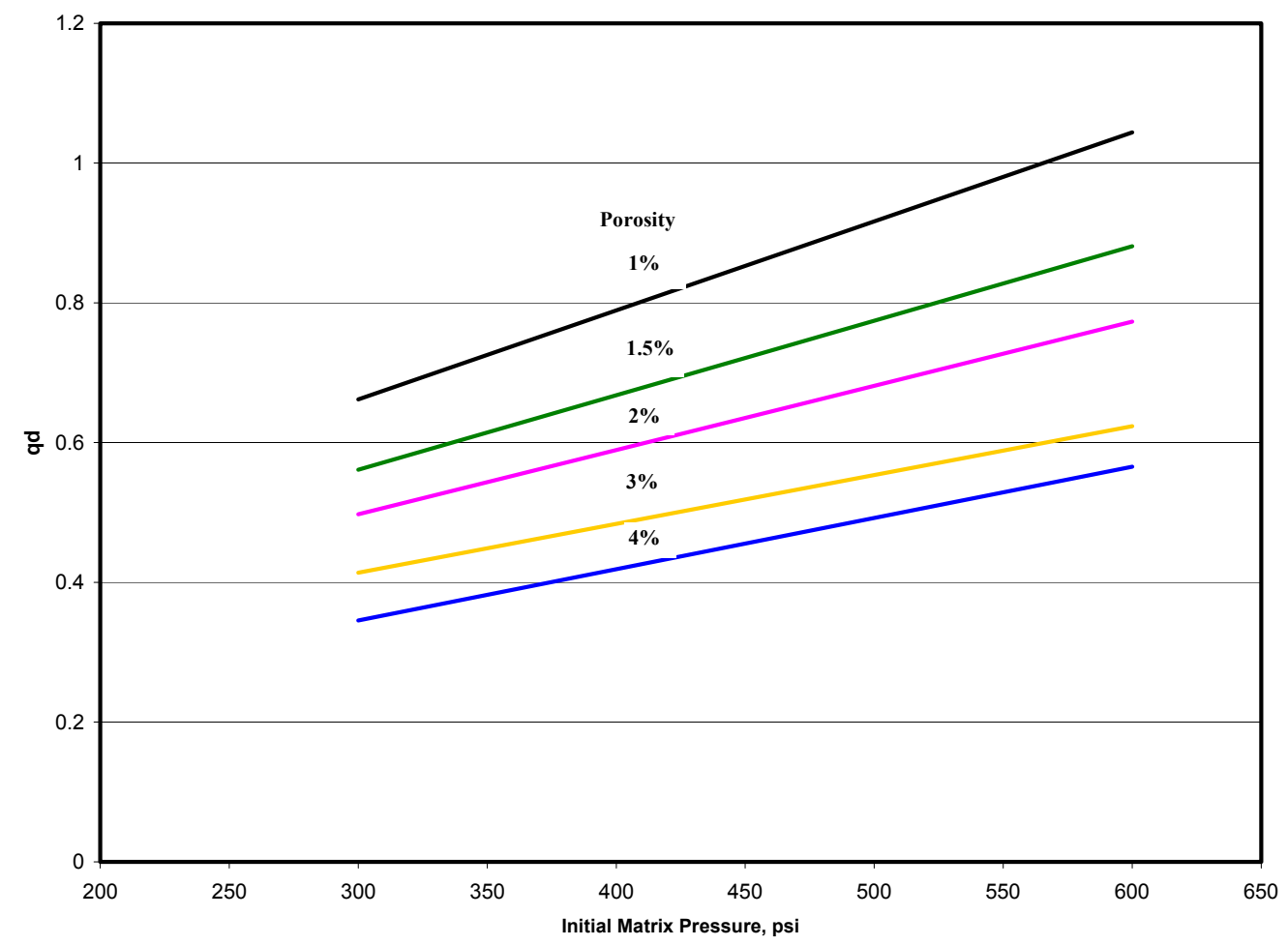

Figure 4.37. Correlation among dimensionless peak gas rate, porosity, and initial matrix pressure

This approach was validated by comparing the peak gas rate from the correlation and from the simulated data for case one and two. Using the values of porosity and initial matrix pressure for each case, the correlation was applied. For case one, a peak gas rate of 18,568.2 SCFD was found by using the numerical simulator and 20,664 SCFD by applying the plot (Figure 4.37) and solving equation 11 for peak gas rate. For case two, the values for peak gas rate were 15,407.1 and 16,656.7 SCFD from the correlation and the numerical simulator respectively. As it can be seen, the correlation provides a reasonable estimation of peak gas rate in order to be able to use the production type curves without starting the gas production. This correlation allows the use of the type curve for gas production forecast in order to evaluate the feasibility and economics between several projects to facilitate the decision making. 


\section{CHAPTER V}

\section{CONCLUSIONS AND RECOMENDATIONS}

The main focus of this research is to study, analyze, and evaluate the impact of geological and reservoir characteristics on coalbed methane production in order to provide an efficient and economical tool to predict and analyze CBM production data. The following conclusions were inferred from this research.

1. A unique set of gas production type curves for coalbed methane was developed as a simple and economical tool for gas performance analysis and prediction. It involves the knowledge of gas in place and peak gas production. However, a correlation for peak gas rate estimation was also proposed as an alternative to forecast gas production without having production data.

2. A functional dimensionless group was identified for the construction of the production type curves for coalbed methane. The effect of nine properties was studied and tested to validate that the dimensionless group provides a reasonable and accurate unique curve.

3. The effects of cleat permeability, cleat porosity, sorption time, flowing bottomhole pressure, area, thickness, initial fracture pressure, initial matrix pressure, and relative permeability on the type curve were studied.

4. The maximum deviation caused by varying different properties was found to be less than $10 \%$ for each property. This verified the applicability of the type curve. The properties that experience higher error values were area $(9 \%)$, cleat permeability $(9 \%)$, and thickness $(9 \%)$. Initial fracture pressure and sorption time has an error of $3 \%$ and $2 \%$ respectively. Cleat porosity and initial matrix pressure represent the properties with the less error $(1 \%)$ in the group. 
5. Flowing bottomhole pressure represents one of the properties with highest impact on CBM performance. A set of type curves for several flowing bottomhole pressure were developed.

6. The sensitivity of the production type curve to the impact of relative permeability curve was evaluated. Two different sets of relative permeability data were evaluated and compared with the set of data used for the construction of the production type curve. The results showed that the production type curve provides an average behavior of gas production performance.

7. The validation of the production type curve for coalbed methane was performed comparing the results with the outputs from two cases. The prediction of gas rate using the production type curve provided results that were close to the simulated data.

8. The production type curve provides much precise results than the exponential decline analysis.

9. A production type-curve based on a history-matching method was found to provide accurate prediction for coalbed methane reservoirs. It represents a simple and economical tool for small producers to better understand, analyze, and predict production data in order to evaluate economic feasibility, increase recovery, and maximize efficiency.

This study represents a contribution to the development and growth of gas reservoirs in the Northern Appalachian Basin. This approach has provided an accurate tool that can be easily used for small producers in order to analyze and forecast the gas production for coalbed methane. Production data that has reached the peak is recommended to use to obtain more precise match with the type curve. If the peak gas rate has not been reached or there is no production data available, the use of the correlation between initial matrix pressure and porosity is recommended to have an estimation of peak gas rate and obtain more accurate gas prediction. 
However, the stimulation effect and the behavior of the gas production for horizontal wells still remain to be important to studied and developed. CBM wells usually need to be stimulated in order to achieve economic production. The impact of the stimulation in CBM well performance has not been studied. Therefore, the evaluation of the effect of stimulation and the impact of horizontal wells in CBM production in combination with the proposed production type curve would provide a powerful tool for analyzing and predicting gas production for coalbed methane. 


\section{REFERENCES}

Aminian K., Ameri S. Stark J., and Yost A. (1988). "Gas-Well Production Decline in Multiwell Reservoirs," paper SPE 18268, 1988 SPE Annual Technical Conference and Exhibition, Houston.

Boyer II C. M., Kelafant J. R., Kuuskraa V. A., and Manger K. C. (1990). "Methane Emissions from coal mining: Issues and opportunities for reduction”.

Chainansutcharit, T., Her-Yuan C., Teufel L. W. (2001). "Impacts of permeability anisotropy and pressure interference on coalbed methane production", paper SPE 71069, SPE Rocky Mountain Petroleum Technology Conference, Keystone, Colorado.

Computer Modelling Group, Inc. (2003). "Tutorial: Building, running, and analyzing coalbed methane model using BUILDER and GEM".

Conway M. W., Saulsberry J., and Schraufnagel R. A. (1995). "Multi-phase flow properties for coalbed methane wells: a laboratory and field study”, paper SPE 29576, 1995 Joint Rocky Mountain Regional Meeting and Low Permeability Reservoir Symposium, Denver, Colorado.

Gas Research Institute. (1996) "A guide to coalbed methane reservoir engineering". Chicago, Illinois, USA, GRI 94/0397.

Gash, B. W. (1991). "Measurement of rock properties in coal for coalbed methane production", paper SPE 22909, $66^{\text {th }}$ Annual Technical Conference and Exhibition of the Society of Petroleum Engineers, Dallas, TX.

Gray, I. (1985). "Reservoir Engineering in Coal Seams: Part 1, the Physical Process of Gas Storage and Movement in Coal Seams,” paper SPE 12514. 
Hunt, A. M., and Steele D. J. (1992). "Coalbed methane technology development in the Appalachian Basin”. Final Report, GRI 92/0138.

Jan B. M., Siagian U. W., Lee R. L., and Othman R. (2002). "A new and robust simulation model for coalbed methane reservoir", paper SPE 78696, SPE Eastern regional meeting, Lexington, Kentucky.

Kelafant, J. R., Wicks D. E., and Kuuskraa V. A. (1988). "A geologic assessment of natural gas from coal seams in the Northern Appalachian Coal Basin”. Topical Report, Contract \# 5084-214-1066, GRI 88/0039.

Kuuskraa, V. A., and Brandenburg C. F. ( 1989). "Coalbed methane sparks a new energy industry". Oil and Gas Journal.

Mohaghegh S., and Ertekin T. (1991). "Type-Curve Solution for Coal Seam Degasification Wells Producing Under Two-Phase Flow Conditions," paper SPE 22673, $66^{\text {th }}$ Annual Technical Conference and Exhibition of the Society of Petroleum Engineers in Dallas, Texas.

Rightmire C. T., Eddy G. E., and Kirr J. N. (1984). "Coalbed Methane Resource of the United States". The American Association of Petroleum Geologists.

Seidle J. P. (1992). “A numerical study of coalbed dewatering”, paper SPE 24358, SPE Rocky Mountain Regional Meeting, Casper, Wyoming.

Coalbed Methane, (1992), Society of Petroleum Engineers Reprint Series No. 35.

Spivey J. P. and Semmelbeck M. E. (1995). "Forecasting long-term gas production of dewatered coal seams and fractured gas shales," paper SPE 29580, SPE Rocky Mountain Regional/Low permeability reservoirs, Denver, CO. 
Young G., Paul G. W., Saulsberry J. L., and Schraufnagel R. A. (1993). "A simulation based analysis of multiseam coalbed well completions", paper SPE 26628, 68 ${ }^{\text {th }}$ Annual Technical Conference and Exhibition of the Society of Petroleum Engineers, Houston, TX. 
Appendix A.

Comparison between gas production using different permeability values and the CBM production type curve. 


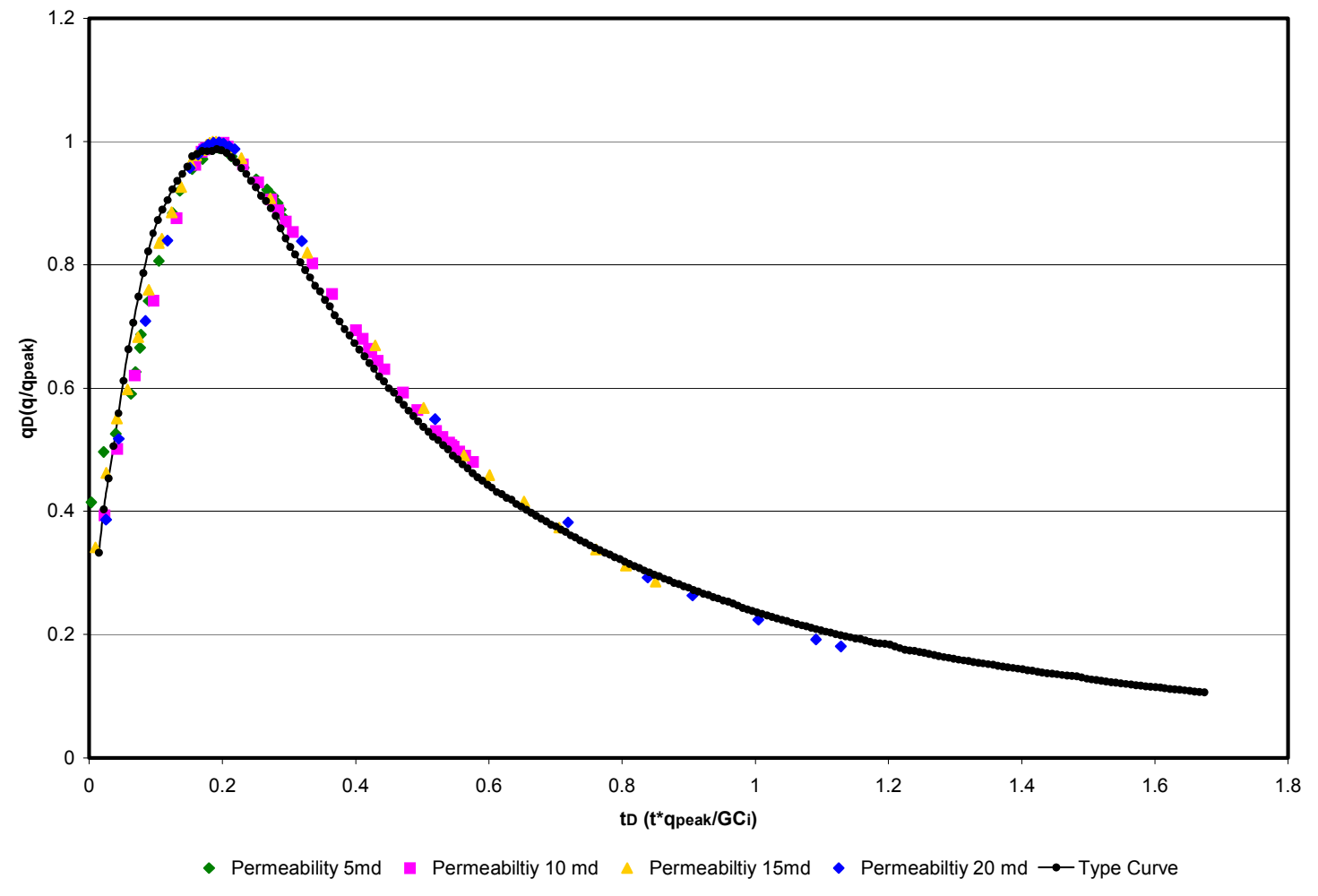

Appendix A. Comparison between gas production using different permeability values and the CBM production type curve. 


\section{Appendix B.}

Comparison between gas production using different porosity values and the CBM production type curve. 


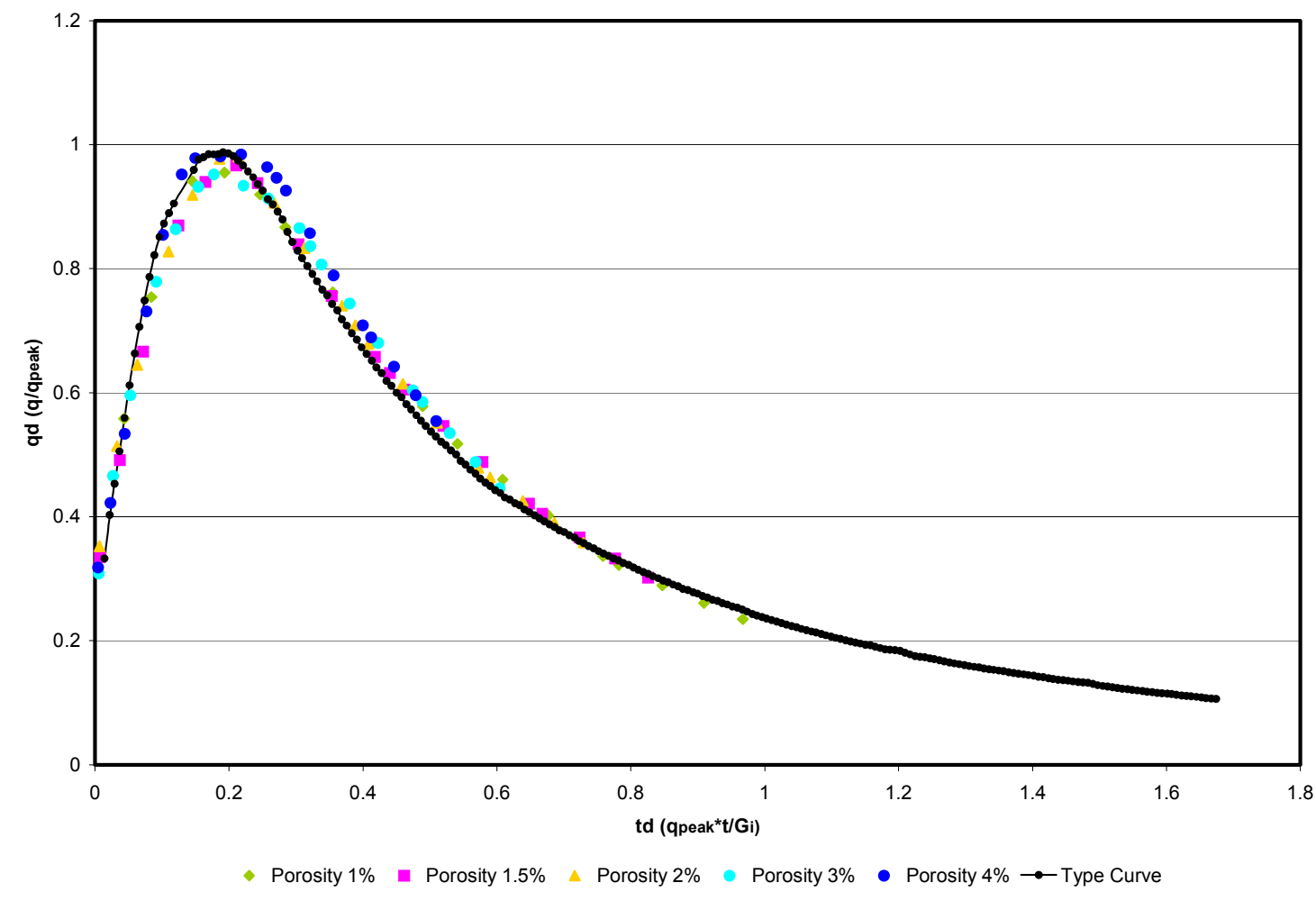

Appendix B. Comparison between gas production using different porosity values and the CBM production type curve. 
Appendix C.

Comparison between gas production using different areas and the CBM production type curve. 


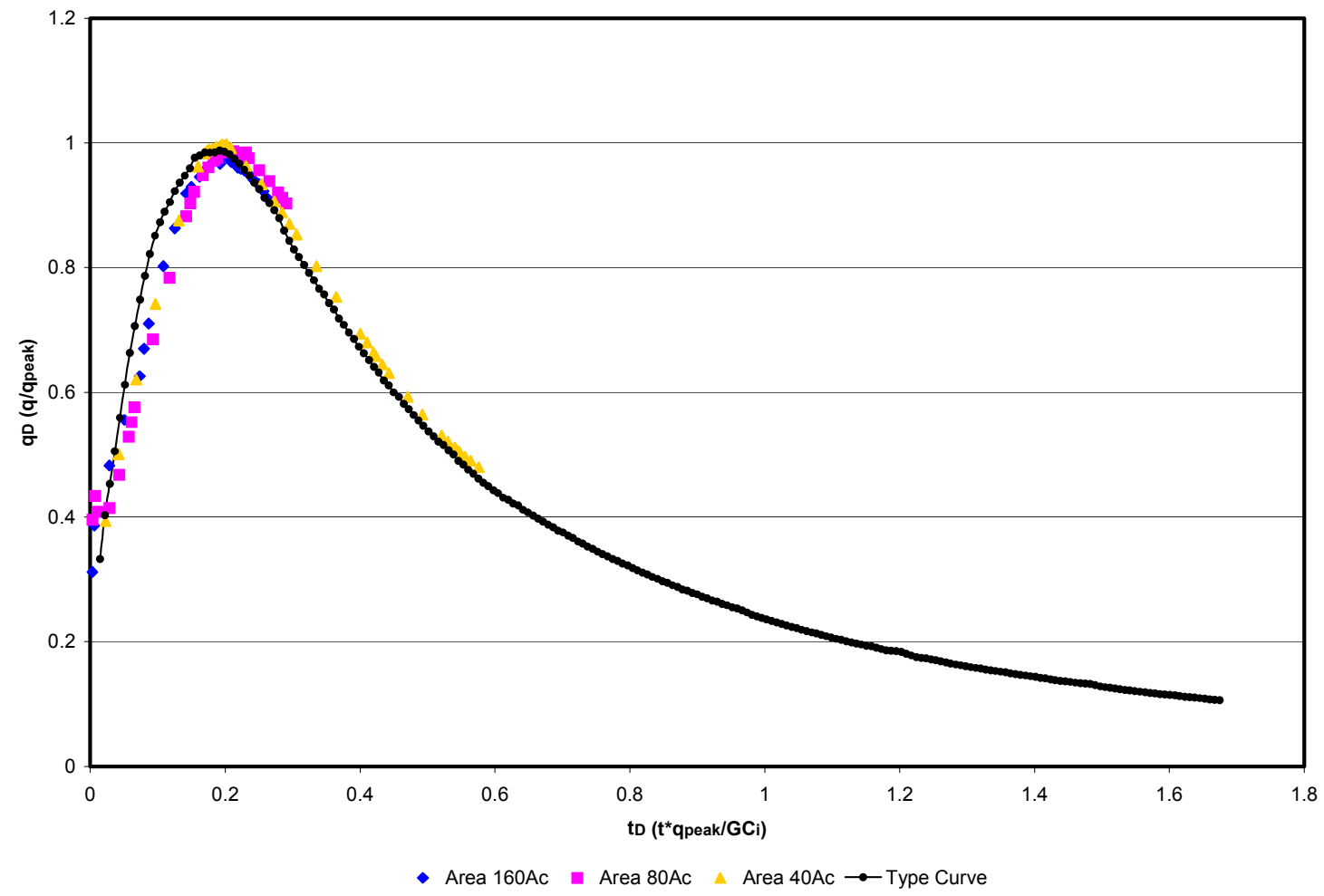

Appendix C. Comparison between gas production using different areas and the CBM production type curve. 


\section{Appendix D.}

Comparison between gas production using different thickness and the CBM production type curve. 


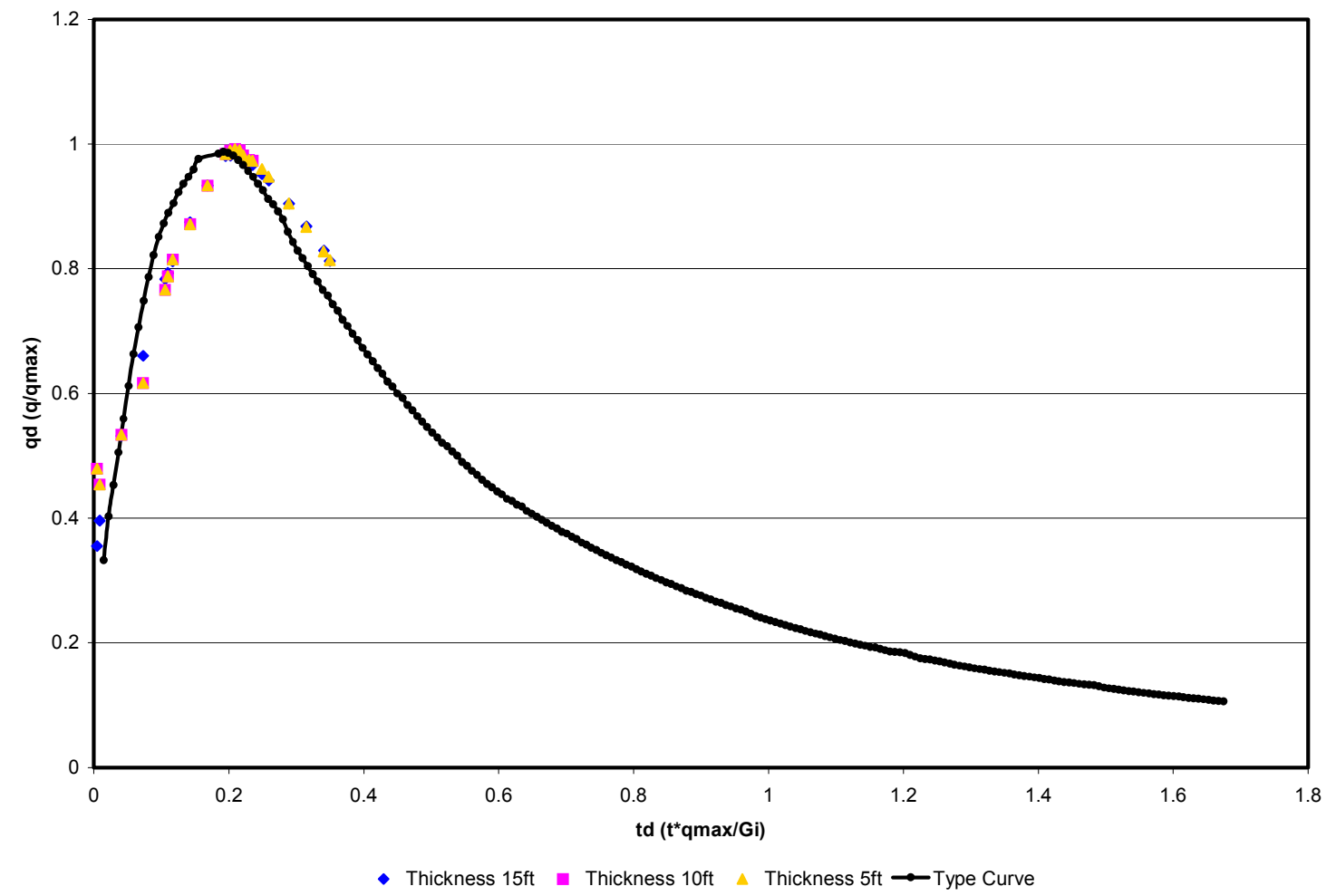

Appendix D. Comparison between gas production using different thickness and the CBM production type curve. 


\section{Appendix E.}

Comparison between gas production using different matrix pressures and the CBM production type curve. 


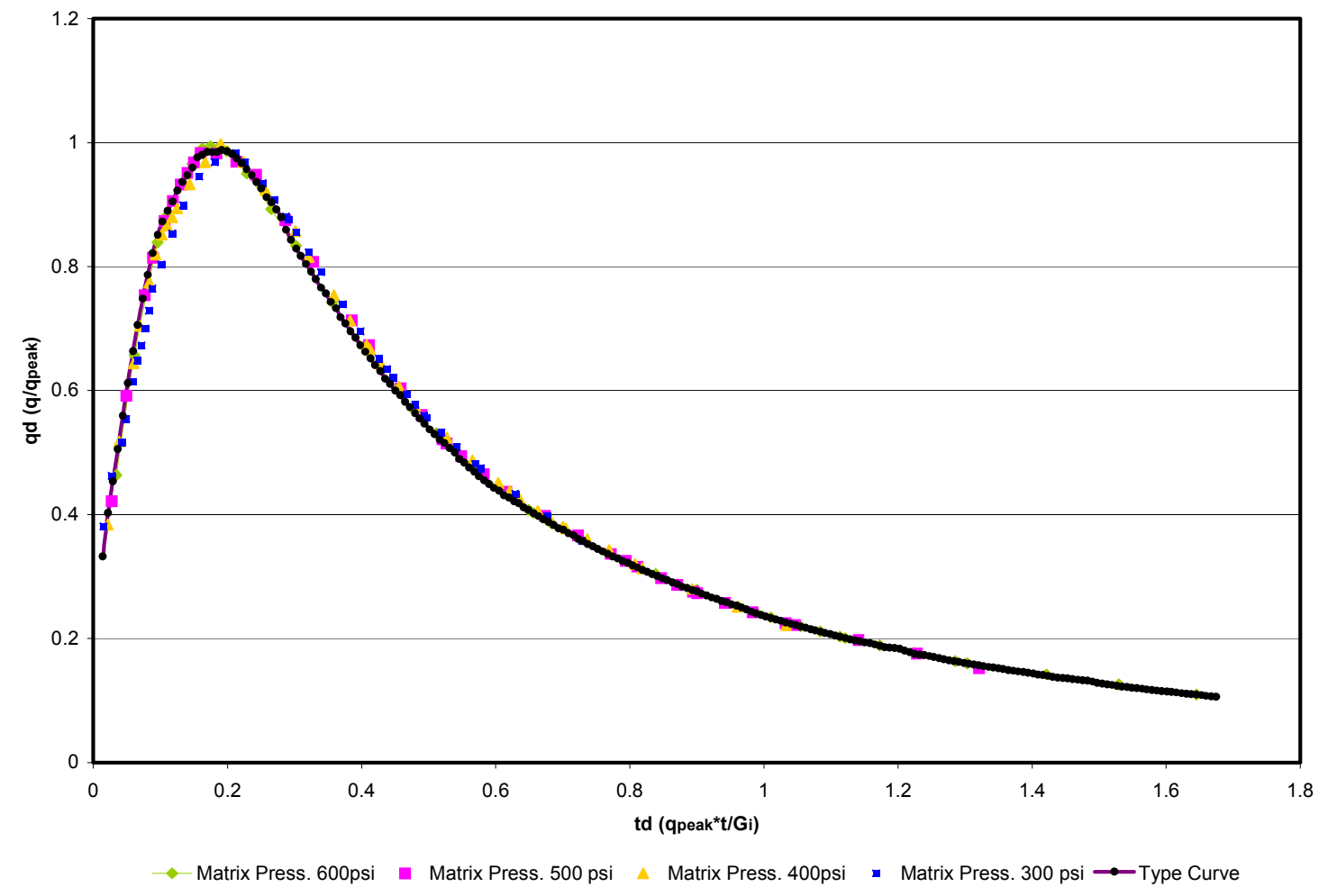

Appendix E. Comparison between gas production using different matrix pressures and the CBM production type curve. 


\section{Appendix F.}

Comparison between gas production using different fracture pressures and the CBM production type curve. 


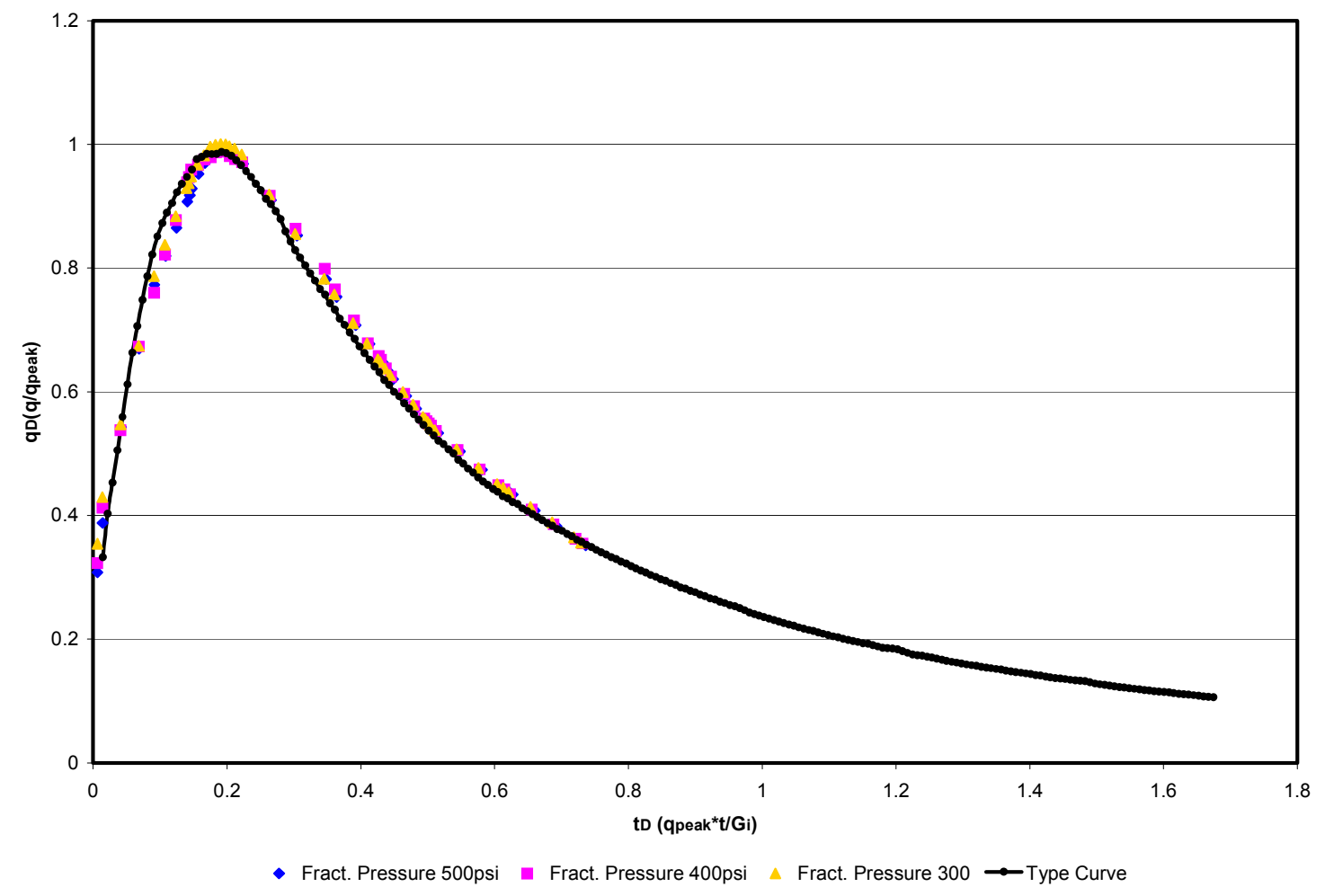

Appendix F. Comparison between gas production using different fracture pressures and the CBM production type curve. 


\section{Appendix G.}

Comparison between gas production using different sorption times and the CBM production type curve. 


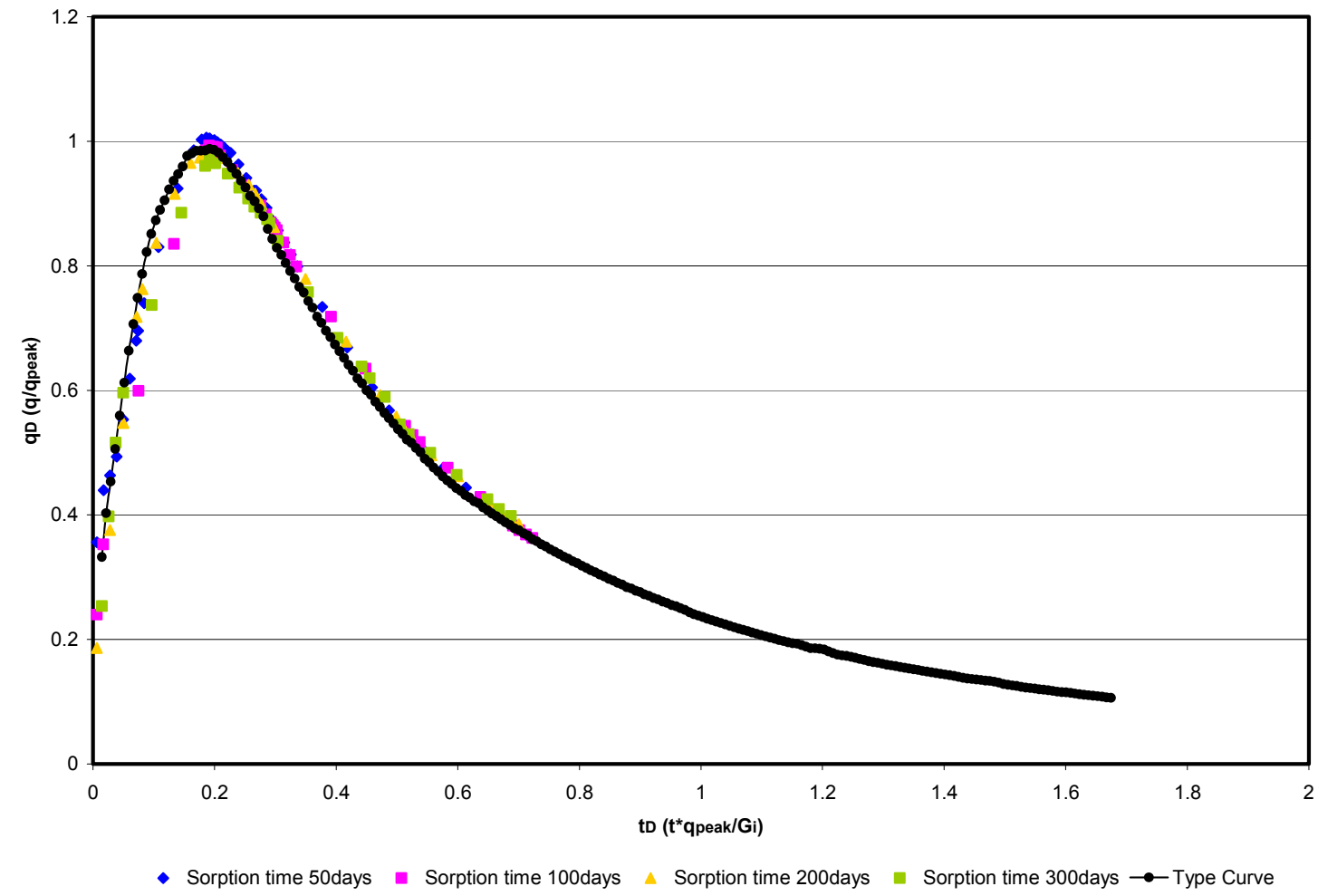

Appendix G. Comparison between gas production using different sorption times and the CBM production type curve. 
Appendix H.

Comparison between gas production using different flowing bottomhole pressures and the CBM production type curve. 


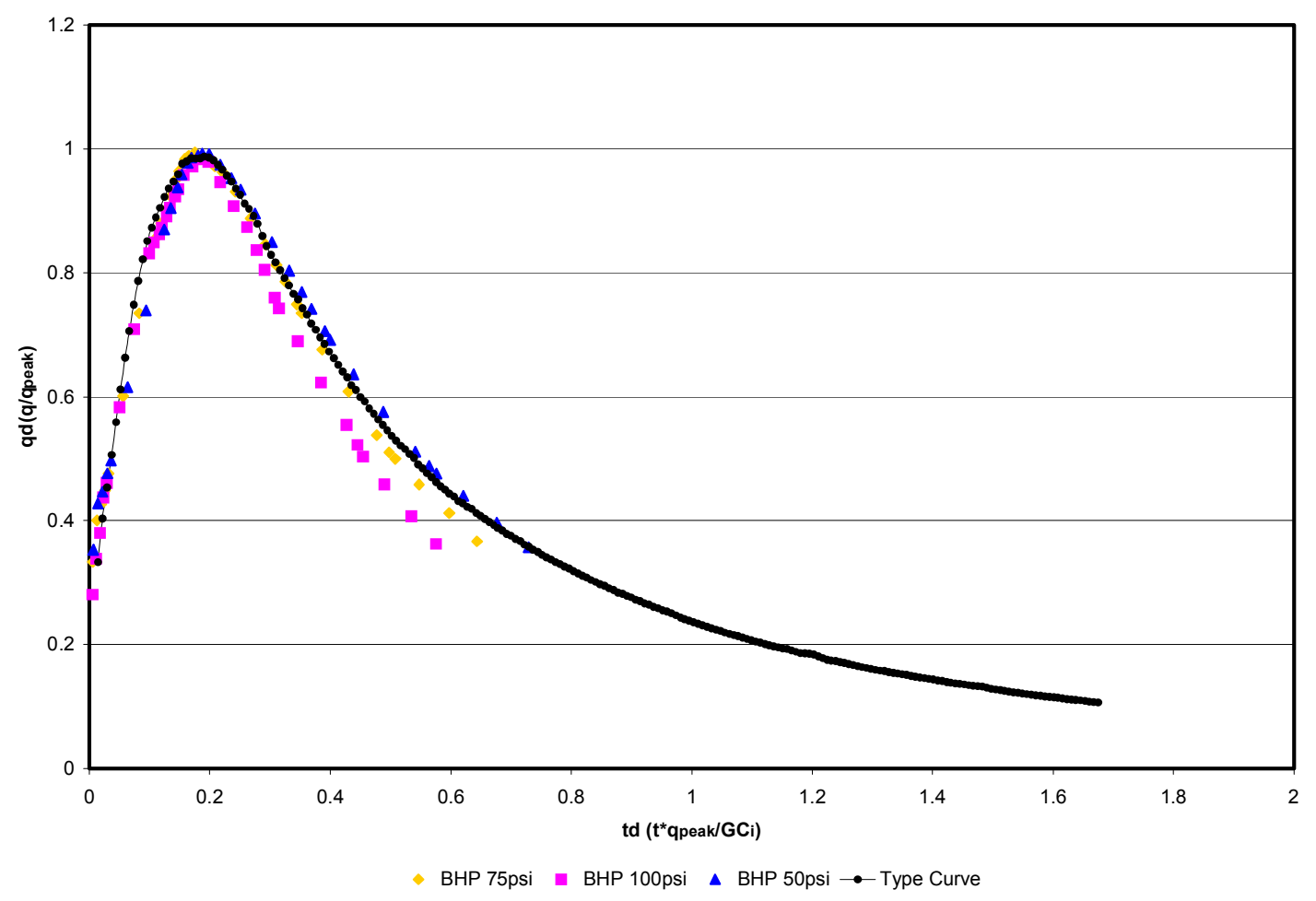

Appendix H. Comparison between gas production using different flowing bottomhole pressures and the CBM production type curve. 
Appendix I.

CBM Production Type Curve in log-log scale. 


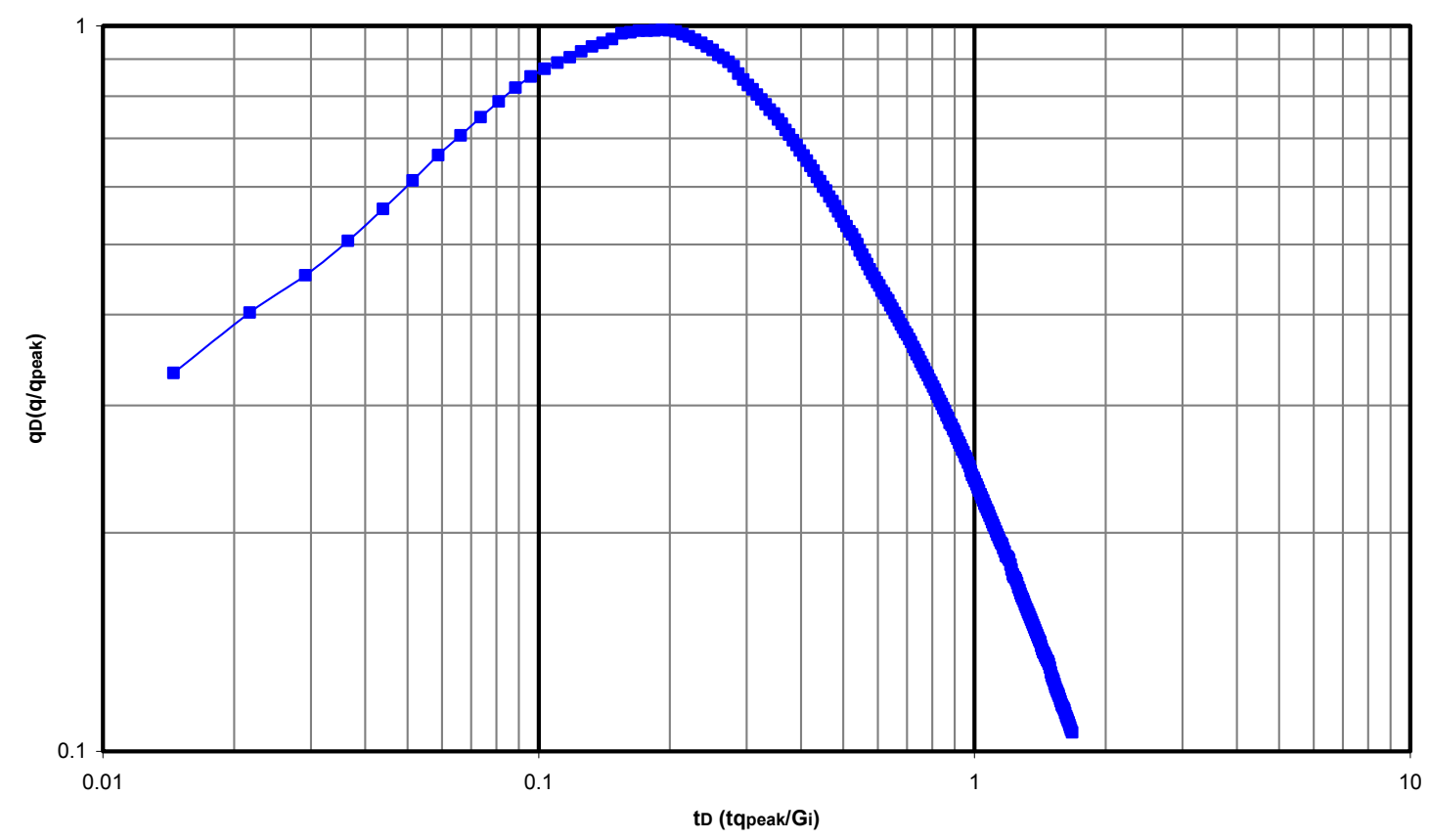

Appendix I. CBM Production Type Curve in log-log scale. 